\title{
INTAKE FLOW ANALYSIS OF A PULSED DETONATION ENGINE
}

\author{
by \\ JOSHUA A. STRAFACCIA \\ SEMIH OLCMEN, COMMITTEE CHAIR \\ JOHN BAKER \\ JOHN HOKE
}

\begin{abstract}
A THESIS
Submitted in partial fulfillment of the requirements for the degree of Master of Science in the Department of Aerospace Engineering in the Graduate School of The University of Alabama
\end{abstract}

TUSCALOOSA, ALABAMA 
Copyright Joshua A. Strafaccia 2014 ALL RIGHTS RESERVED 


\begin{abstract}
A CFD program is converted and modified to explore unsteady flow within the intake system of a pulse detonation engine (PDE). Using a quasi-one-dimensional approach the program provides insight into the unsteady nature of localized equivalence ratios to include their effects on PDE performance. The original FORTRAN program is converted into the MATLAB architecture, taking full advantage of user availability and post processing convenience. The converted program was validated against the original program and modified to include a primitive intake manifold system with a single fuel injector located approximately 10 feet upstream of the primary intake valve. Constant fuel mass flow rate at the injector end creates local variations in equivalence ratio throughout the PDE that may have significant impact on overall engine performance. The results of the current thesis research suggest that performance effects of up to $21 \%$ can be attributed to non-uniform fuel distribution throughout the detonation process and are most prevalent at lower frequencies and fill ratios.
\end{abstract}




\section{DEDICATION}

This thesis is dedicated to my family. In particular, to my wife and daughter who endured the many late nights and long hours needed to fulfill this lifelong academic goal and to my parents who taught me the meaning of hard work, commitment and sacrifice. 


\section{LIST OF ABBREVIATIONS AND SYMBOLS}

A non-dimensional cross-sectional area

$A^{*} \quad$ reference cross-sectional area

$a^{*} \quad$ reference speed of sound

Cf friction coefficient

$D^{*} \quad$ reference diameter

F flux vector

$h \quad$ obstacle element height

$K_{0} \quad$ non-dimensional reaction rate constant

$\lambda \quad$ cell width

$L \quad$ tube length

$L_{v} \quad$ valve lift

$\dot{m} \quad$ mass flow rate

$p \quad$ non-dimensional pressure

$p^{*} \quad$ reference pressure

$\operatorname{Pr} \quad$ Prandtl number

$q_{0} \quad$ non-dimensional mixture heating value

$q_{0} * \quad$ reference mixture heating value

$\rho \quad$ non-dimensional density

$\rho^{*} \quad$ reference density 


$\begin{array}{ll}\Phi & \text { equivalence ratio } \\ \Phi^{*} & \text { reference equivalence ratio } \\ R e_{D} * & \text { Reynolds number based on the reference diameter. } \\ S & \text { source vector } \\ S t & \text { Stanton number } \\ t & \text { non-dimensional time } \\ T & \text { non-dimensional temperature } \\ T^{*} & \text { reference temperature } \\ u & \text { non-dimensional velocity } \\ V & \text { non-dimensional volume } \\ w & \text { conserved flow vector } \\ z & \text { reactant fraction }\end{array}$




\section{ACKNOWLEDGMENTS}

I am forever grateful for the many individuals who have contributed to the success of this research project. I am especially thankful for the guidance of my advisor Dr. Semih Olcmen as well as the significant contributions of Dr. Dan Paxson both in the use of his source code as well as his hours of support throughout the tedious conversion process. I would also like to extend my gratitude to Dr. John Hoke for focusing my research into a manageable, meaningful study and for providing the experimental data needed to validate the accuracy of the program. I would also like to thank Dr. Semih Olcmen for acting as chairman of this thesis, along with the committee members, Dr. John Baker and Dr. John Hoke for their time and effort in support of this endeavor. 


\section{CONTENTS}

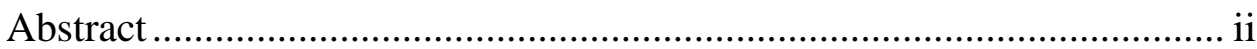

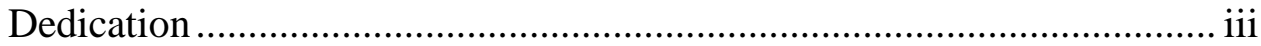

List of Abbreviations and Symbols...................................................... iv

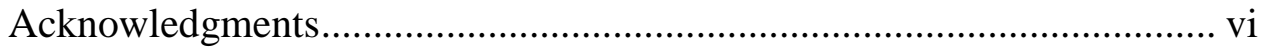

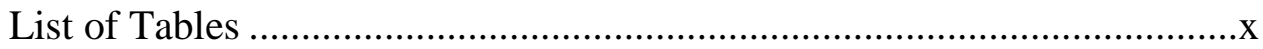

List of Figures ...........................................................................

Chapter 1 - PDE Operation Principles ............................................. 1

1.1 Introduction ...............................................................................

1.2 Pulse Detonation Engine ................................................................... 3

1.3 Deflagration vs. Detonation ......................................................

1.4 Deflagration-to-Detonation Transition (DDT) ................................ 8

Chapter 2 - PDE Design Parameters .................................................11

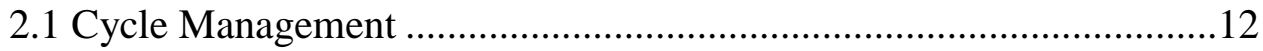

2.2 Nozzles and Ejectors ......................................................... 15

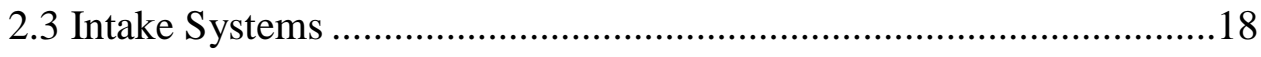

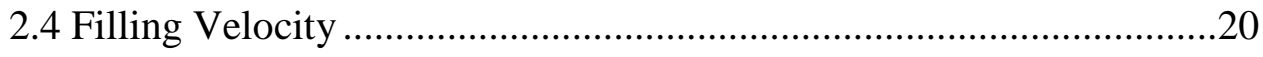

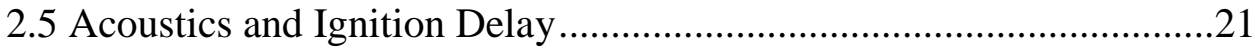


2.7 Equivalence Ratio ...................................................................25

Chapter 3 - Experimental Setup \& Simulation Model Details .................28

3.1 Experimental Setup ..................................................................28

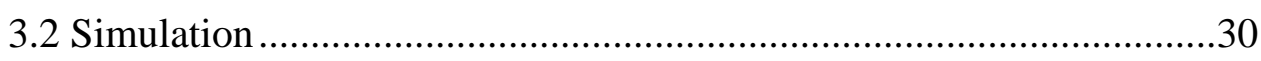

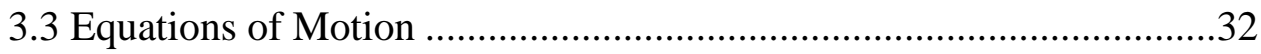

3.4 Automotive Head Sub-Model ......................................................33

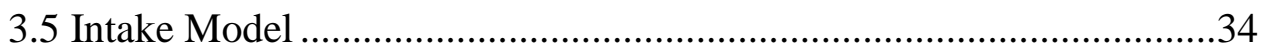

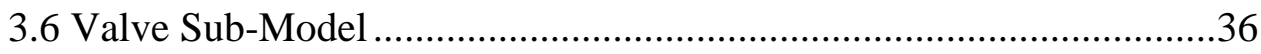

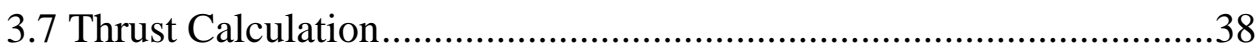

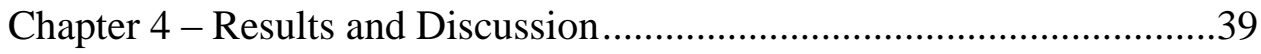

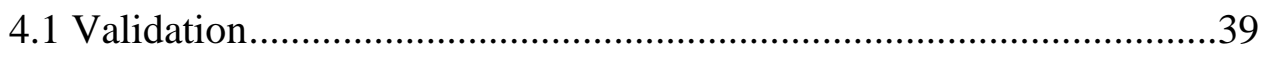

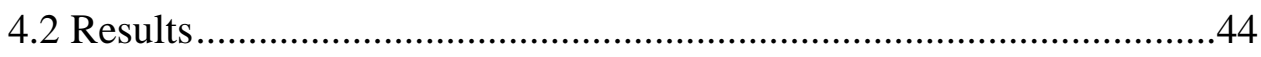

4.2.1 Unsteady Equivalence Ratio in PDE .........................................44

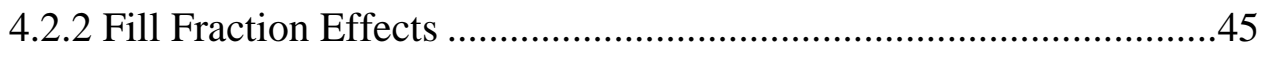

4.2.3 Ignition Delay Effects ........................................................49

4.2.4 Head Pressure Profile....................................................................51

4.2.5 Cold Flow Comparisons ......................................................53

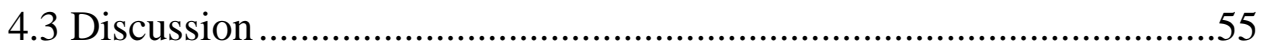

Chapter 5 - Conclusions and Future Work ..........................................57 


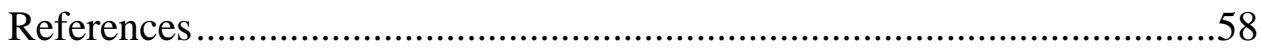

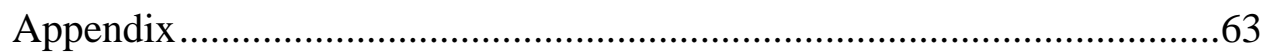




\section{LIST OF TABLES}

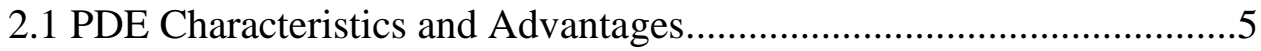




\section{LIST OF FIGURES}

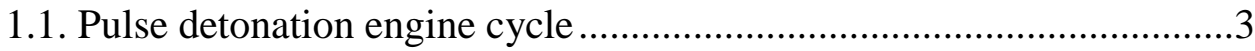

1.2. Specific impulse of propulsion forms at various Mach numbers ........4

1.3 Comparison of PDE and Constant Volume Cycle .............................

1.4 Pressure vs. Specific Volume \& Temperature vs. Entropy ...................7

1.5 DDT Distance vs. Reynolds Number............................................

1.6 Flame Speed vs. Reynolds Number ..............................................10

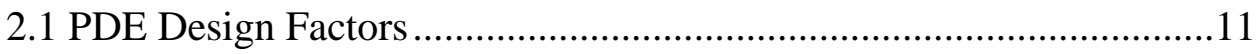

2.2 Frequency, Thrust, \& Specific Impulse vs. Valve Response Time .....12

2.3 Emission and Laser Transmission Data...........................................13

2.4 Effects of Fill Fraction ....................................................................

2.5 Pressure history profiles for straight nozzle and C-D nozzle .............16

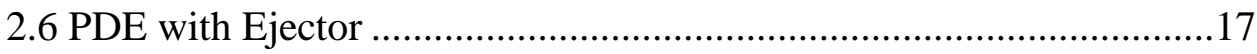

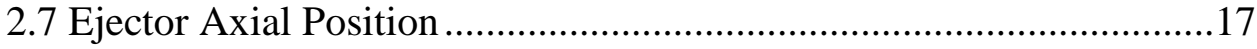

2.8 An example of a single tube, valved PDE ...................................18

2.9 An example of a single tube, valveless PDE ..................................19

2.10 Specific Impulse vs. Filling Velocity..........................................20

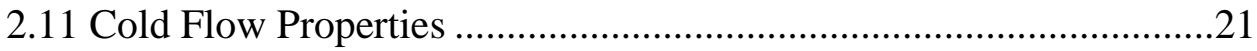

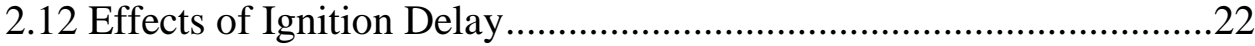


2.14 ITR-2 PDE with Common Nozzle .....................................................24

2.15 Effects of Equivalence Ratio on Thrust............................................25

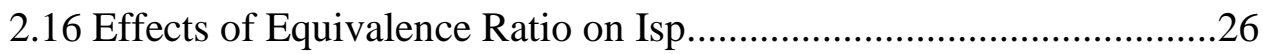

2.17 Effects of ER on Cell Width and Critical Initiation Energy ..............27

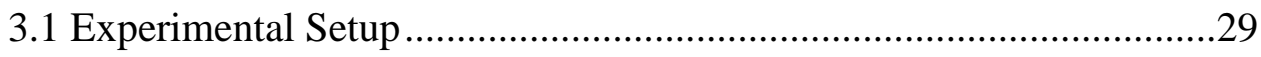

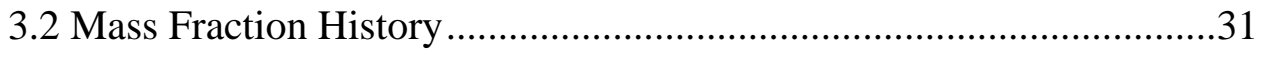

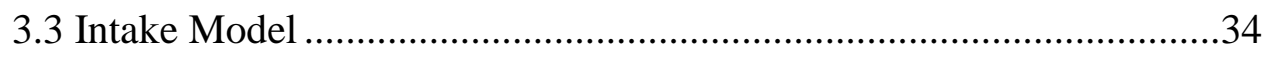

3.4 Valve Model Mass Flow Rate..............................................................37

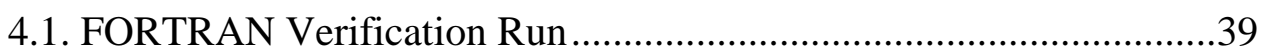

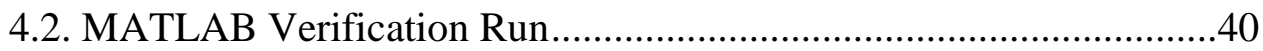

4.3. Fill Fraction - Experimental Results $(\Phi=1.0) \ldots \ldots \ldots \ldots \ldots \ldots \ldots \ldots \ldots \ldots \ldots \ldots . . . .41$

4.4. Fill Fraction - Model Results - No Intake Model $(\Phi=0.7)$...............41

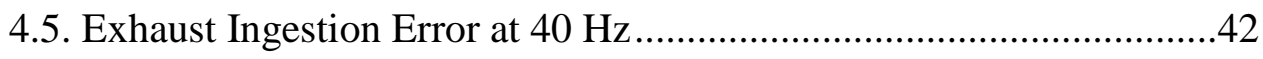

4.6. Ignition Delay - Experimental Results $(\Phi=1.0) \ldots \ldots \ldots \ldots \ldots \ldots \ldots \ldots \ldots \ldots \ldots . . . . .43$

4.7. Ignition Delay - Model Results - No Intake $(\Phi=1.0) \ldots \ldots \ldots \ldots \ldots \ldots \ldots . . . . . .43$

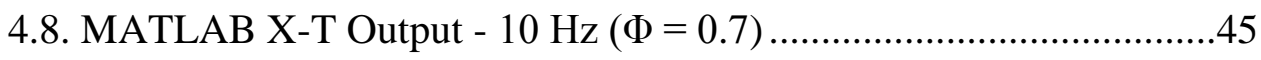

4.9. Fill Fraction - Model Results - Intake Model $(\Phi=0.7)$....................46

4.10. Normalized Fill Fraction - Experimental Results ..............................47

4.11. Normalized Fill Fraction - Model Results - No Intake Model .........47

4.12. Normalized Fill Fraction - Model Results - Intake Model................48

4.13. Effects of intake model on performance ...........................................49

4.14. Ignition Delay - Model Results - Intake Model $(\Phi=0.7)$................50 
4.15. Effects of intake model on performance ....................................50

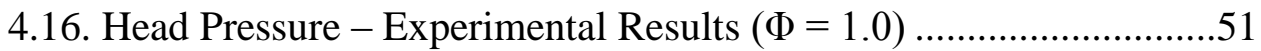

4.17. Head Pressure - Model Results - No Intake $(\Phi=0.7) \ldots \ldots \ldots \ldots \ldots \ldots . . .52$

4.18. Head Pressure - Model Results - Intake Model $(\Phi=0.7)$...............52

4.19. Cold Flow Pressure at $30 \mathrm{~Hz}-$ Experimental Results .....................53

4.20. Cold Flow Pressure at $30 \mathrm{~Hz}-$ Intake Model Results ......................54

4.21. Cold Flow Pressure from 10-30 Hz - Experimental Results ............54

A.1. Sample MATLAB Model Command Output..................................63

A.2. Sample MATLAB X-T Output - No Intake .................................63

A.3. Sample MATLAB Model Command Output - Intake Model...........64

A.4. Sample MATLAB X-T Output - Intake Model..............................64 


\section{CHAPTER 1 - PDE OPERATION PRINCIPLES}

\subsection{INTRODUCTION}

In order to better understand the dynamic nature of pulse detonation engines (PDEs) a quasione-dimensional (Q1D) CFD program developed by Daniel Paxson, NASA Glenn Research Center, has been converted and modified to model the intake system of a PDE located at Air Force Research Labs (AFRL), Wright Patterson Air Force Base (WPAFB), OH. The original program was used previously to model PDE properties such as the performance impact of deflagration-to-detonation obstacles, however, emphasis of these simulations was placed on the combustion tube and neglected effects contributed by the intake manifold configuration ${ }^{1}$.

Although considerable insight into PDE operation can be gained without modeling intake manifold effects, it has been shown that non-uniform distributions of equivalence ratios can have a significant impact on overall PDE performance ${ }^{2}$. One source of these variations results from unsteady intake flow over a constant mass flow rate fuel injector. This phenomenon requires a model of the intake system to fully explore the impact of these effects and the goal of this thesis was to create a user-friendly computer model of an existing AFRL intake system in hopes of better understanding its impact on PDE performance.

In order to accomplish the user friendly objective, the original PDE program was first converted from its native FORTRAN language and brought into the MATLAB environment. Although this process created a significant increase in processing time, it allowed the user to take advantage of the many post processing capabilities and popular user familiarity of the 
programming language. The converted program was then validated against the original program to ensure an accurate conversion before a model of the intake system was added. Finally, the intake augmented program was compared against the unmodified program and experimental data to explore the effects of the intake system on overall performance results.

The first chapter of this thesis will cover a brief discussion of general PDE principles of operation. Chapter II will focus on wide array of design parameters that have been shown to affect PDE operation and performance. In chapter III, the results of this thesis will be discussed and the significance of PDE performance effects due to unsteady intake flow conditions will be addressed. More specifically the discussion will focus on the effects of localized variations in equivalence ratio produced by unsteady mass flow rate across the fuel injector throughout the PDE cycle. Finally, chapter IV will present conclusions and discuss potential directions for future work. 


\subsection{PULSE DETONATION ENGINE}

PDE technology harnesses the combustion efficiencies of chemical detonation into a practical form of propulsion. In its simplest form a PDE is a long tube filled with a fuel-oxidizer mixture, ignited from one end and optimized to achieve detonation as the combustion transits towards the opposite end. Immediately following this detonation, high pressure gasses within the tube are allowed to relax creating thrust. As the pressure neutralizes the tube is purged using clean air in preparation for the next cycle. This fill-fire-purge cycle is repeated in rapid successiontypically on the order of 10 to $100 \mathrm{~Hz}$ - to produce a quasi-constant thrust. Figure 1.1 illustrates this process.

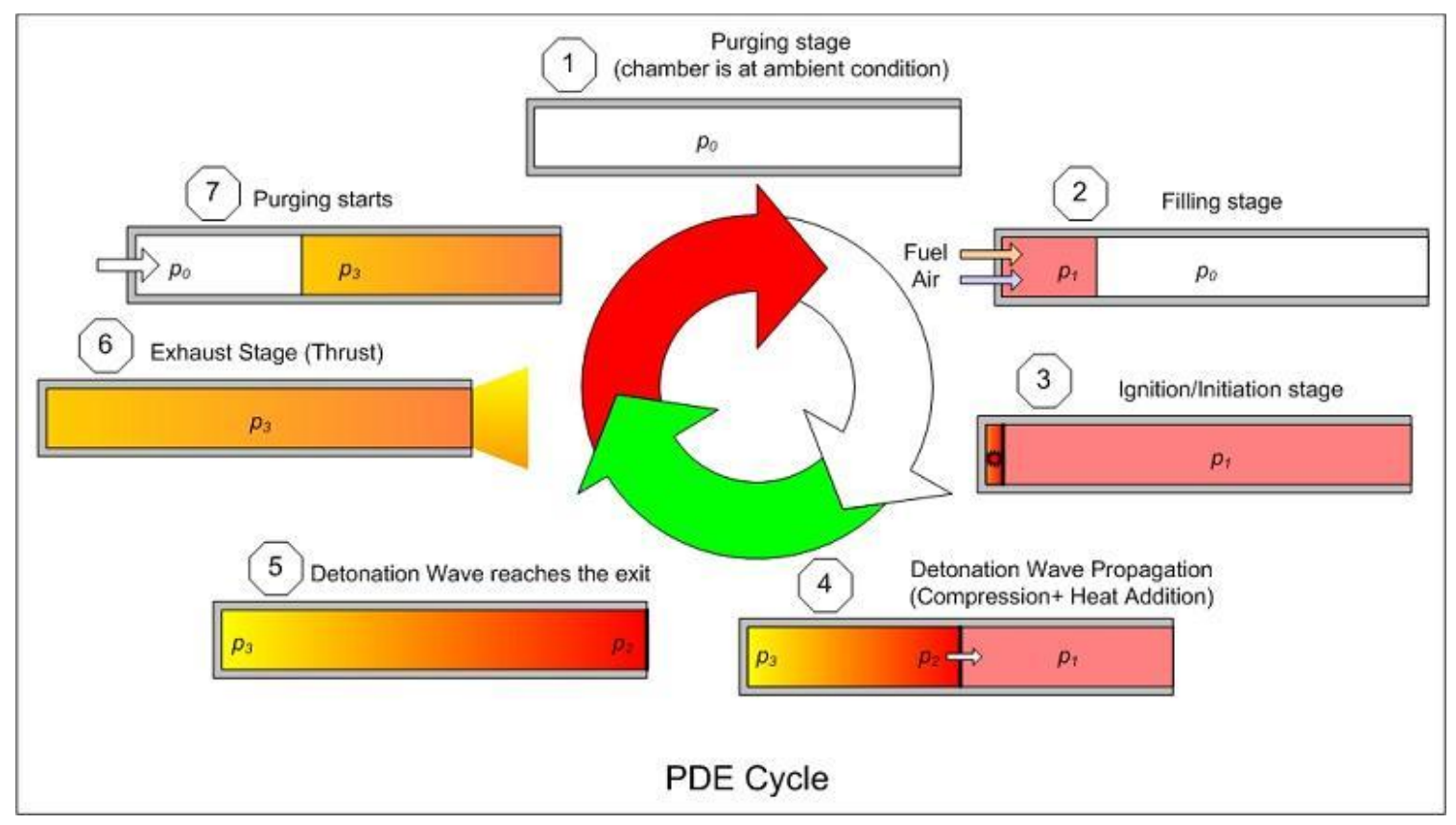

Figure 1.1. Pulse detonation engine cycle ${ }^{3}$ 
PDE technology offers several unique advantages when compared to traditional forms of propulsion. In theory, PDEs are able to operate over an extremely wide range of speeds—static thrust thru approximately Mach 5-at efficiencies comparable to that of turbofan/turbojet engines. Not only does this provide more capability, but the technology utilizes very simple and reliable mechanical components as opposed to traditional turbine-based propulsion. Efforts to calculate static Isp for multiple PDE engines in various configurations have produced results on the order of 1500-2000s, however theoretical expectations may be as high as 6000-8000s for an optimally developed $\mathrm{PDE}^{4-6}$.

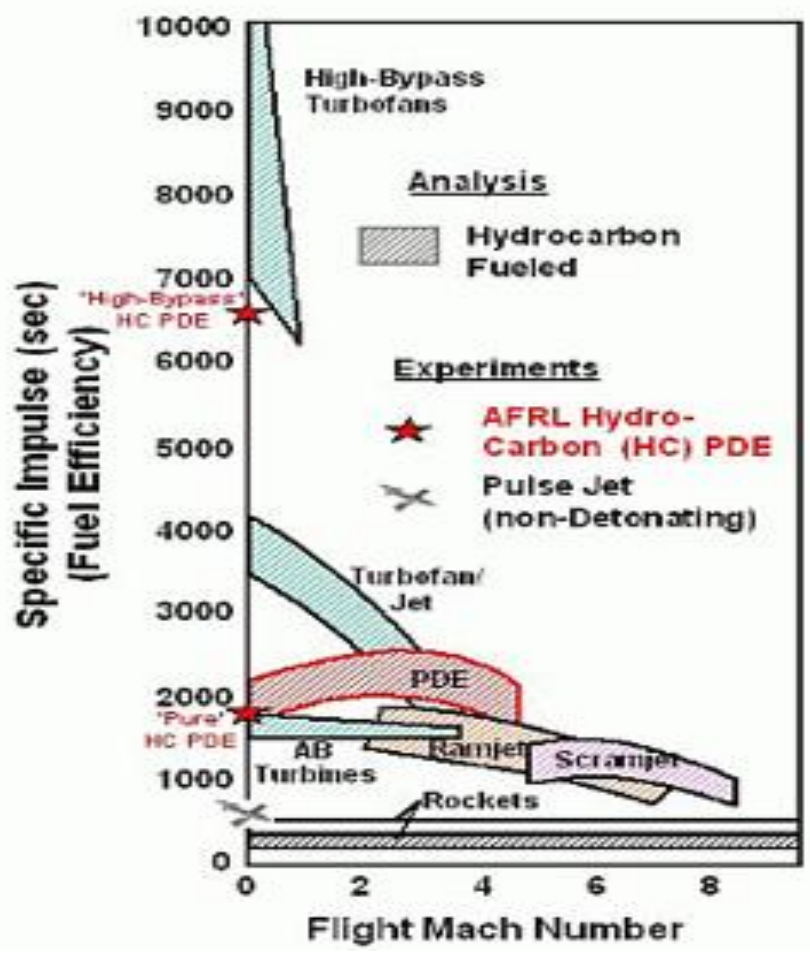

Figure 1.2. Specific impulse of propulsion forms at various Mach numbers ${ }^{7}$

The theoretical possibilities of this technology have made PDEs a potential replacement for ramjet propulsion and companies such as Pratt \& Whitney and Boeing have been working for several years to produce a Mach 2.5 strike missile ${ }^{8}$. Compared to ramjet propulsion Harris et $\mathrm{al}^{9}$ has calculated increases in Isp ranging from 4-36\% for PDEs dependent on speed; however, even 
if practical PDE designs have only marginal efficiency increases, the ability for such an engine to eliminate the ramjet's need for an assisted takeoff system may still produce a net advantage.

Other applications of PDE technology range from pulse detonation rocket engines (PDRE) to PDE afterburners, to PDEs utilized in high efficiency combustion chambers within traditional turbine engines. Regardless of the application, it is estimated that the development of practical PDE technology will require an investment of $\$ 50-100 \mathrm{M}$ per year over a period of 7-9 years ${ }^{10}$.

Table 1.1 presents several advantages of PDRE propulsion.

\begin{tabular}{|c|c|c|}
\hline PDRE Characteristics & Advantage & Engine Performance Improvement \\
\hline High cycle efficiency & $\begin{array}{l}\text { Efficient constant volume nonsteady } \\
\text { cycle. Direct thrust generation. }\end{array}$ & $\begin{array}{l}\text { Increase payload and reduce cost for lunar and } \\
\text { planetary excursion vehicles }\end{array}$ \\
\hline $\begin{array}{l}\text { Hybrid mode using } \\
\text { atmospheric air and } \\
\text { oxygen at high altitude }\end{array}$ & $\begin{array}{l}\text { Same engine volume can be used for } \\
\text { air/fuel or oxygen/fuel detonations }\end{array}$ & $\begin{array}{l}\text { Reduce cost of ETO transportation as a result of } \\
\text { expected } 2000 \mathrm{sec} \mathrm{I}_{\text {sp }} \text { in air }\end{array}$ \\
\hline $\begin{array}{l}\text { High structural } \\
\text { efficiency }\end{array}$ & $\begin{array}{l}\text { Simple nonmoving parts design. No } \\
\text { need for turbines and compressors }\end{array}$ & Reduce system cost and increase reliability. \\
\hline $\begin{array}{l}\text { No exotic materials or } \\
\text { technologies needed for } \\
\text { operation }\end{array}$ & $\begin{array}{l}\text { Low thermal load due to } \\
\text { intermittent cycle, Uses } \\
\text { conventional fuels. }\end{array}$ & $\begin{array}{l}\text { Simple fabrication methods and materials will } \\
\text { result in space propulsion systems produced } \\
\text { using manufacturing methods similar to } \\
\text { automotive technology at low cost. }\end{array}$ \\
\hline $\begin{array}{l}\text { Vector thrust from an } \\
\text { array of PDREs. }\end{array}$ & $\begin{array}{l}\text { Simple device with no geometrical } \\
\text { constraints can be integrated into an } \\
\text { array. Every cycle controlled sepa- } \\
\text { rately. }\end{array}$ & $\begin{array}{l}\text { High maneuverability. Reduces number of } \\
\text { propulsion systems since one engine can be used } \\
\text { for both power generation and trajectory correc- } \\
\text { tions. }\end{array}$ \\
\hline $\begin{array}{l}\text { Variable power } \\
\text { generation from } 0 \text { to } \\
\text { Max }\end{array}$ & $\begin{array}{l}\text { Independent generation of every } \\
\text { cycle and full control over cycle } \\
\text { frequency. }\end{array}$ & $\begin{array}{l}\text { Optimized propulsion sy stem achieved by } \\
\text { matching power output to mission requirements. }\end{array}$ \\
\hline $\begin{array}{l}\text { Scalability from less } \\
\text { than } 1 \mathrm{lb} \text { to more than } \\
100,000 \mathrm{lb} \text { thrust }\end{array}$ & $\begin{array}{l}\text { Simple design. Ease of integration } \\
\text { of multiple sections. Operation cycle } \\
\text { feasible for a wide range of } \\
\text { conditions and engine sizes. }\end{array}$ & $\begin{array}{l}\text { Revolutionary technology applicable to a wide } \\
\text { range of engine classes. }\end{array}$ \\
\hline
\end{tabular}

Table 1.1 PDRE Characteristics and Advantages ${ }^{10}$ 


\subsection{DEFLAGRATION VS. DETONATION}

Combustion is an exothermic chemical reaction between a fuel and an oxidizer that, given the appropriate conditions, is able to propagate by two principal means - thermal radiation and pressure forces. These two combustion mechanisms relate to two very different and distinct combustion phenomena known as deflagration and detonation. Deflagration is the relatively slow combustion that occurs when thermal radiation from a chemical reaction is sufficient to propagate the reaction without an external heat source. Specifics regarding these phenomena are dependent on physical and thermal properties of the reactants, but the process is generally confined on the order of 1 to $30 \mathrm{~m} / \mathrm{s}$. Detonation, unlike deflagration, propagates via a supersonic shock wave that rapidly compresses reactants thereby increasing the temperature and sustaining the reaction ${ }^{11}$. Contrast to deflagration this violent process can attain speeds from 1.5 to 3.0 $\mathrm{km} / \mathrm{s}$. The speed of a one dimensional detonation wave can be estimated as a function of the heat release per mass of the fuel/oxidizer mixture:

$$
\mathrm{V}_{\mathrm{D}}=\sqrt{2\left(\gamma^{2}-1\right) \mathrm{q}_{0}{ }^{*}}
$$

Applying Equation 1 to a stoichiometric hydrogen-oxygen mixture results in a detonation wave velocity of $2956 \mathrm{~m} / \mathrm{s}^{12}$. These extreme speeds are responsible for the rapid combustion that allows PDEs to attain near constant-volume combustion efficiencies ${ }^{13}$. Figure 1.3 illustrates the similarities between this process and constant volume combustion. 


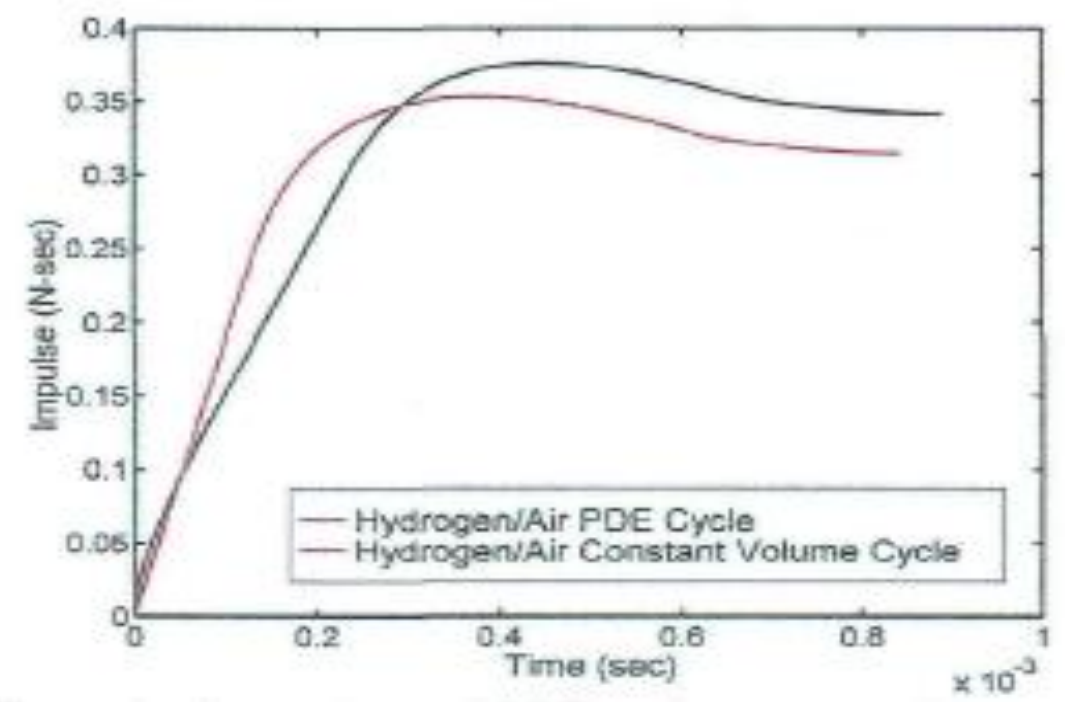

Figure 1.3 Comparison of PDE and Constant Volume Cycle ${ }^{14}$

Using the constant-volume cycle as a conservative estimate, PDE efficiencies can be illustrated using the Brayton and Humphrey thermodynamic cycles shown in Figure 1.4. The Brayton cycle represents a typical constant-pressure combustion cycle associated with deflagration. The Humphrey cycle differs from this in that combustion takes place at a constant volume (2-3) allowing it to achieve higher temperatures at lower entropies. The net result is a substantial increase in efficiency. For example, theoretical improvements in efficiency at a compression ratio of 12 are as high as $20-35 \%^{11}$.

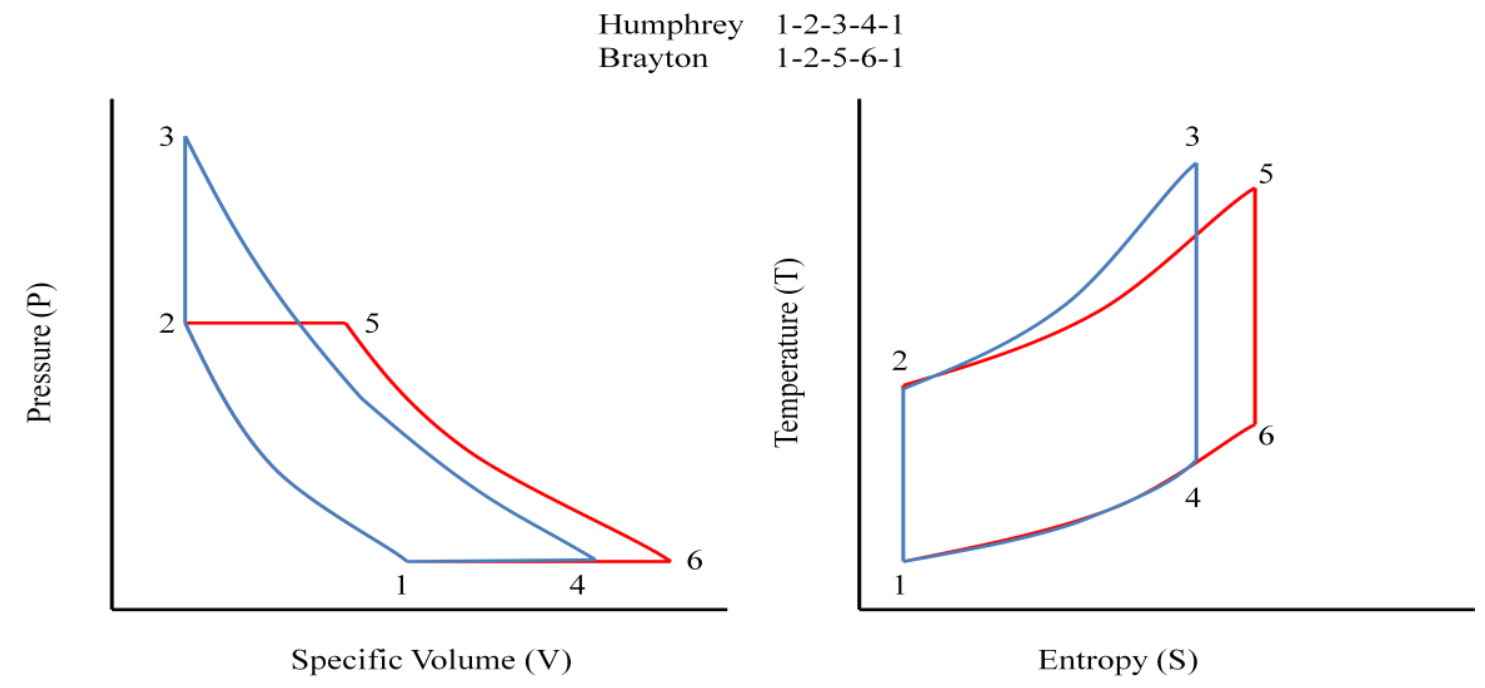

Figure 1.4 Pressure vs. Specific Volume and Temperature vs. Entropy Diagrams 


\subsection{DEFLAGRATION-TO-DETONATION TRANSITION (DDT)}

The benefits of detonation as a combustion phenomenon illustrated above are easily recognized. The successful implementation of this technology, however, is contingent upon the ability to achieve reliable detonation as quickly as possible during the combustion process. This minimizes the amount of fuel burned via deflagration, and maximizes the efficiencies of detonation. The ability to initiate detonations on a consistent, reliable basis poses a significant challenge and there are multiple methods under investigation to resolve this problem. One approach is to initiate a detonation directly. These detonations are typically initiated by either a high-energy arc discharge/laser or incorporate some form of staged system where a smaller more easily detonable initiator is used to detonate a larger charge. Staged detonation systems often incorporate fuel-oxygen mixtures as DDT distance is shorter for these as compared to their fuelair equivalents. The size of such a detonator must be carefully considered; however, as a large fuel/oxygen initiator can substantially reduce specific impulse ${ }^{15}$.

An alternative to direct initiation is a process known as deflagration-to-detonation transition. DDT uses a low-energy ignition source to initiate deflagration within a tube, permitting the combustion to accelerate until a detonation wave forms. The detonation wave propagates along the remaining length of the combustion tube igniting the remaining fuel ${ }^{16}$. Obstacles strategically placed within the combustion tube can help accelerate this process and significantly decrease the distance required to achieve detonation by creating complex flow structures. It has also been shown that DDT distance can be reduced by as much as $80 \%$ by simply increasing the Reynolds number. These results are attributed to the effects of similar flow structures created as velocity over the intake valve is increased. This approach also has the advantage reducing performance degrades associated with DDT obstacles ${ }^{1,17}$. Figures 1.5 and 1.6 show the effects of Reynolds 
number on DDT distance and average flame speed for various nitrogen dilutions ( $\beta$ ). Nitrogen dilution is controlled in this particular study to explore its impact on DDT distance as dilutions approach those required for air breathing PDEs. The figures suggest a strong correlation exists between a minimum DDT distance and a maximum average flame speed. Obstacles produce the same net effect leading to shorter DDT distances and higher average flame speeds; however, losses generated by these obstacles can be significant and require substantial optimization in order to balance these effects ${ }^{5}$.

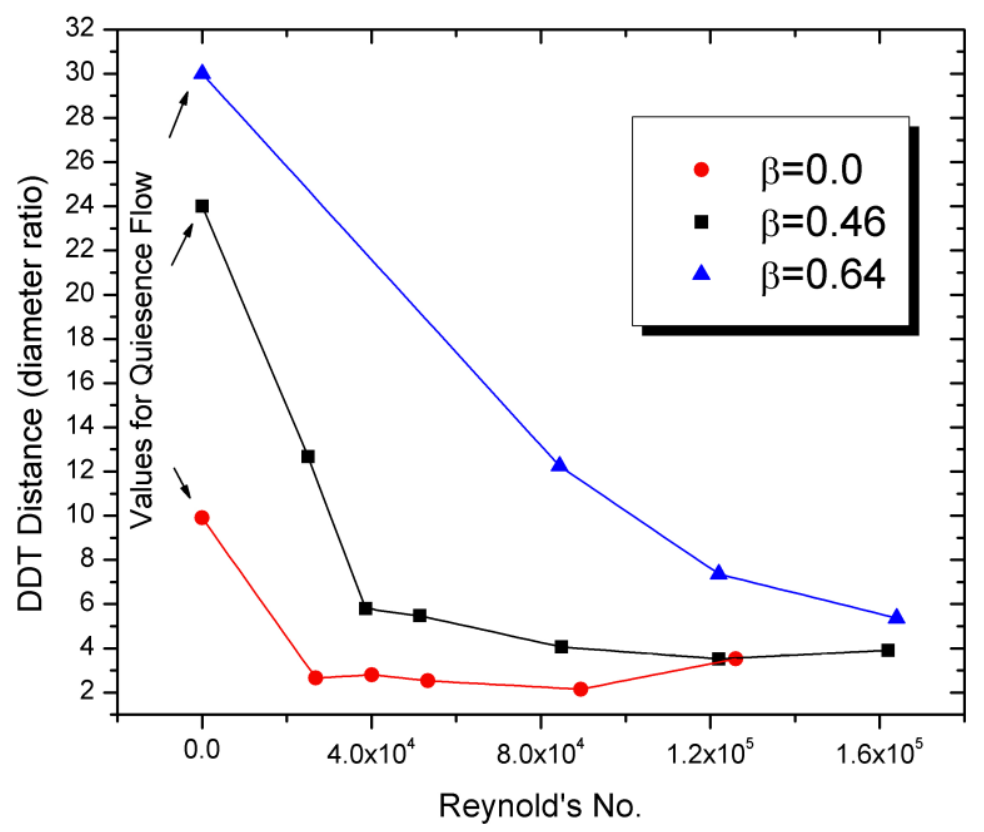

Figure 1.5 DDT Distance vs. Reynolds Number ${ }^{17}$ 


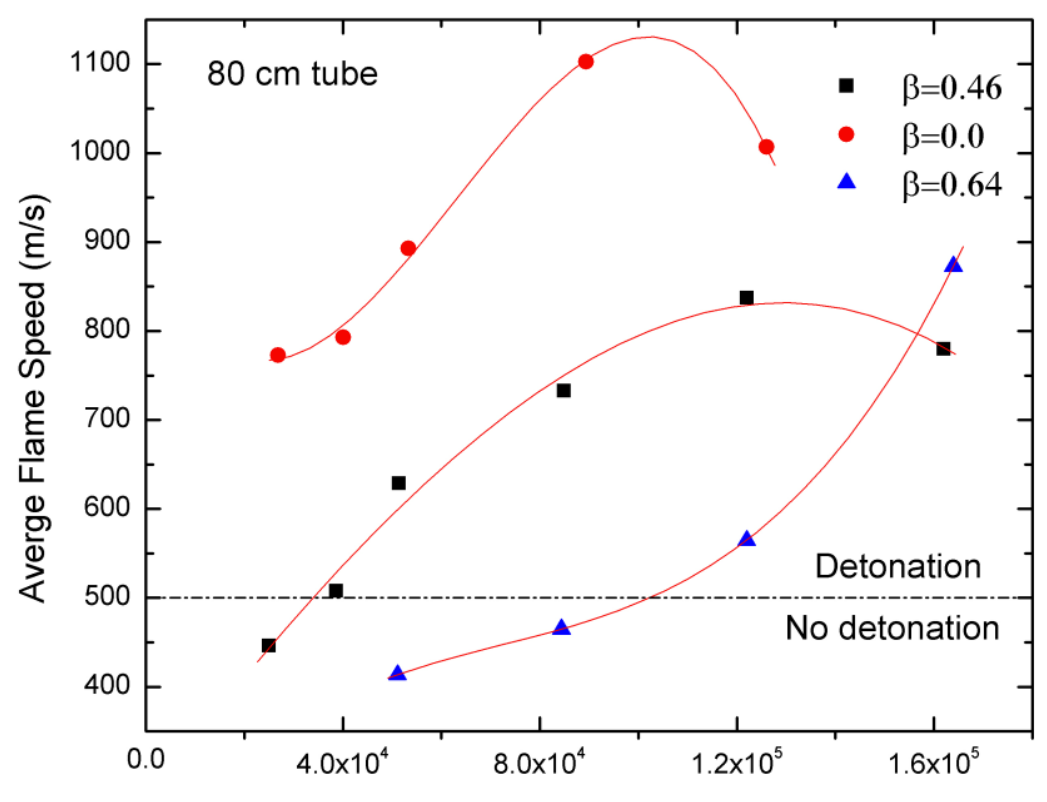

Reynold's No.

Figure 1.6 Flame Speed vs. Reynolds Number ${ }^{17}$ 


\section{CHAPTER 2 - PDE DESIGN PARAMETERS}

In addition to successfully initiating consistent detonations and optimizing DDT obstacles there are many other factors that must be optimized before PDE technology will become a viable form of propulsion. As we attempt to enhance PDE performance there is a vast number of characteristics that must be considered. Some of these factors include, but are not limited to cycle management, nozzles, ejectors, intake design, filling velocity, acoustics, ignition delay, arrangement, and equivalence ratio. Figure 2.1 alludes to the complex couplings that exist between PDE properties and the following section provides a brief overview of several properties that have been demonstrated to affect the performance and/or operation of PDE propulsion. Although each of these factors plays an important role in the optimization of PDE technology, the experimental results of this thesis will focus primarily on the effects of equivalence ratio.

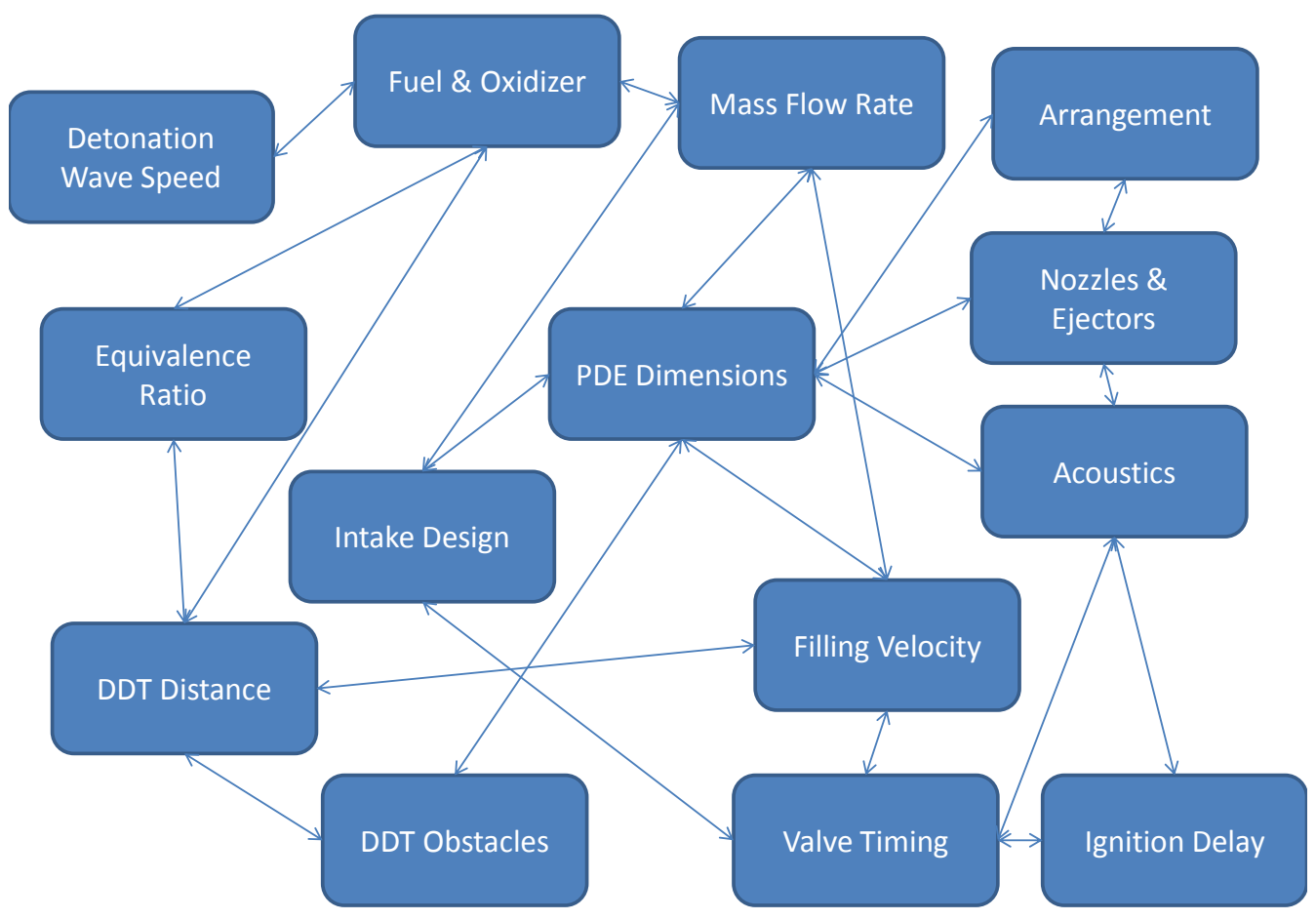

Figure 2.1 PDE Design Factors 


\subsection{CYCLE MANAGEMENT}

The unsteady nature of PDE operation makes impulse measurement somewhat challenging. The largest portion of this impulse actually occurs immediately following the detonation wave as the rarefaction wave travels back to the thrust wall ${ }^{14}$. Considering this relaxation period of actively produced thrust accounts for only 6-9\% of the PDE cycle, a well-managed cycle is critical for continuous strong detonations ${ }^{18}$. As noted earlier, nozzle effects on pressure relaxation as well as other factors such as valve response time can affect the maximum cycle frequency of the PDE. As shown in Figure 2.2, cycle frequency is directly proportional to thrust and while the Isp remains fairly constant, a poorly managed PDE cycle can be devastating to thrust performance.
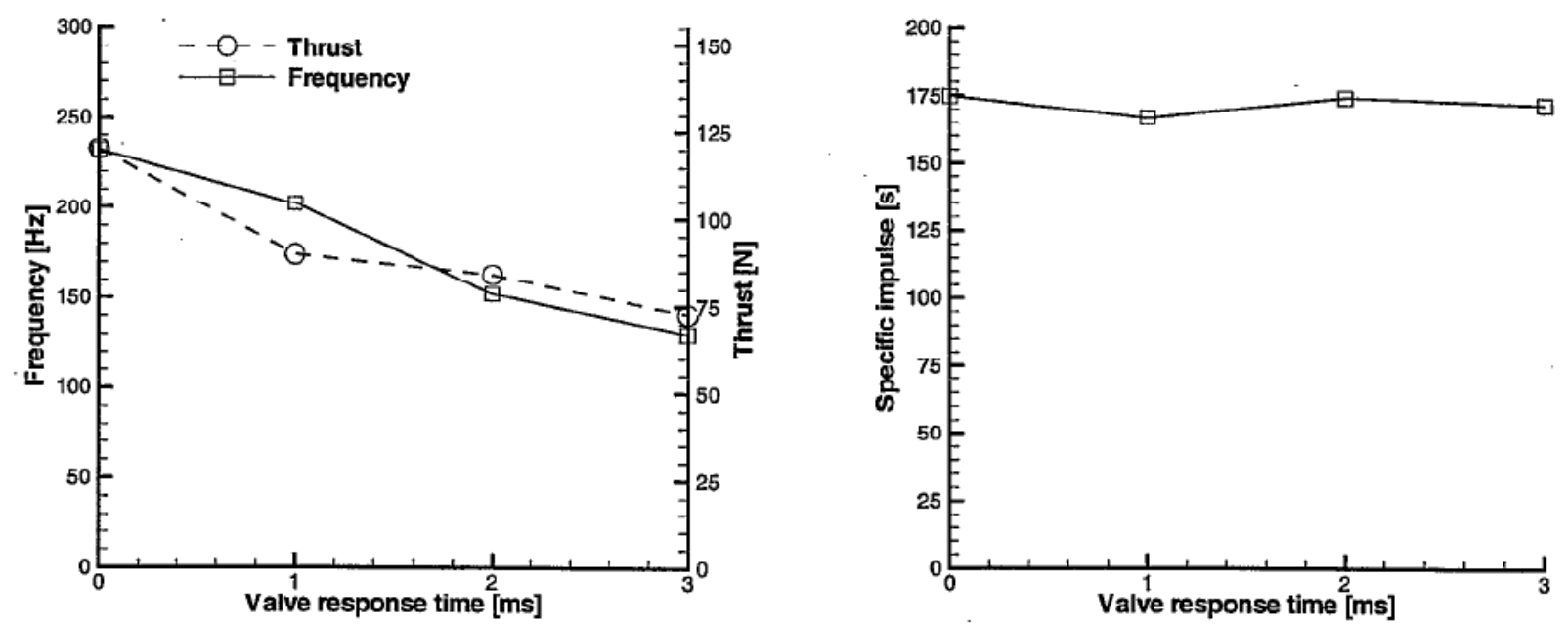

Figure 2.2 Frequency, Thrust, and Specific Impulse vs. Valve Response Time ${ }^{12}$

Aside from physical limitations such as valve timing, a significant concern regarding cycle management that can affect the maximum frequency of operation is the incomplete combustion of fuel. One study in particular was able to determine that not all of the fuel within a PDE combustion tube was being consumed by a detonation wave. Incomplete burning during the detonation cycle was evident and could potentially lead to a decrease in performance and the 
possibility of premature ignition of fuel from subsequent cycles ${ }^{19}$. As cycle frequencies increase the challenge of preventing these issues becomes more difficult. Figure 2.3 provides an example of just such a behavior. Note the inter-cycle combustion that is still present over $7 \mathrm{~ms}$ after the detonation wave exits the combustion tube. This would produce overlaps between the active combustion of one cycle and the filling of the next cycle at frequencies as low as $95 \mathrm{~Hz}$ and could very well produce premature ignition.

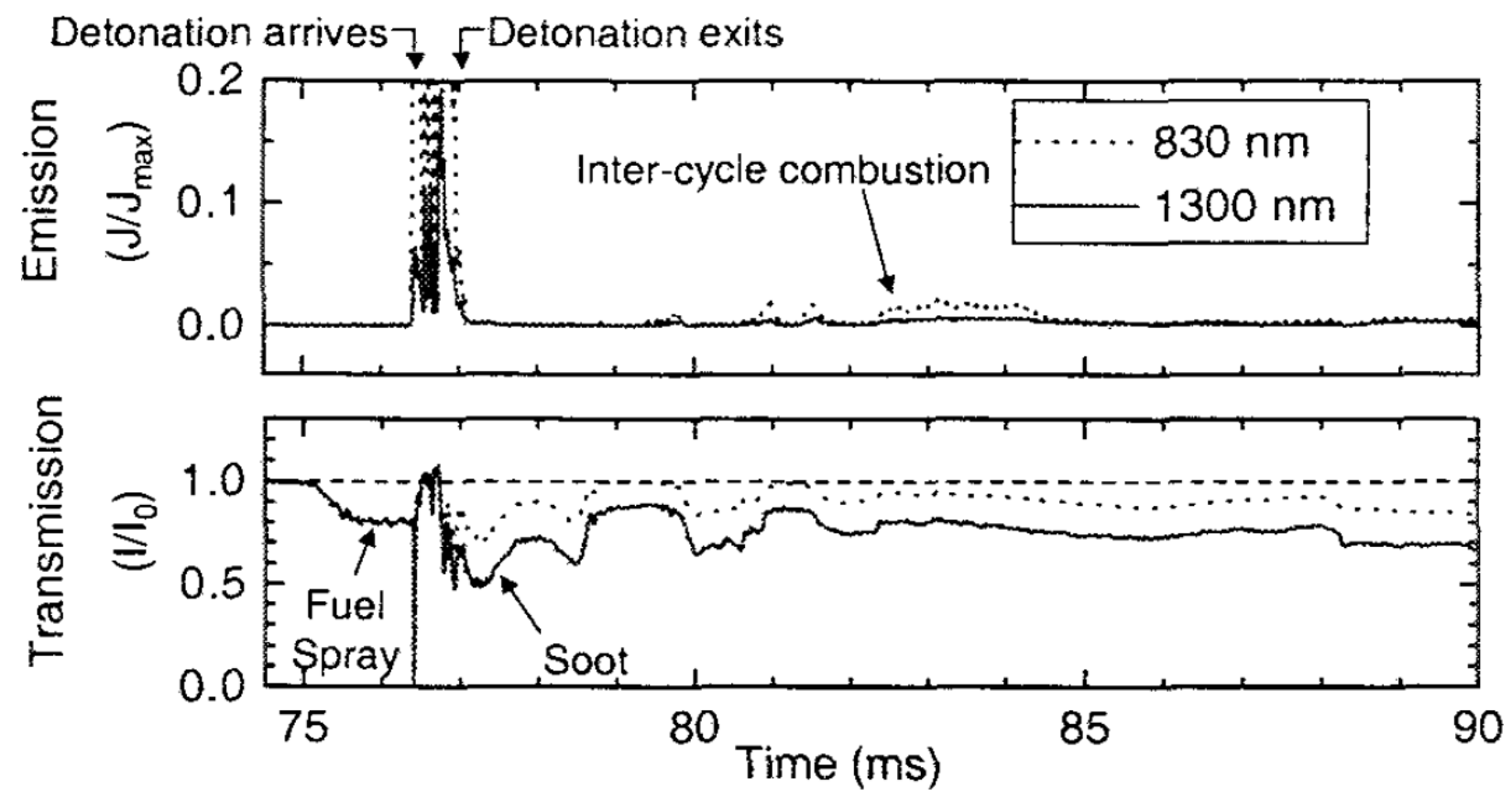

Figure 2.3 Emission and Laser Transmission Data ${ }^{19}$

Cycle management can also affect efficiency. One method that has been shown to increase PDE efficiency is referred to as partial filling. Partial filling of the combustion tube occurs when only a fraction of the tube is filled with a fuel-oxidizer mixture and the remainder is filled with purge air. This ratio between fueled and un-fueled gas is commonly referred to as fill fraction. It is believed this technique increases the relaxation time and thereby the efficiency of the cycle $^{20,21}$. The detonation wave produces a shock, compressing the noncombustible material and extending the blow-down process within the tube ${ }^{21}$. This time duration of positive pressure 
against the thrust wall is the limiting time at which the purge/refueling cycle can begin and is a limiting factor on the maximum operational frequency ${ }^{22}$. An additional concern studied by Qiu et $\mathrm{al}^{23}$ investigated the decreased thermal efficiency produced by the heating residual purge air. The heat transferred from hot combustion products to the cool purge air during partial filling effectively reduces the amount of work available for extraction from the hot gasses, thus lowering the thermal efficiency of the cycle. The net effects of partial filling are still very encouraging and can be seen in Figure 2.4.

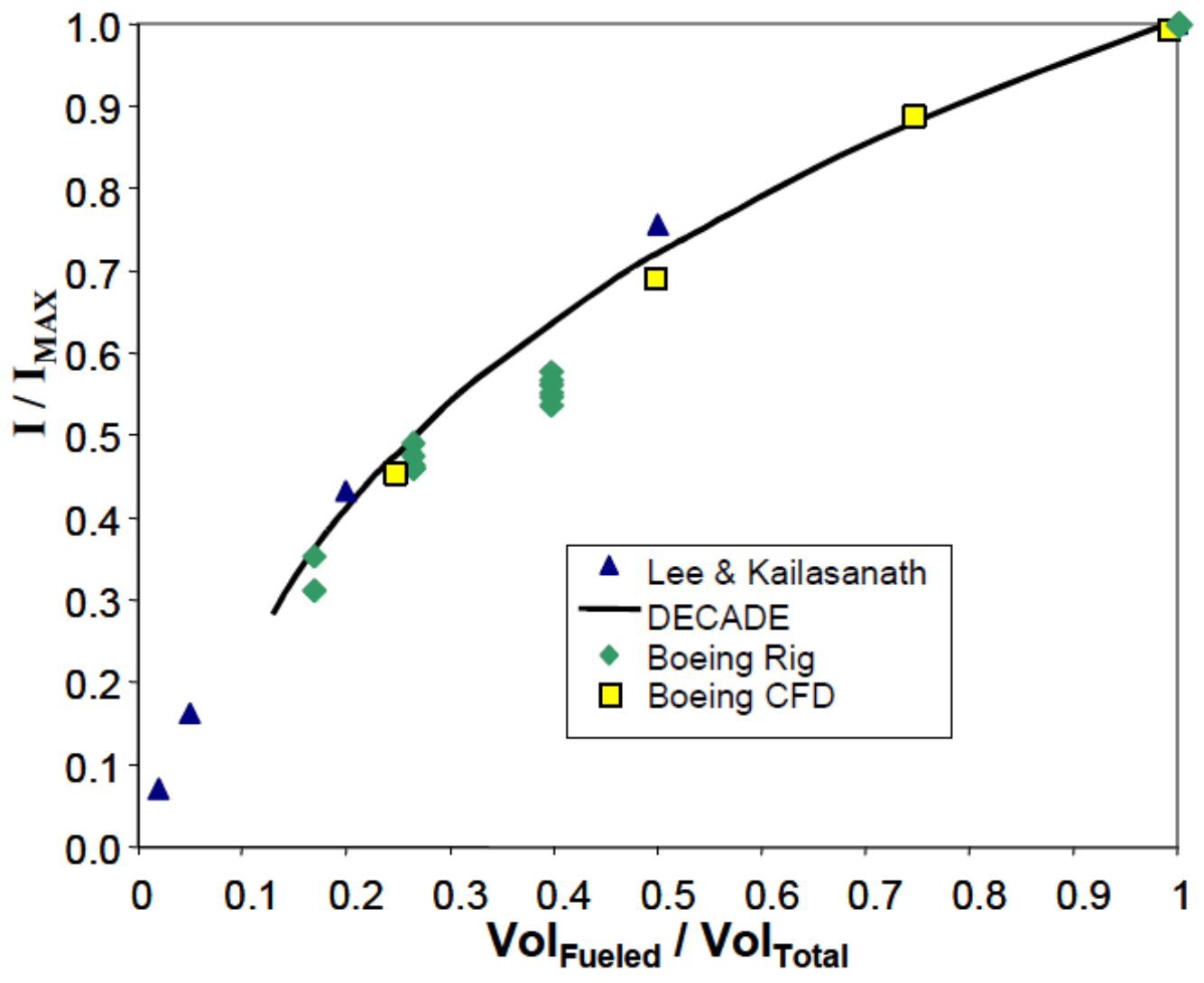

Figure 2.4 Effects of partial filling on PDE impulse ${ }^{24}$ 


\subsection{NOZZLES AND EJECTORS}

Perhaps the most intuitive way to increase the specific impulse of a PDE is through the addition of some form of nozzle or ejector. The incorporation of nozzles or ejectors are required in order to capture the energy contained within the detonation shock wave as it exits the tube ${ }^{25}$, however, the unsteady nature of PDE operation make nozzle optimization anything but straightforward. Ideal nozzle operation would require a variable nozzle capable of continuously varying its geometry throughout the detonation cycle ${ }^{8}$.

As with traditional nozzle design, several factors must be considered when designing a PDE nozzle. For one, the effectiveness of such a nozzle depends greatly on the speed of the detonation wave, and hence, the chemical properties of the combustion mixture - higher detonation speeds produce more drastic increases in specific impulse ${ }^{22}$. Fill fraction is also an important factor to consider in nozzle design. Allgood $\mathrm{et}^{2{ }^{26}}$ discovered that optimum nozzle area ratio is highly dependent on fill-fraction. In fact, for fill-fractions less than 0.5 it was determined that no nozzle produced an optimum performance. Multi-tube configurations further complicate nozzle design in that the use of either independent or common nozzles must be considered.

In addition, when examining the effects of nozzle design it is important to consider the impact of multiple detonation cycles. Yungster ${ }^{22}$ noted that although nozzles contributed as much as $80 \%$ increases in Isp during the initial cycle, the net contribution was negligible during subsequent detonations. He noted that while the initial cycle contained ambient air within the nozzle at the time of detonation, following cycles contained low density gases. It appears these gases must be purged from the nozzle in order to realize any benefits provided by the configuration. Additionally, while nozzles can be used to increase efficiency, they have also been shown to delay the relaxation rate of the combustion tube. As discussed earlier, relaxation occurs 
once the detonation wave has exited the combustion tube and the high pressure gasses are allowed to exit the combustion tube. The time required for this process to occur is referred to as the relaxation rate. Although this relaxation impediment has been shown to increase performance, such a delay could lead to longer cycle times and an overall reduction in thrust ${ }^{20}$. C-D nozzles in particular have been shown to produce slower relaxation times and have also been shown to produce pressure spikes significantly faster than without the nozzle ${ }^{27}$. These effects are seen in Figure 2.5.
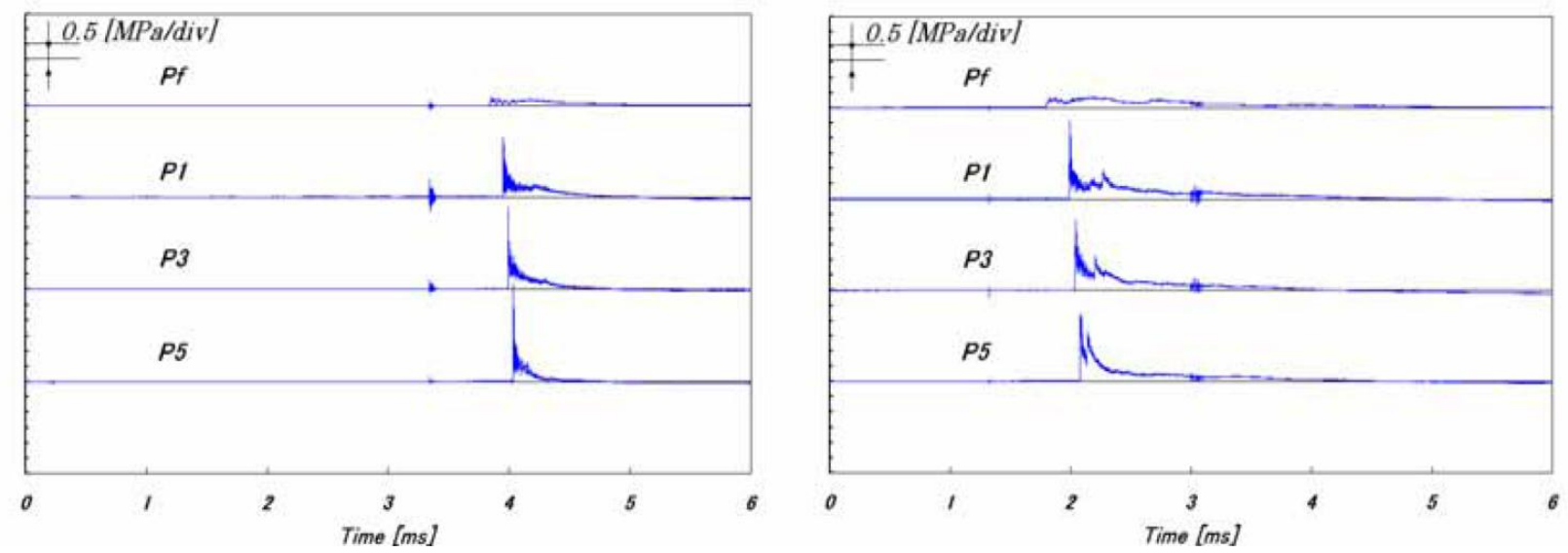

Figure 2.5 Pressure history profiles for (a) straight nozzle and (b) C-D nozzle. ${ }^{27}$

Like nozzles, ejectors such as the one shown in Figure 2.6 have demonstrated substantial increases in PDE specific impulse. In at least one study, increases of as much as 50\% have been observed. Figure 2.7 shows the effectiveness of one particular ejector and illustrates the strong dependence of performance on ejector axial position. It was also noted that the ejector outer surface does not significantly affect the flow and does not have to be well contoured in order to operate effectively ${ }^{28}$. 


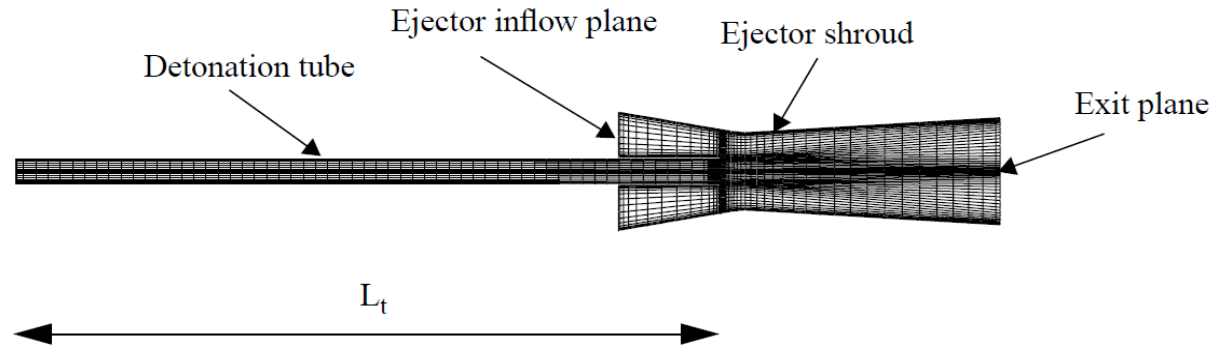

Figure 2.6 PDE with Ejector ${ }^{25}$

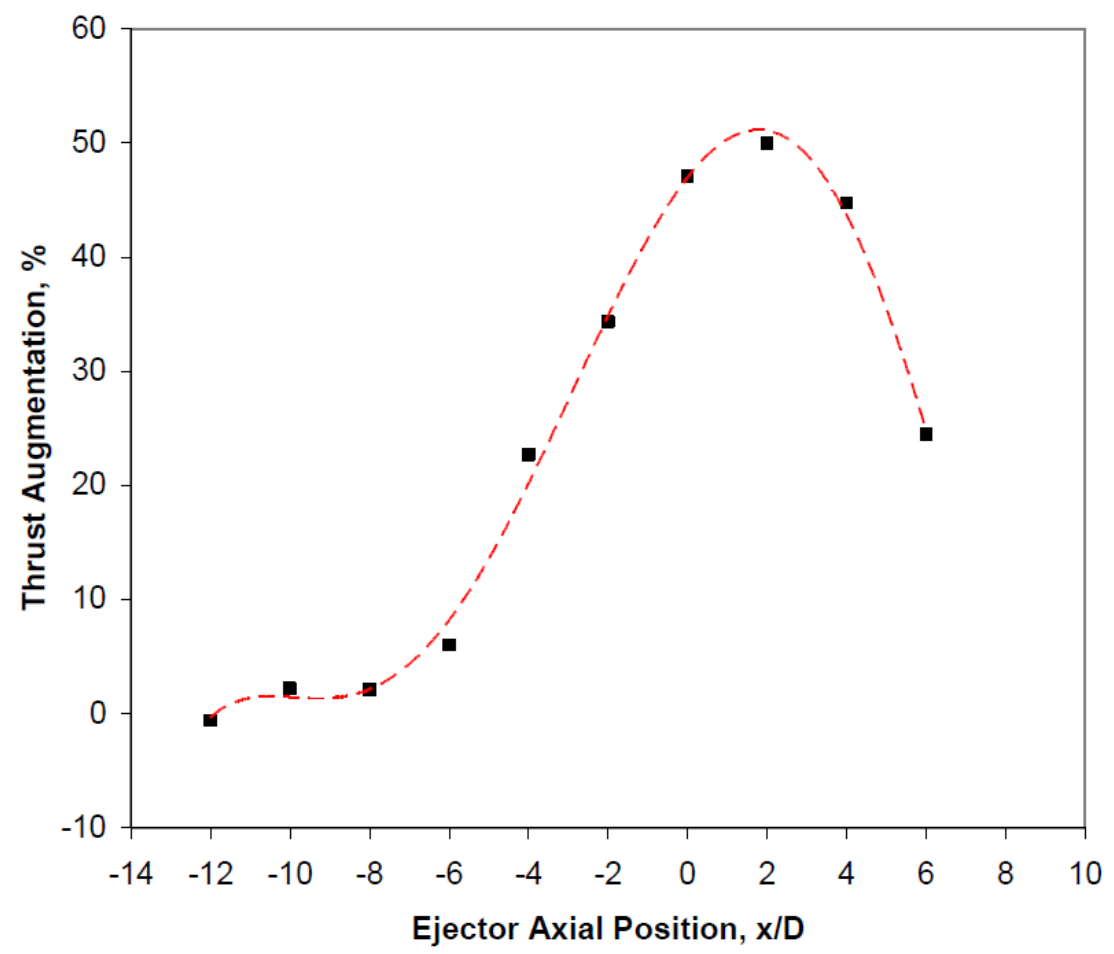

Figure 2.7 Ejector Axial Position ${ }^{28}$ 


\subsection{INTAKE SYSTEMS}

In consideration of air-breathing PDEs, inlet design presents further challenges to the advancement of this technology. The unsteady nature of operation requires a design that ultimately allows for constant flow at the engine inlet. This has been typically accomplished in one of two ways. The first is to create a large intake volume that can dampen out the unsteady oscillations of the PDE. The second is to use a single stream of air to supply multiple detonation tubes out of phase, creating a quasi-steady flow through the intake system ${ }^{29}$. Figure 2.8 show an example of how a large intake system could be configured. Potential problems with this setup include a significant increase in cross sectional area for the entire engine.

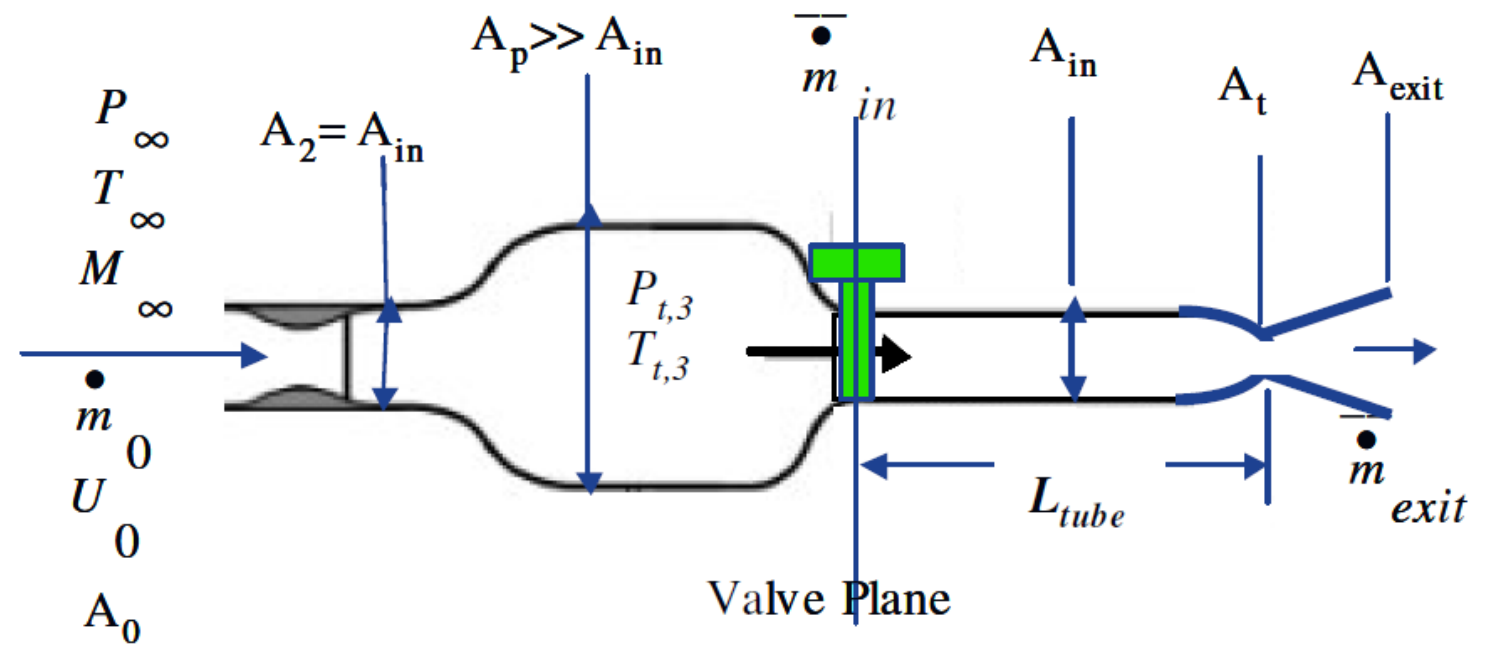

Figure 2.8 An example of a single tube, valved PDE. ${ }^{30}$

A PDE design must also include a method of isolating the upstream intake system from the combustion process. There are two primary methods of accomplishing this and, as such, PDE designs fall into one of two categories-valved PDEs or valveless PDEs. A typical valved intake system consists of either automotive poppet valves or some manner of rotary valve. This thesis is primarily focused on the automotive poppet valves used by AFRL, however, successful models 
have been developed demonstrating consistent and reliable rotary-valved PDE operation ${ }^{31}$. Experiments with valveless PDE operation are also under investigation in hopes of reducing mechanical complexity as well as to do away with the unsteady intake problem ${ }^{32}$. The use of valveless designs would significantly reduce the number of moving parts and could potentially affect the reliability of the engine. An example of a valveless PDE design is in Figure 2.9.

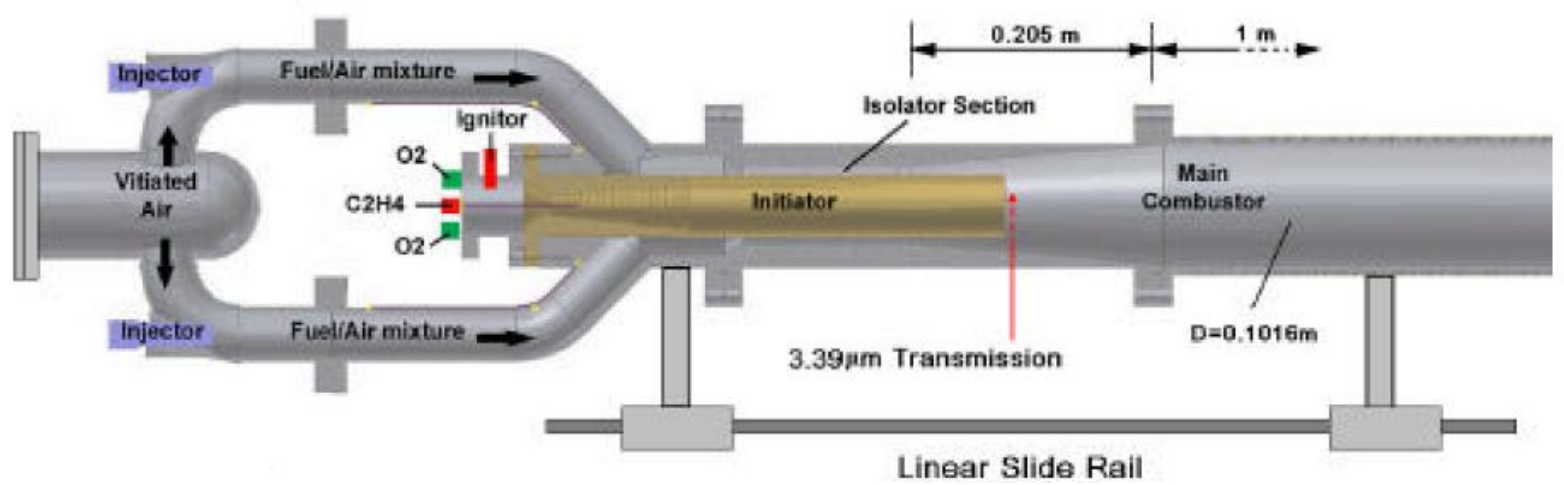

Figure 2.9 An example of a single tube, valveless PDE. ${ }^{32}$ 


\subsection{FILLING VELOCITY}

Another consideration faced by PDE design is the speed of intake gasses flowing through the combustion tube. As thrust increases the total mass flow rate increases requiring an increase in filling velocity. As the fill speed increases, the relative speed of the detonation wave to the PDE increases with it and the time spent in the combustion tube decreases. This effect has been shown to have a strong impact on the completeness of combustion. A technique known as tail-initiated detonation has been investigated as a possible solution to combat these high filling velocities. A detonation wave of this type is initiated at the exhaust end of the detonation tube and travels forward to the intake end. This allows the detonation wave to travel slower relative to the combustion tube and allow for a more complete combustion ${ }^{33}$. Figure 2.10 illustrates these effects along with a diverging trend between head and tail detonations as filling velocity is increased. While tail-initiated detonations may provide greater efficiencies under certain circumstances, they make it more difficult to exploit efficiencies from techniques such as partial filling.

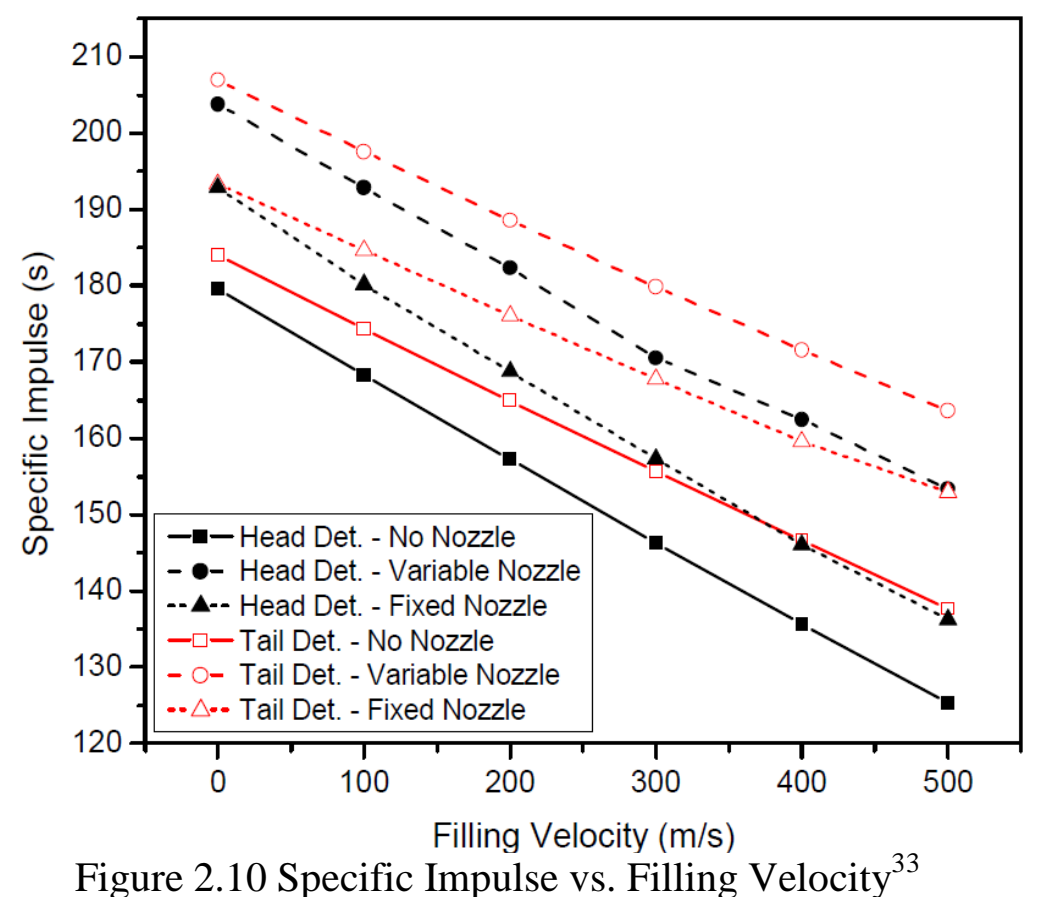




\subsection{ACOUSTICS AND IGNITION DELAY}

Acoustic properties of PDE design play a critical role in designing an optimized PDE cycle. As shown in Figure 2.11, the resonance frequency of the combustion tube creates sinusoidal pressure waves during the "fire" portion the PDE cycle-defined as the time between the closing of the intake valve and the opening of the purge valve. This effect can be harnessed to produce higher levels of efficiency than would otherwise be observed in static experimental setups by optimizing an ignition timing delay into the cycle.

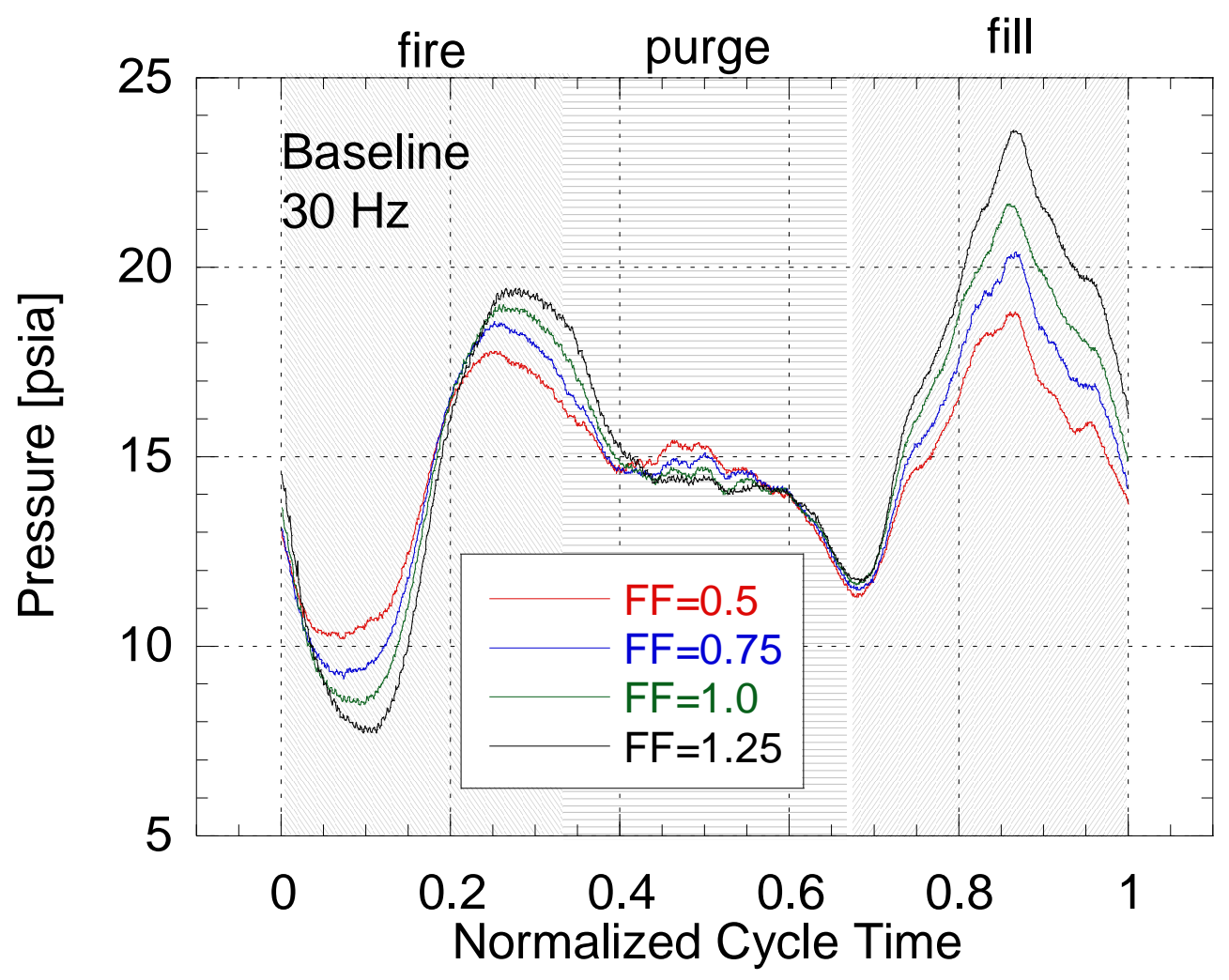

Figure 2.11 Cold flow pressures at various fill fractions (FF) (courtesy of AFRL)

As expected, a sinusoidal behavior has been demonstrated producing as much as an $8 \%$ increase and 5\% decrease from the average thrust produced by simply modifying the ignition 
timing. This behavior is due to the local pressure state at the time of ignition and is dependent on the acoustical properties of the tube as mentioned ${ }^{26}$. These effects can be seen in figure 2.12 .

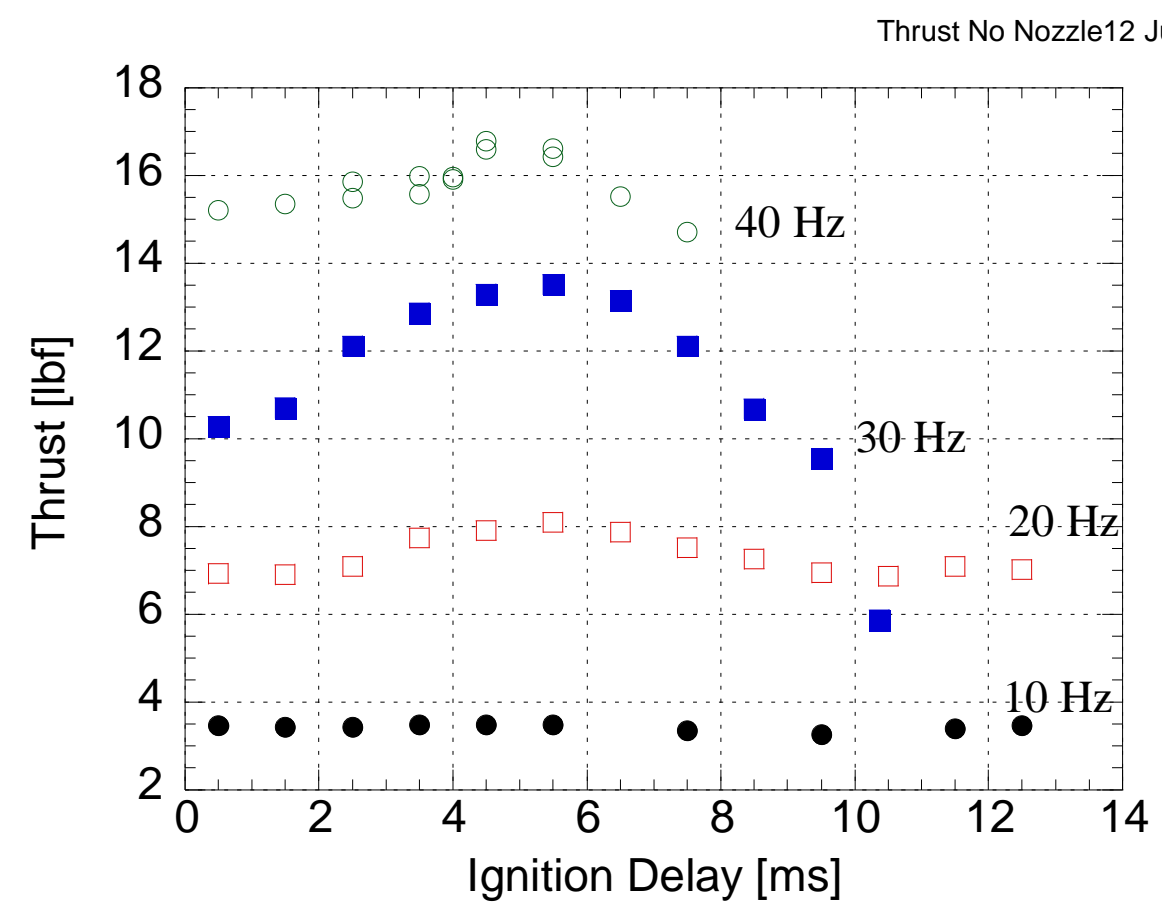

Figure 2.12 Effects of ignition delay at various PDE operating frequencies. (courtesy of AFRL)

An additional concern regarding PDE development is the noise and vibration produced during operation. In order to make PDE technology practical, the environmental noise constraints that will inevitably be required by the aviation industry must be taken into consideration. Multiple studies ${ }^{34,35}$ have been conducted to determine what factors influence noise levels during PDE operation. Results suggest nozzle length, area ratio, and fill-fraction all contribute to the acoustic properties of $\mathrm{PDEs}^{35}$. Vibrations themselves are also of concern. Initial data shows an asymptotic limit of approximately $140 \mathrm{~dB}$ at $9.5 \mathrm{ft}^{34}$. 


\subsection{ARRANGEMENT}

In order to avoid impractical PDE dimensions that would accompany large single tube operations, arrays of smaller PDE combustion tubes have been operated in a variety of configurations to produce adequate thrust within practical package sizes. An example of this is the ITR-2 PDE being developed by the Office of Naval Research (Figure 2.13). In addition, the use of multiple detonation tubes in concert with a common nozzle has been shown to increase backpressure wherein a common choke point can be achieved ${ }^{8,36}$. This configuration has also been tested on the ITR-2 PDE (Figure 2.14).

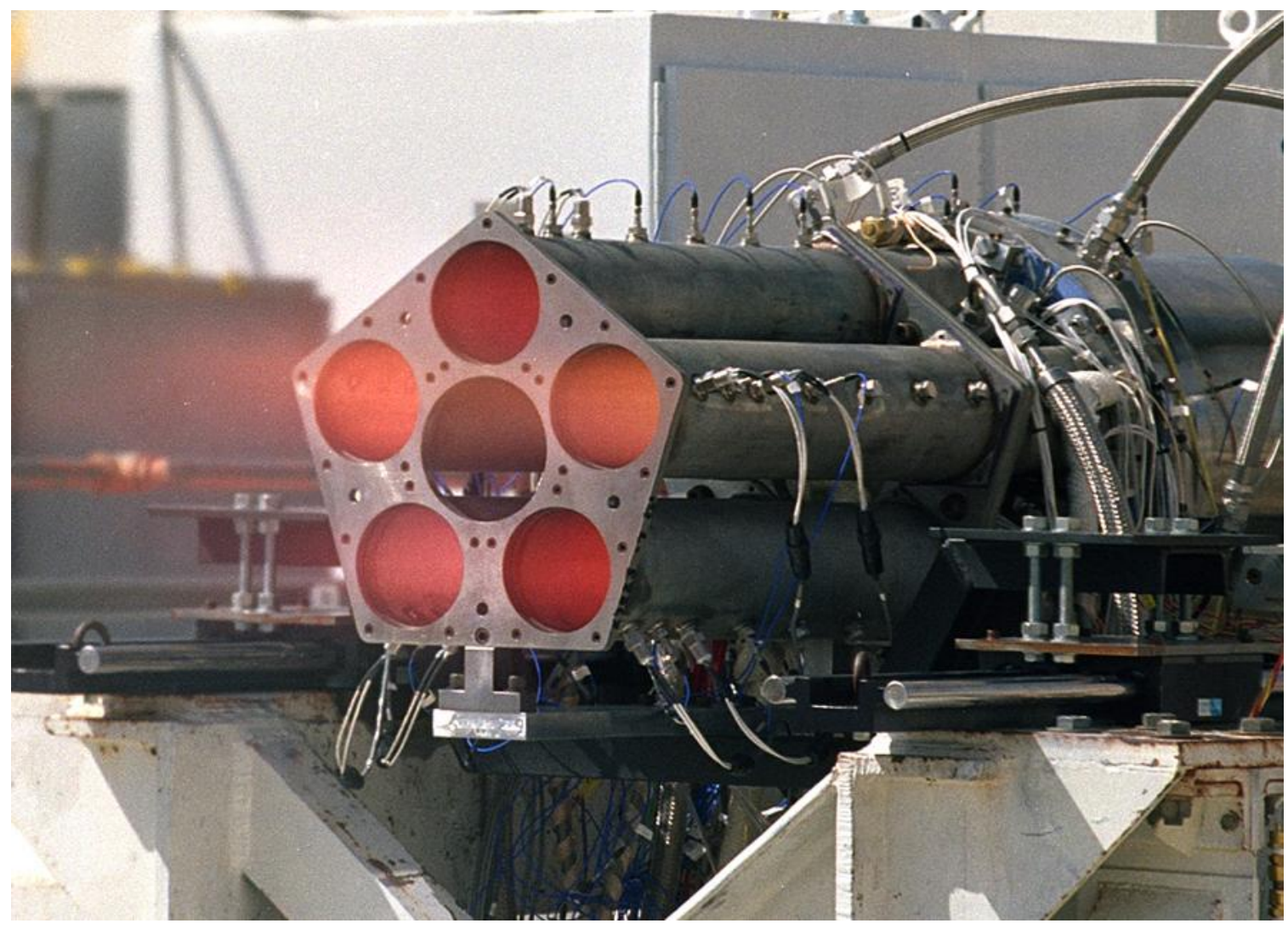

Figure 2.13 ITR-2 PDE ${ }^{8}$ 


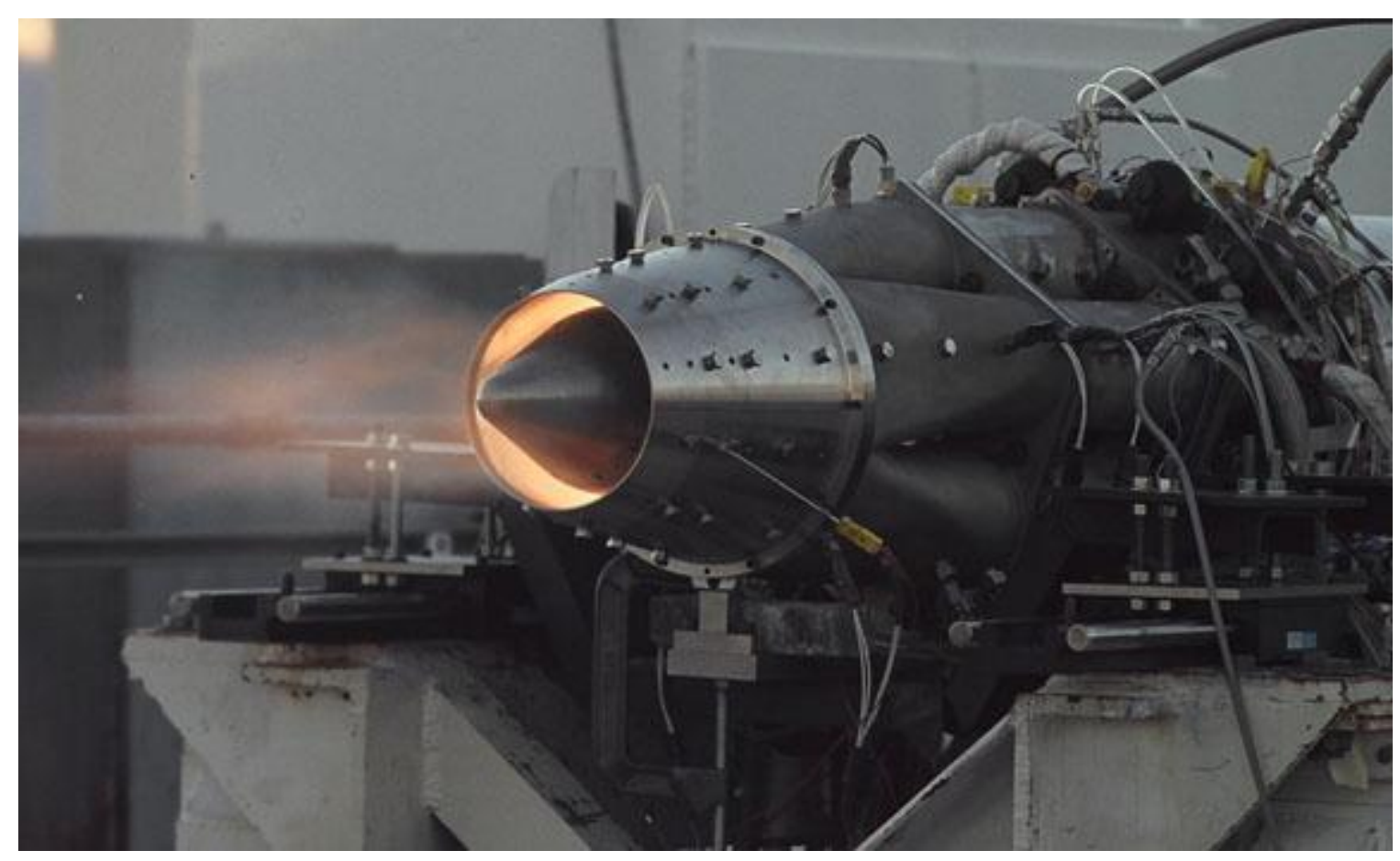

Figure 2.14 ITR-2 PDE with Common Nozzle ${ }^{8}$

In addition to permitting manageable dimensions, multiple tube configurations provide additional variables that can be used to enhance efficiency as well as performance. For example, the firing order of detonation has been investigated and can drastically affect Isp. It was noted that firing multiple tubes simultaneously, rather than in sequence, resulted in lower exit temperatures and hence an increase in efficiency ${ }^{37}$. Furthermore, multiple detonation tube configurations may allow for thrust vectoring applications by varying individual PDE output across an array of combustion tubes ${ }^{36}$. 


\subsection{EQUIVALENCE RATIO}

Equivalence ratio also has a significant impact on the performance of PDEs, however, much of the research available regarding this topic focuses on an overall idealized equivalence ratio for the entire system as shown in Figure $2.15^{24}$. As expected, hydrogen-air equivalence ratios less than one produce less thrust, yet the thrust initially decreases at a slower rate producing increased efficiencies. This ultimately results in higher Isp values, to include below stoichiometric values, and can be seen in Figure 2.16. This continues to down to a ratio of about 0.67 where a significant drop in both experimental thrust and Isp values suggest that equivalence ratios less than this value will not transition to detonation. ${ }^{38}$

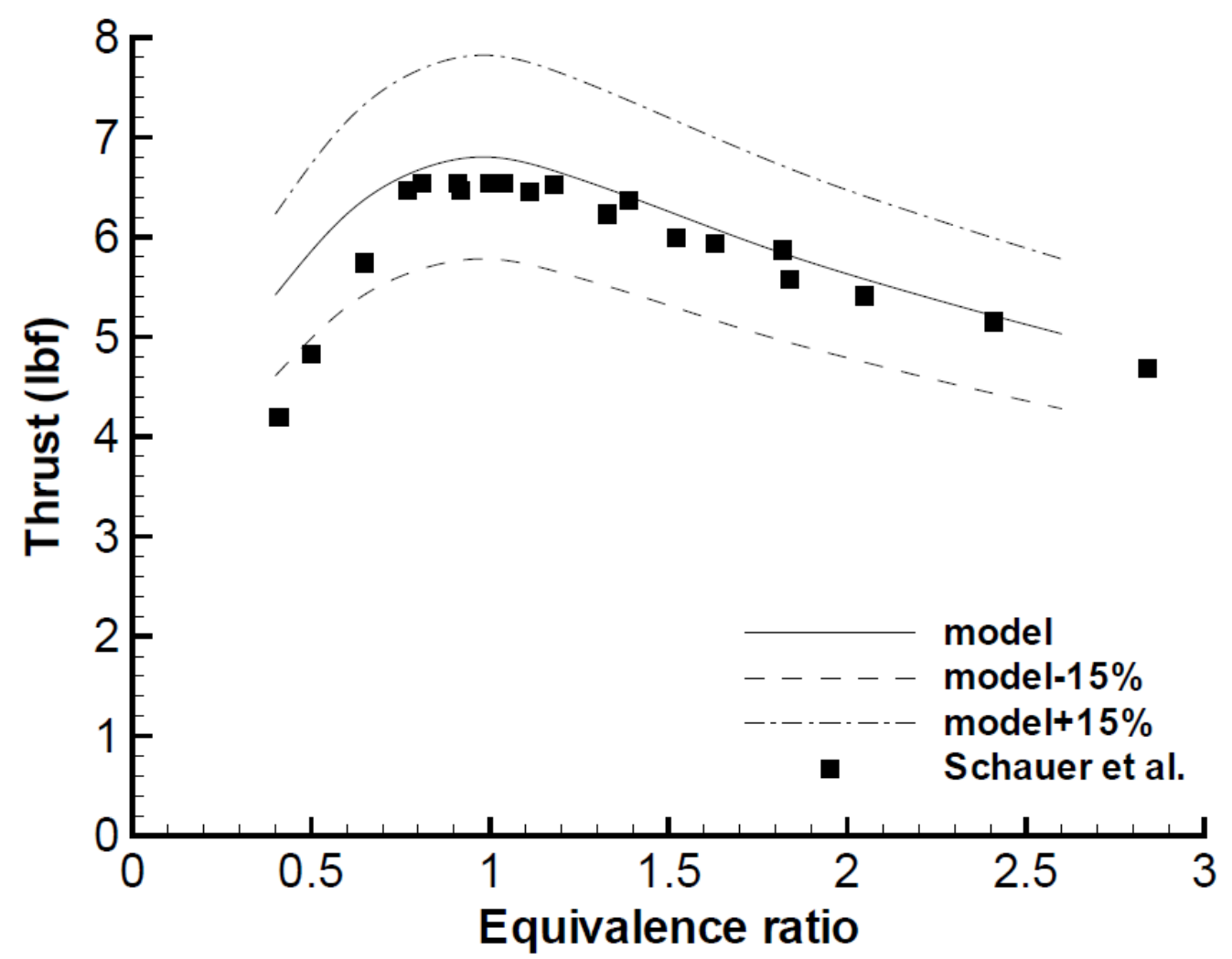

2.15 Effect of equivalence ratio on thrust ${ }^{38}$. Reader is referred to reference 39 for model details. 


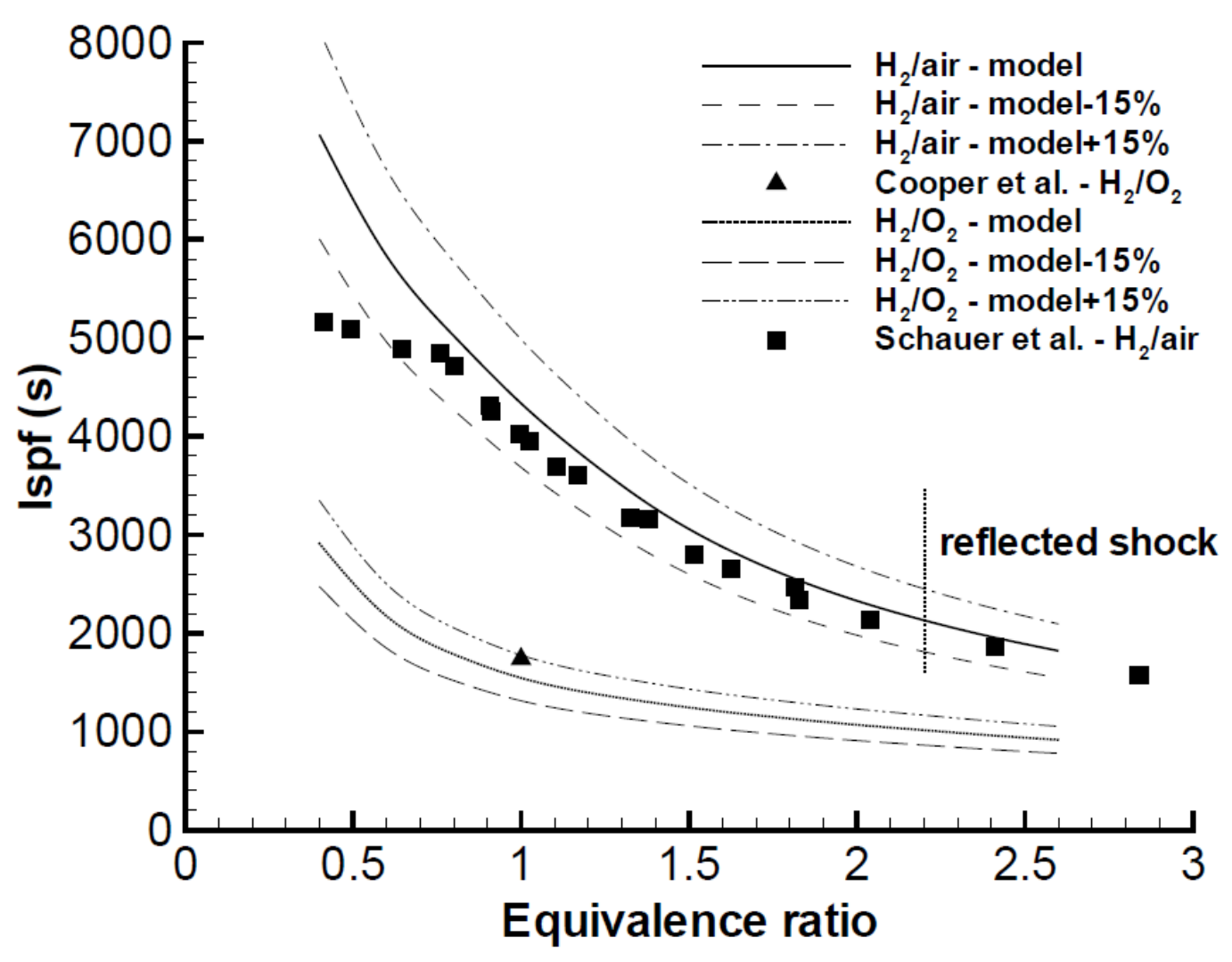

Figure 2.16 Effects of Equivalence Ratio on Isp ${ }^{38}$

The program discussed in this thesis focuses not only on this average equivalence ratio, but will also investigate local perturbations due to non-ideal fuel injection considerations. It has been noted that non-uniform equivalence ratios within the PDE cycle can have a significant impact on PDE performance. If fuel-air mixtures are not kept nearly homogeneous, detonation can "quickly become impractical." It has also been shown that equivalence ratio plays a critical role in detonation cell structure. Schauer et $\mathrm{al}^{2}$ noted that "large droplets and poor mixing will significantly increase cell width and dramatically impact initiation energy or DDT distance."

Cell width is a term that references intersecting transverse waves that travel laterally behind the detonation shock wave. These intersections produce triple point phenomena that generate extremely high local pressures and temperatures and increase the speed and stability of the detonation wave. ${ }^{13}$ It has been shown that successful detonation requires a cell size such that $7 \lambda$ 
is less than the length of the DDT obstacles used. In a similar manner, critical initiation energythe energy required to initiate detonation—is also affected by equivalence ratio. These effects can be seen below in Figure 2.17. As equivalence ratios stray from stoichiometric, we see a substantial increase in both cell width and critical initiation energy. Although the intricacies of these detonation cell structures are not captured in the Q1D model used, the macroscopic nonuniform equivalence ratios should produce measurable effects on PDE performance. ${ }^{38}$
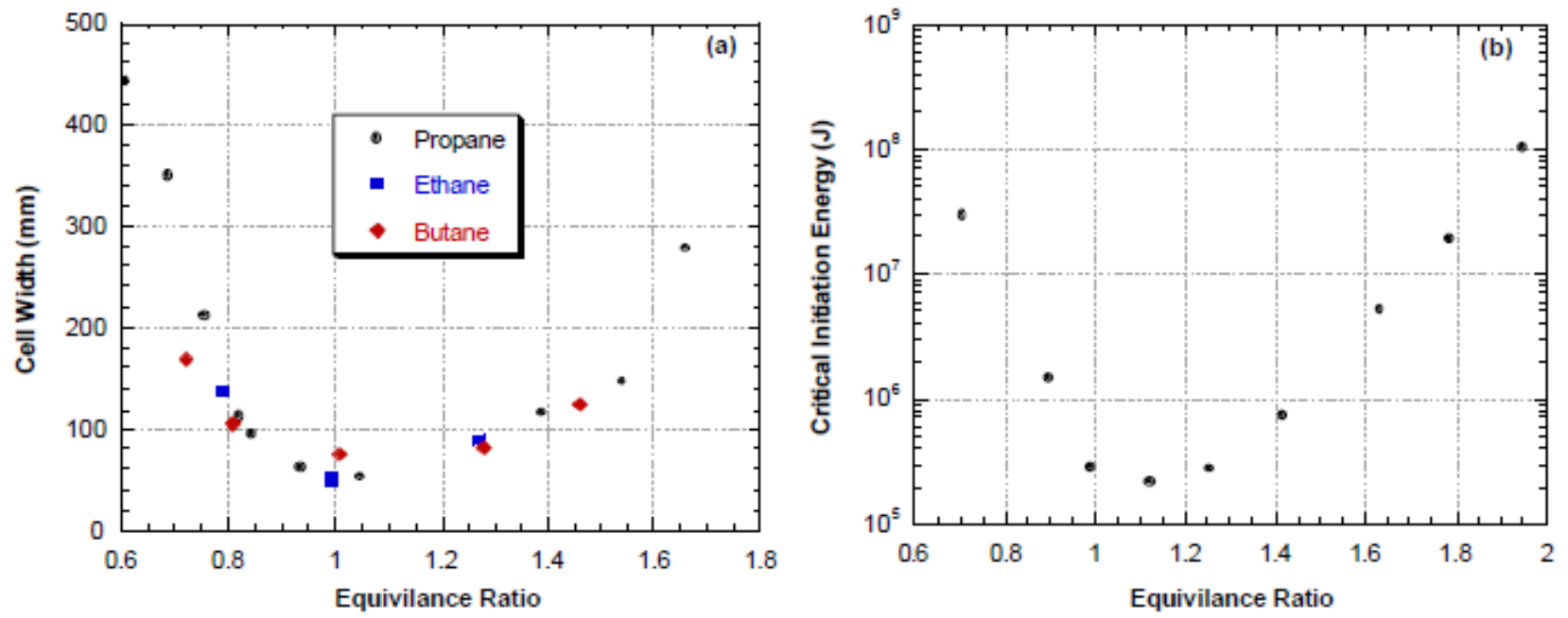

Figure 2.17 Effects of equivalence ratio on hydrocarbon-air cell width and propane-air critical initiation energy ${ }^{24}$ 


\section{CHAPTER 3 - EXPERIMENTAL SETUP \& SIMULATION MODEL DETAILS}

\subsection{EXPERIMENTAL SETUP}

A convenient advantage afforded PDE research is the availability of off-the-shelf commercial automotive components that are well suited for PDE prototype design. Automotive engine heads such as the Chevrolet Vortec 4200 and GM Quad 4 along with standard spark plugs, ignition systems, turbochargers, and many other components are just a few examples of items used in the fabrication process ${ }^{39}$. While these parts may not be optimized for PDE operation, they provide a practical means for expediting proof of concept development. This also provides substantial cost savings by reducing part fabrication requirements.

The PDE rig modeled in this thesis and shown in Figure 3.1 consists of a modified Quad 4 automotive head mounted on a thrust stand and driven by an electric motor. As many as four stainless steel detonation tubes can be mounted to the head, which is fed a premixed supply of hydrogen and air. During operation, the variable speed electric motor drives four valves in each combustion tube - two intake valves and two purge valves. The timing is restricted by the camshaft and is fixed at $1 / 3$ of each cycle dedicated to each of the fill, detonation, and purge phases. Variable fill ratios are controlled using choked mass flow upstream of the intake system. The ignition performed by a standard automotive coil and spark plug producing a $40 \mathrm{~mJ}$ spark to ignite the fuel. The engine is mounted to a thrust stand designed to measure average thrust of operation. Actuators consistently move the stand back and forth throughout the test negate static friction effects. Since the net thrust from these actuators is zero, the average thrust measured is 
purely that generated by the PDE. The entire system is controlled by a LabView interface allowing simple access to multiple input parameters ${ }^{37}$.

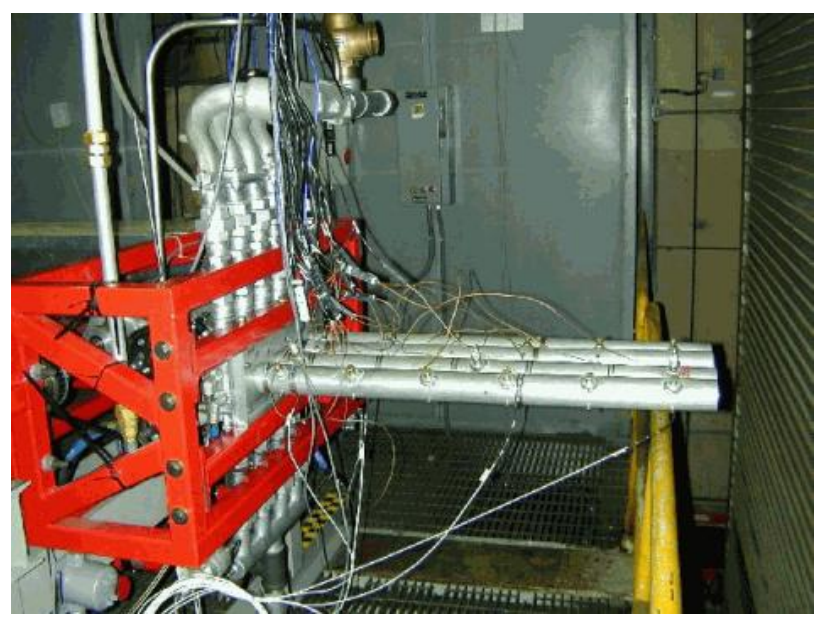

Figure 3.1 PDE experimental setup at WPAFB-AFRL (courtesy of AFRL).

The intake system is approximately 20 feet long and is primarily constructed of 2-inch ID metal tubing. Flow into the intake is choked to ensure constant mass flow into the system. Constant fuel flow is injected at a point 10 feet from the intake valve. The fuel mass flow rate is set to ensure an average equivalence defined by the user is maintained. Although this equivalence ratio is constant for the overall cycle, there is considerable variation in local equivalence ratios throughout the PDE cycle. The near constant flow of fuel into an unsteady stream of air is the source of these variations. The effects of this dynamic process will be discussed in later sections. 


\subsection{SIMULATION}

There are two principal approaches used to model PDE operation. One of these utilizes thermodynamic and analytic models while the second approach involves numerical simulations ${ }^{9}$. While each approach has unique advantages and disadvantages, this thesis will focus on numerical simulations alone. We also confine ourselves to a simple quasi-one-dimensional model (Q1D). While the development of programs such as General Propulsion Analysis Chemical Kinetic and Two-Phase (GPACT) are powerful tools used to model three-dimensional, finite-rate chemistry flow fields ${ }^{40}$, it comes at a substantial computational cost. That said, there is still substantial insight to be gained from simple Q1D models, providing a balance between computational requirements and physical representation of PDE operation ${ }^{36}$.

The ability of Q1D simulations to accurately model PDE operation has already been shown. Watanabe et al ${ }^{41}$ was able to produce a simple Q1D model that delivered wave speed results within $2 \%$ of the chemical equilibrium software AISTJAN, at less than a tenth of the computation time. Aside from their low computational cost, Q1D codes are also able to accurately model longitudinal wave dynamics that are essential to understanding the dynamic PDE environment ${ }^{33}$. Typical convergence rates observed in at least one other Q1D model were 5-7 detonations cycles ${ }^{36}$.

The model used in this thesis incorporates the Euler equations of motion coupled with an additional source term to account for the chemical energy released during combustion as well as the effects of shear forces and heat transfer to the combustion tube wall. In order to ensure that the chemical kinetics shown in Figure 3.2 are properly modeled, an integration time step of 10${ }^{12} \mathrm{~S}$ would be required ${ }^{42}$. This fidelity, however, is not practical and presents an unrealistic computational cost. Instead, we treat sources as digital logic with respect to a user-defined 
reaction temperature threshold and cells are integrated separately modeling transition from product to reactant using a simple reaction constant. ${ }^{1}$

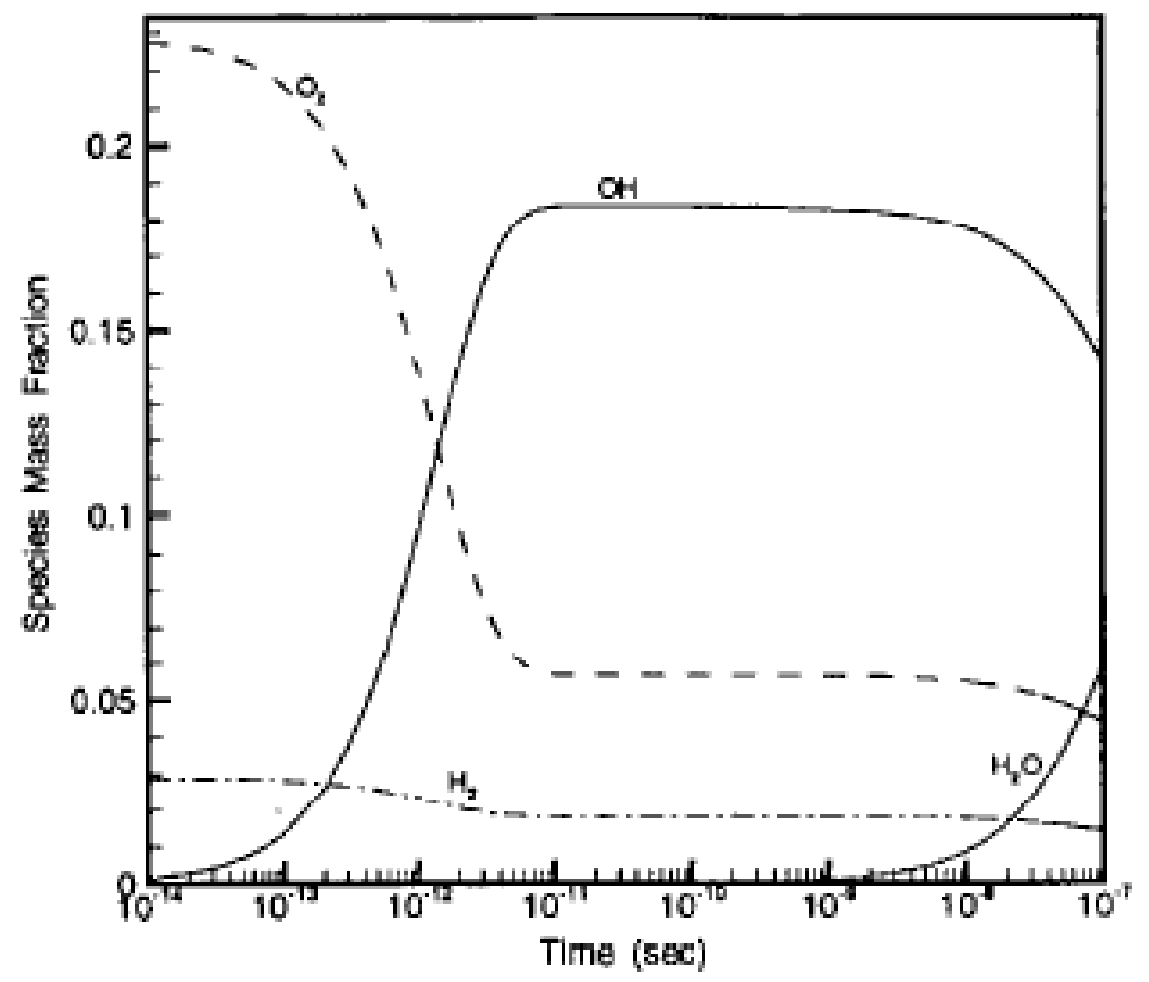

Figure 3.2 Mass Fraction History ${ }^{42}$ 


\subsection{EQUATIONS OF MOTION}

The simulation is built around a "high-resolution, time-accurate, single progress variable, reactive Q1D CFD code which integrates differential equations of motion for a calorically perfect gas."1 The equation of motion is of the form

$$
\frac{\partial \mathrm{w}}{\partial \mathrm{t}}+\frac{\partial \mathrm{F}(\mathrm{w})}{\partial \mathrm{x}}=\mathrm{S}(\mathrm{w}, \mathrm{x})
$$

where

$$
\begin{gathered}
\mathrm{w}=\left[\begin{array}{c}
\rho \mathrm{A} \\
\rho \mathrm{uA} \\
\left(\frac{\mathrm{p}}{\gamma(\gamma-1)}+\frac{\rho \mathrm{u}^{2}}{2}+\rho \mathrm{zq}_{0}\right) \mathrm{A} \\
\rho \mathrm{zA}
\end{array}\right] \\
\mathrm{F}=\left[\begin{array}{c}
\rho \mathrm{uA} \\
\left(\frac{\mathrm{p}}{\gamma}+\rho \mathrm{u}^{2}\right) \mathrm{A} \\
\mathrm{u}\left(\frac{\mathrm{p}}{\gamma-1}+\frac{\rho \mathrm{u}^{2}}{2}+\rho \mathrm{zq} \mathrm{q}_{0}\right) \mathrm{A} \\
\rho \mathrm{uzA}
\end{array}\right] \\
\mathrm{S}(\mathrm{w}, \mathrm{x})=\left[\begin{array}{c}
0 \\
\mathrm{p} \frac{\mathrm{dA}}{\mathrm{dx}}-2 \mathrm{C}_{\mathrm{f}}\left(\frac{\mathrm{L}}{\mathrm{D}^{*}}\right) \sqrt{\mathrm{A}} \mathrm{u}|\rho \mathrm{u}| \\
\frac{-4 \mathrm{St} \sqrt{\mathrm{A}}}{\gamma-1}\left(\frac{\mathrm{L}}{\mathrm{D}^{*}}\right)|\rho \mathrm{u}|\left(\mathrm{T}-\mathrm{T}_{\mathrm{wall}}\right) \\
-\mathrm{A} \rho \mathrm{z}\left\{\begin{array}{c}
\mathrm{K}_{0} ; \mathrm{T} \geq \mathrm{T}_{\mathrm{C} 0} \\
0 ; \mathrm{T}<\mathrm{T}_{\mathrm{C} 0}
\end{array}\right\}
\end{array}\right]
\end{gathered}
$$

All variables are non-dimensional and have been normalized using reference states and/or dimensions. Combustion is achieved any time the temperature of the fluid exceeds the predetermined ignition temperature $\left(\mathrm{T}_{\mathrm{C} 0}\right)$. The program assumes ideal gas laws and accounts for heat transfer effects from both the tube and any DDT obstacles that may or may not be present. 


\subsection{AUTOMOTIVE HEAD SUB-MODEL}

An automotive head sub-model is coupled with an inlet code to provide boundary conditions for the primary Roe solver and is governed by the following equations.

$$
\begin{gathered}
\frac{\mathrm{d} \rho_{\mathrm{H}}}{\mathrm{dt}}=\frac{\mathrm{LA}}{\mathrm{V}_{\mathrm{H}}}\left(\frac{\dot{\mathrm{m}}_{\text {in }}}{\rho^{*} \mathrm{a}^{*} \mathrm{~A}^{*}}-\rho_{0} \mathrm{u}_{0} \mathrm{~A}_{0}\right) \\
\frac{\mathrm{dp}}{\mathrm{dt}}=\frac{\gamma \mathrm{LA} A^{*}}{\mathrm{~V}_{\mathrm{H}}}\left(\frac{\dot{\mathrm{m}}_{\text {in }} \mathrm{T}_{\mathrm{in}}}{\rho^{*} \mathrm{a}^{*} \mathrm{~A}^{*}}-\rho_{0} \mathrm{u}_{0} \mathrm{~A}_{0} \mathrm{~T}_{\mathrm{H}}\right)+\gamma(\gamma-1) \mathrm{K}_{0} \rho_{\mathrm{H}} \mathrm{Z}_{\mathrm{H}} \\
\frac{\mathrm{d}\left(\rho_{\mathrm{H}} \mathrm{z}_{\mathrm{H}}\right)}{\mathrm{dt}}=\frac{\mathrm{LA}}{\mathrm{V}_{\mathrm{H}}}\left(\frac{\dot{\mathrm{m}}_{\text {in }} \mathrm{z}_{\text {in }}}{\rho^{*} \mathrm{a}^{*} \mathrm{~A}^{*}}-\rho_{0} \mathrm{u}_{0} \mathrm{~A}_{0} \mathrm{Z}_{\mathrm{H}}\right)+\mathrm{K}_{0} \rho_{\mathrm{H}} \mathrm{Z}_{\mathrm{H}}
\end{gathered}
$$

The stagnation state of the head cavity model is calculated using first order Euler integration and was originally calculated using predetermined constant mass flow rates and equivalence ratios. The modified program now includes dynamic mass flow rates into this head model, subject to intake manifold conditions, and will be discussed in detail below. In order to model the automotive ignition system the temperature restriction for combustion within the head cavity is temporarily removed and a significantly smaller value for $\mathrm{K}_{0}$ is used in order to mimic spark initiated combustion ${ }^{1}$. 


\subsection{INTAKE MODEL}

The addition of an intake system to the original program was undertaken to explore the effects of local variations in equivalence ratio on performance. The intake manifold is fed with a constant mass flow rate of air by a choked valve well upstream of the model. At a point much closer to the inlet valve, fuel is injected at a constant rate. The opening and closing of the inlet valve with each cycle creates unsteady air mass flow rates over the injector and produces local fluctuations in equivalence ratios throughout the system. The same CFD code used in the original program was adapted to calculate the intake flow. In order to accomplish this, the automotive head sub-model above was also adapted to provide stagnation conditions at three of the four boundaries as shown in Figure 3.3. This same process is used to produce boundary conditions at each end of the intake system.

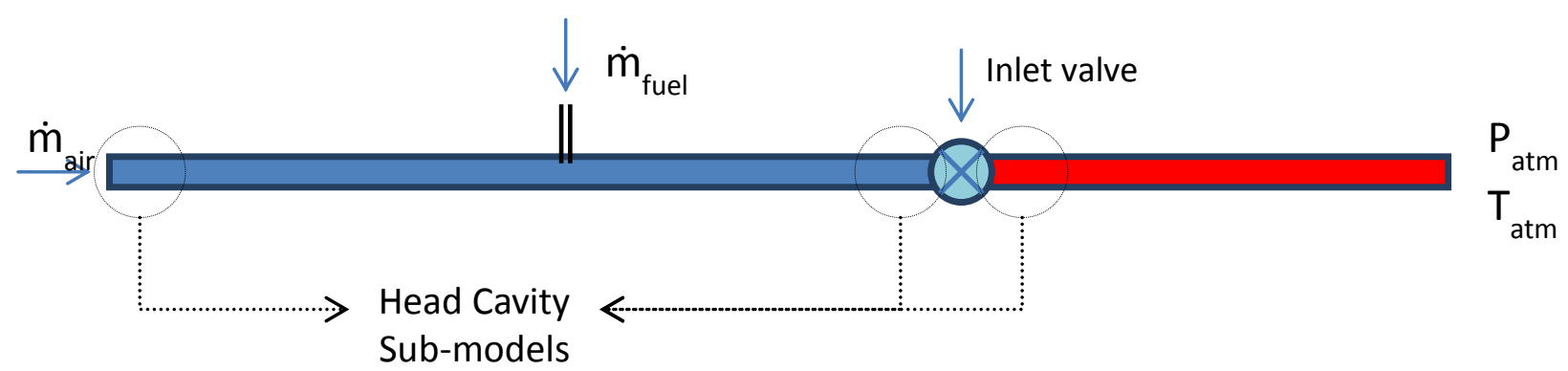

Figure 3.3 Valve Model Mass Flow Rate

In order to model the constant fuel flow the addition of a source term was required to produce an average overall equivalence ratio as specified by the user. If we assume steady flow the equation of motion becomes.

$$
\frac{\partial \mathrm{F}(\mathrm{w})}{\partial \mathrm{x}}=\mathrm{S}_{\mathrm{inj}}(\mathrm{W}, \mathrm{X})
$$

We also assume that $\dot{\mathrm{m}}_{\mathrm{f}} \ll \dot{\mathrm{m}}_{\text {air }}$ 


$$
\mathrm{S}_{\mathrm{inj}}(\mathrm{w}, \mathrm{x})=\left[\begin{array}{c}
0 \\
0 \\
\frac{\partial \mathrm{u}\left(\frac{\mathrm{p}}{\gamma-1}+\frac{\rho \mathrm{u}^{2}}{2}+\rho z \mathrm{zq}_{0}\right) \mathrm{A}}{\partial \mathrm{x}} \\
\frac{\partial \rho \mathrm{uzA}}{\partial \mathrm{x}}
\end{array}\right]
$$

and negligible pressure and kinetic contributions such that

$$
S_{\text {inj }}(w, x)=\left[\begin{array}{c}
0 \\
0 \\
\overline{\rho u} A q_{0} \frac{\partial z}{\partial x} \\
\overline{\rho u} A \frac{\partial z}{\partial x}
\end{array}\right]
$$

where

$$
\partial \mathrm{z}=1
$$

This additional source vector was added to the Roe solver at a user determined point along the intake system. Due to the limitations of the combustion code any equivalence ratio greater than one will result in erroneous data. Therefore, we limit $\varphi$ to values that ensure local deviations do not exceed this constraint within the combustion tube. 


\subsection{VALVE SUB-MODEL}

The intake system described above is linked to the original PDE tube by a simple intake valve model. This valve model accounts for both choked and un-choked flow and is capable of flow reversal. Dimensions of the Quad 4 automotive valves were combined with a sinusoidal valve displacement to estimate the average curtain area opening throughout a cycle ${ }^{43}$.

$$
\bar{A}_{\text {Valve }}=n L_{V} \frac{\int_{0}^{t_{\text {fill }} \frac{1}{2}\left(1-\cos \frac{\omega t}{t_{\text {fill }}}\right) d t}}{t_{\text {fill }}}
$$

The flow is then determined to be choked or un-choked and, if applicable, a subsonic inflow Mach number is calculated.

$$
M=\sqrt{\frac{2}{\gamma-1}\left[\left(\frac{P_{0}}{P_{a t m}}\right)^{\frac{\gamma-1}{\gamma}}-1\right]}
$$

Mass flow rate calculations follow

$$
\dot{\mathrm{m}}_{\text {in }}=\mathrm{C}_{\mathrm{f}} \frac{\mathrm{t}_{\text {fill }}}{\mathrm{t}_{\text {cycle }}} \frac{\overline{\mathrm{A}}_{\text {Valve } \mathrm{P}_{0}}}{\sqrt{\gamma \mathrm{RT}_{0}}} \mathrm{M}\left[\gamma\left(1+\frac{\gamma-1}{2} \mathrm{M}^{2}\right)^{-\frac{\gamma+1}{2(\gamma-1)}}\right]
$$

where

$$
\mathrm{C}_{\mathrm{f}}=\frac{\dot{\mathrm{m}}_{\text {actual }}}{\dot{\mathrm{m}}_{\text {reference }}}
$$

A value of 0.9 for $C_{f}$ provides an excellent approximation of the mass flow rates observed at AFRL. Figure 3.4 is a comparison between the model and this experimental data. 


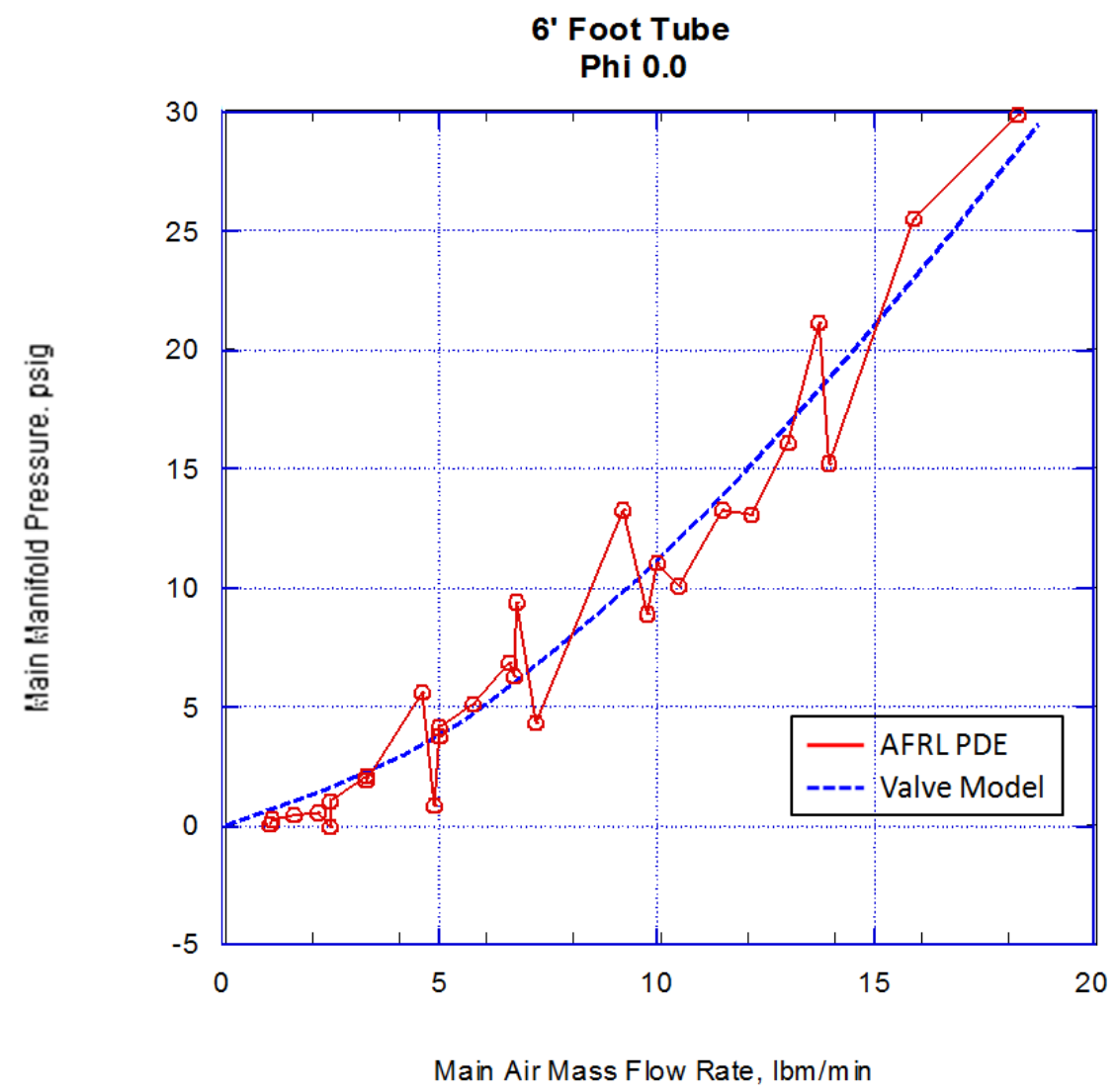

Figure 3.4 Valve model mass flow rate vs. intake manifold pressure. 


\subsection{THRUST CALCULATION}

Glaser et $\mathrm{al}^{44}$ found that thrust predictions using head pressure tend to over-predict measured thrust due to pressure losses generated by obstacles within the PDE tube. To account for this thrust is calculated using the integrated momentum flux at the exit.

$$
\begin{gathered}
\Phi_{\text {mom }}=\mathrm{A} \int\left(\frac{\mathrm{p}}{\gamma}+\rho \mathrm{u}^{2}\right) \mathrm{dt} \\
\overline{\mathrm{T}}=\left(\frac{\Phi_{\text {mom }}}{t_{\text {cycle }}}-\frac{\mathrm{p}_{0 \text { exit }}}{\gamma} \mathrm{A}_{\text {exit }}\right) \mathrm{A}^{*} \mathrm{p}^{*} \gamma
\end{gathered}
$$




\section{CHAPTER 4 - RESULTS AND DISCUSSION}

\subsection{VALIDATION}

The unmodified version of the MATLAB program was initially validated against the original FORTRAN program in order to ensure an accurate conversion. This was accomplished using a 72-inch detonation tube operating at $10 \mathrm{~Hz}$. The equivalence ratio was fixed at 1.0, fill ratio at 1.0 , and purge ratio at 0.5 . No ignition delay was used. Average thrust values agreed within $0.3 \%$ and overall pressure ratios were within $0.0074 \%$. Figures 4.1 and 4.2 provide a side-by-side $\mathrm{x}-\mathrm{t}$ comparison between these two programs. The outputs are nearly identical and any small discrepancies in average thrust or pressure ratio may be attributed to minor required conversions in loop logic as well as double-precision calculations utilized by MATLAB.

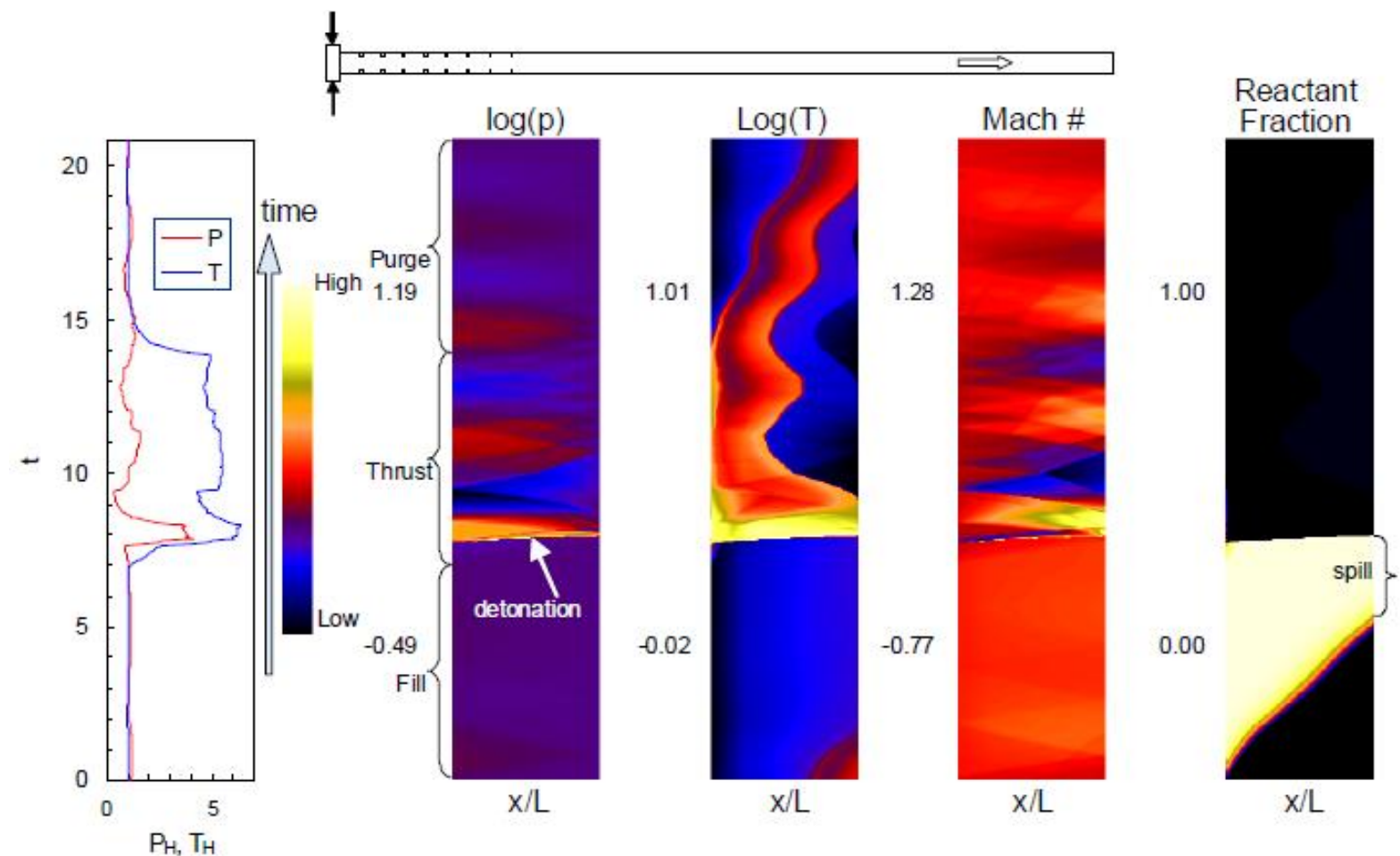

Figure 4.1. FORTRAN Verification Run ${ }^{1}$. 

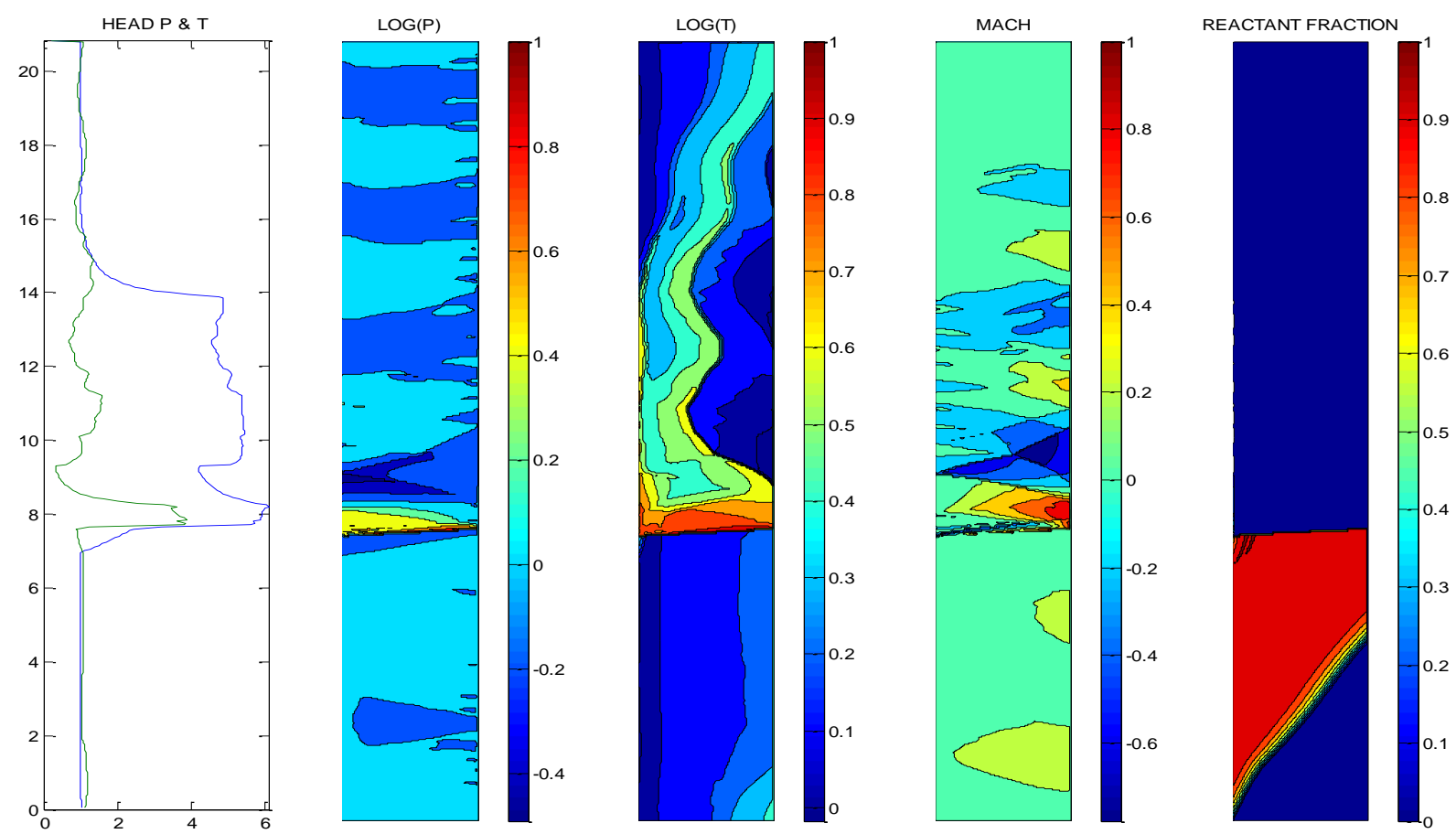

Figure 4.2. MATLAB Verification Run

Validation of the program was completed by comparing model outputs with baseline data collected on a 36-inch detonation tube operating frequencies between 10 and $40 \mathrm{~Hz}$. Fill fraction, and ignition delay were varied to authenticate the versatility of the program and to investigate the operational envelope of its capabilities. In order to account for the simplified chemical reaction code an equivalence ratio of 0.7 was selected to ensure local equivalence ratios of greater than 1.0 did not occur. Equivalence ratios greater than 1.0 will not model correctly and will produce erroneously large thrust values. The value of 0.7 also satisfied the 0.67 minimum limitation discussed in section 2.7. For this reason, thrust values for the model were proportionally lower than those recorded experimentally with stoichiometric ratios. A factor of 1.18 was derived from Figure 2.15 to use as an approximate thrust conversion.

The unmodified MATLAB model produced reasonable results between fill fractions of 0.5 and 1.0 over frequency ranges of $10-40 \mathrm{~Hz}$. Adjusted thrust values used to account for the 0.7 
equivalence ratio provided values within approximately $10 \%$ of experimental results and can be seen in Figures 4.3 and 4.4.

Thrust No Nozzle 22 Jul 02

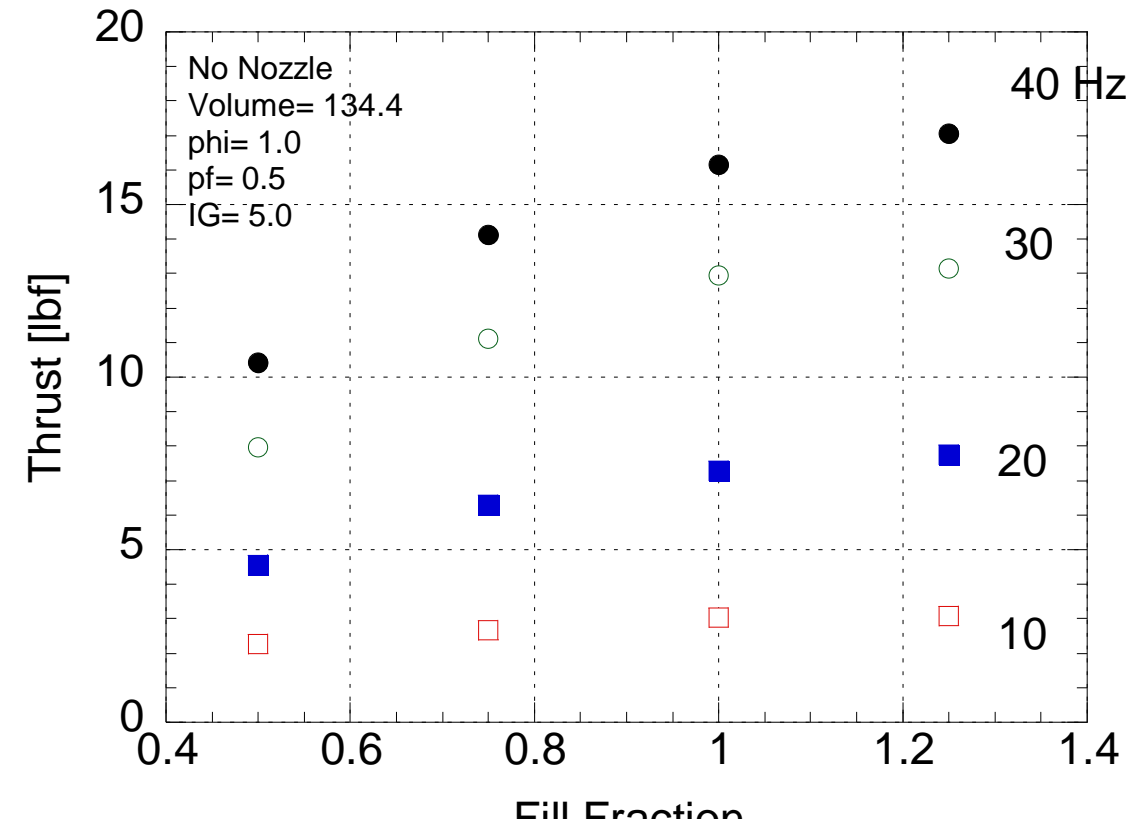

Figure 4.3. Fill Fraction - Experimental Results $(\Phi=1.0)$

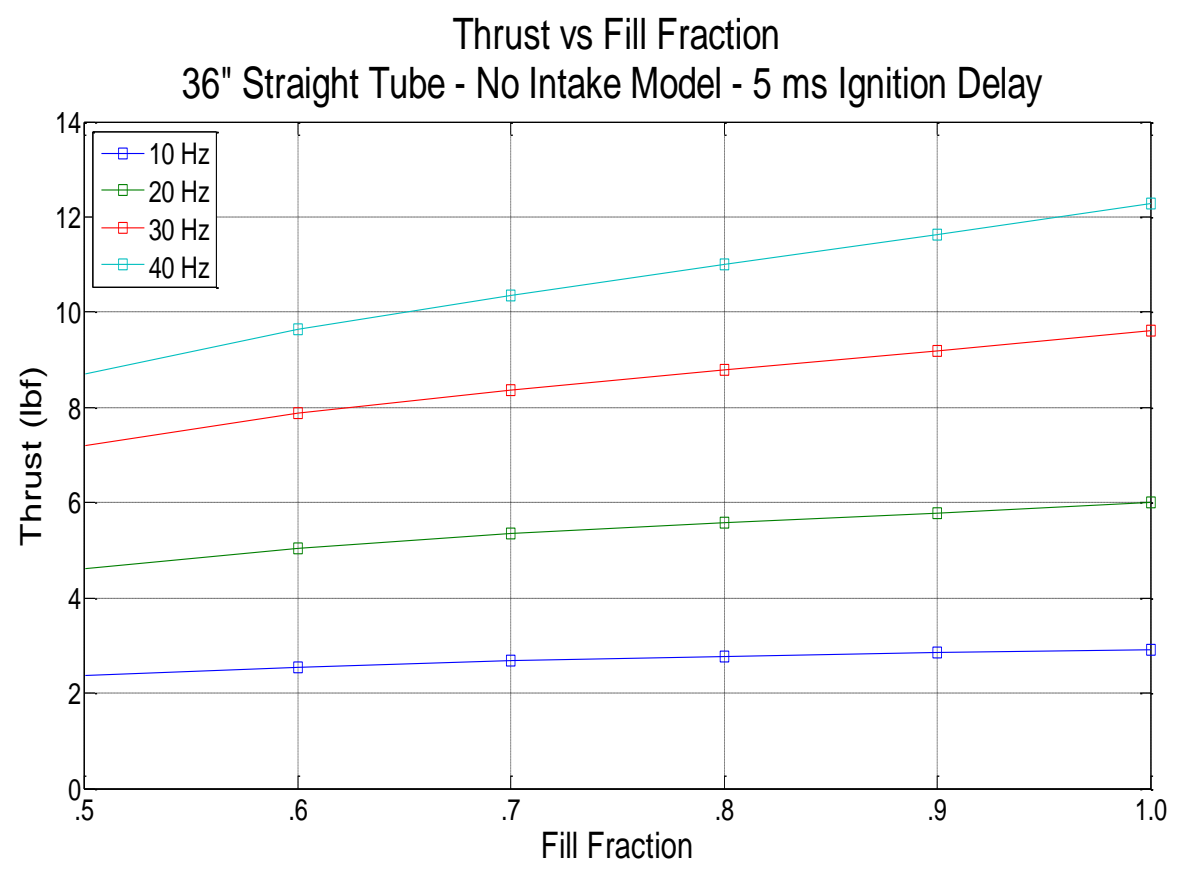

Figure 4.4. Fill Fraction - Model Results - No Intake Model $(\Phi=0.7)$ 
The primary factor affecting these thrust values is the ingestion of exhaust gas during the "fill" portion of the cycle and prior to ignition during the "fire" portion of the cycle. During this flow reversal, the model ingests ambient air at the exhaust end of the tube affecting overall performance. This process can be seen in the circled region of Figure 4.5
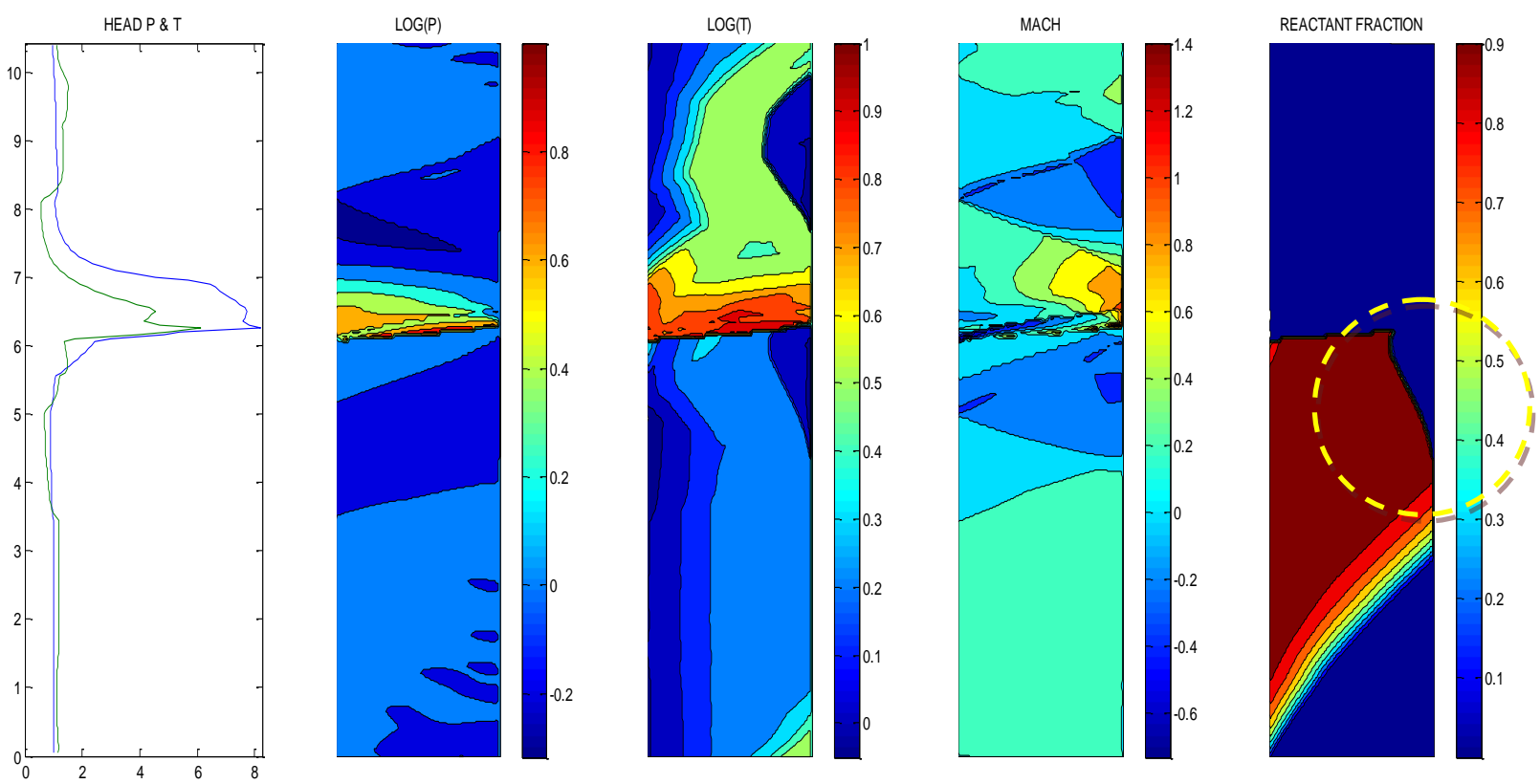

Figure 4.5. Exhaust Ingestion Error at $40 \mathrm{~Hz}$

The unmodified MATLAB program was also able to recreate experimental ignition timing data with delays from 1 to $8 \mathrm{~ms}$ over frequency ranges of 10 to $40 \mathrm{~Hz}$. Thrust values for this data were within approximately $10 \%$ of experimental results as well. This comparison can be seen in Figures 4.6 and 4.7. The program and experimental data both produced peak thrust values at approximately $5 \mathrm{~ms}$ ignition delays. 


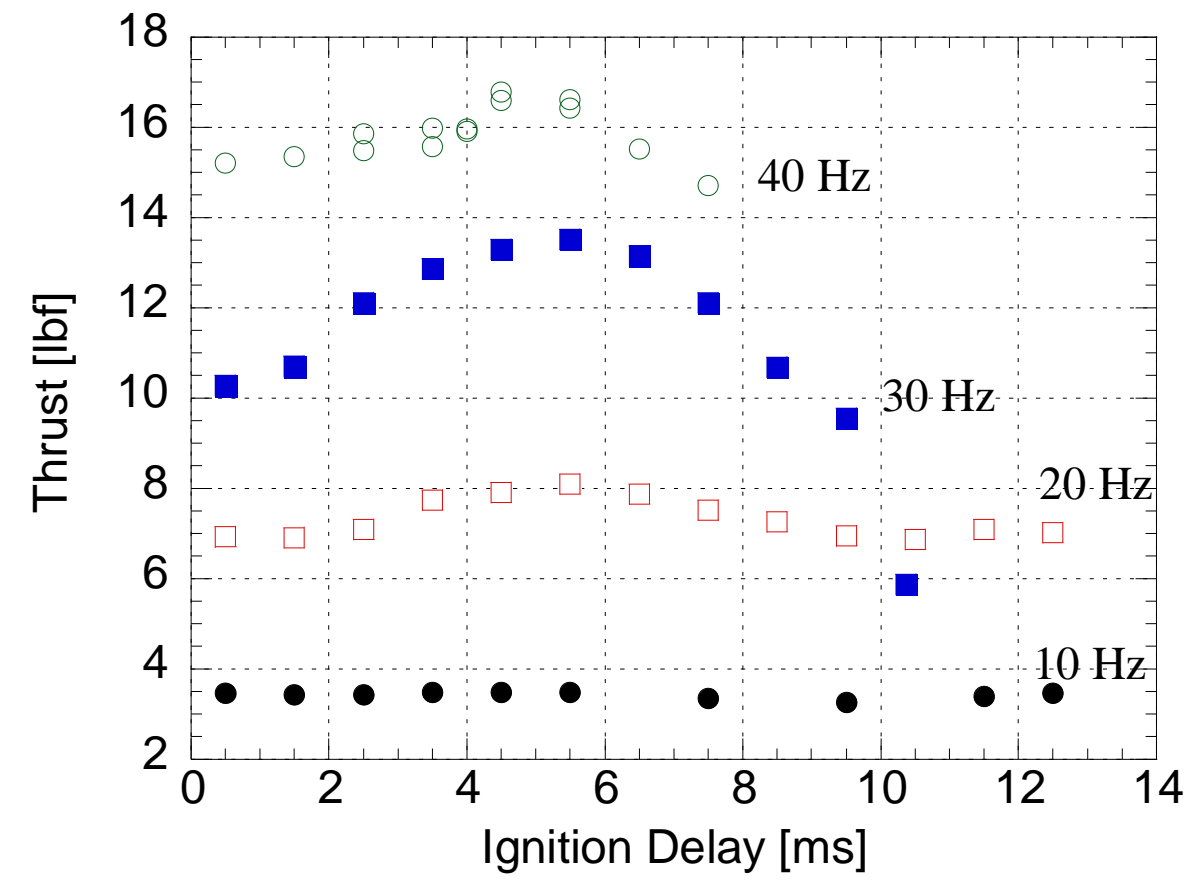

Figure 4.6. Ignition Delay - Experimental Results $(\Phi=1.0)$

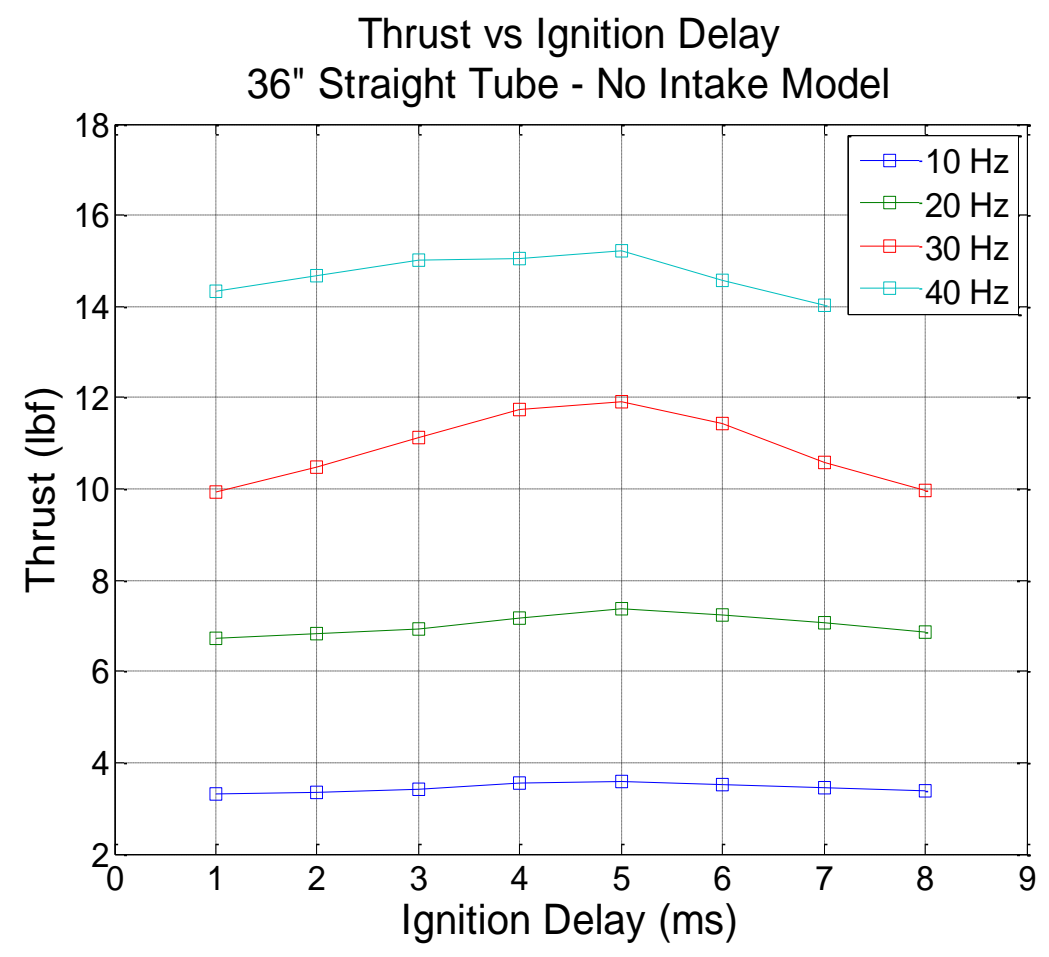

Figure 4.7. Ignition Delay - Model Results - No Intake $(\Phi=1.0)$ 


\subsection{RESULTS}

The validated MATLAB program, in addition to the experimental data, was then used as baseline references in comparison to the intake modified program that included the both the intake manifold and valve models. These comparisons were made at operating frequencies from 10 to $40 \mathrm{~Hz}$ and under the same conditions used in the validation runs. Convergence rates for both models varied and were highly dependent on the initial wall temperature distribution. Mass flow rates tend to converge in less than ten cycles; however overall convergence was not obtained until near steady state wall temperatures were achieved. An amplification factor was used to accelerate this convergence; however discretion was required to prevent unintentional oscillations around the equilibrium state. Examples of both modified and unmodified program outputs can be seen in the appendix.

\subsubsection{UNSTEADY EQUIVALENCE RATIO IN PDE}

The sample output in Figure 4.8 shows the unsteady fuel flow produced by the intake model. It also illustrates that the model, using an average equivalence ratio of 0.7 , predicts variations between 0.5 and 1.0 throughout the majority of the tube. As discussed earlier, this ensures that unrealistic thrust values are not achieved due to unrealistic energy contributions. In addition, the plot confirms the ability of the model to exhibit flow reversal through the valve if pressure conditions dictate such an occurrence. This can be seen approximately half way through the fill timing where flow is reversed due to resonant pressure oscillations. It is important to note that the intake manifold and PDE tube lengths are not identically scaled. 


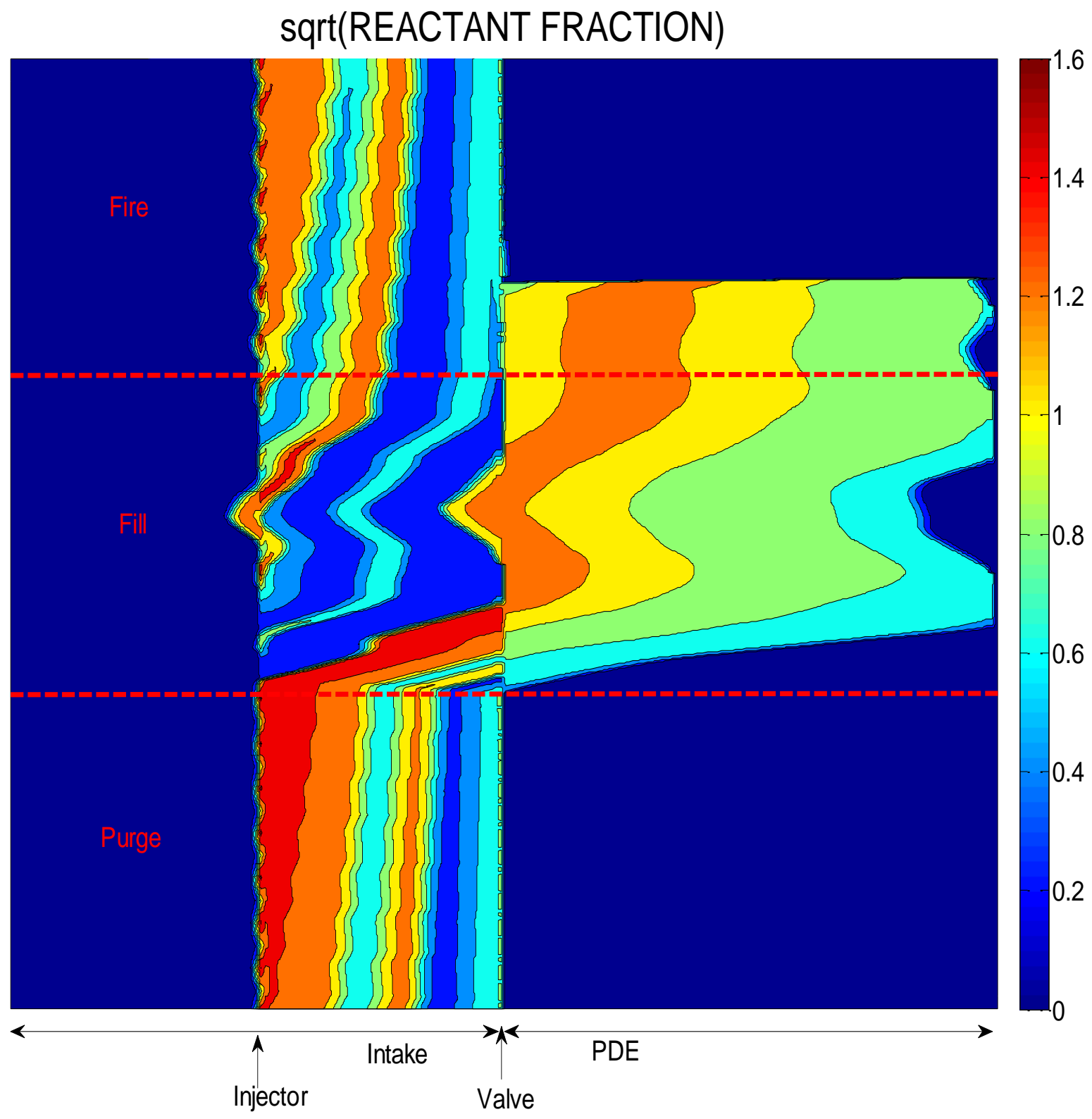

Figure 4.8. MATLAB X-T Output $-10 \mathrm{~Hz}(\Phi=0.7)$

\subsubsection{FILL FRACTION EFFECTS}

The intake modified MATLAB program produced slightly more accurate thrust values with respect to various fill fractions and frequencies than the unmodified program. The values calculated were within approximately $6 \%$ of experimental results when adjusted for equivalence 
ratio. Figure 4.9 contains thrust values for fill fractions between 0.6 and 1.0. Of note, the intake modified program was limited to this range as fill fractions below 0.6 did not produce consistent detonations.

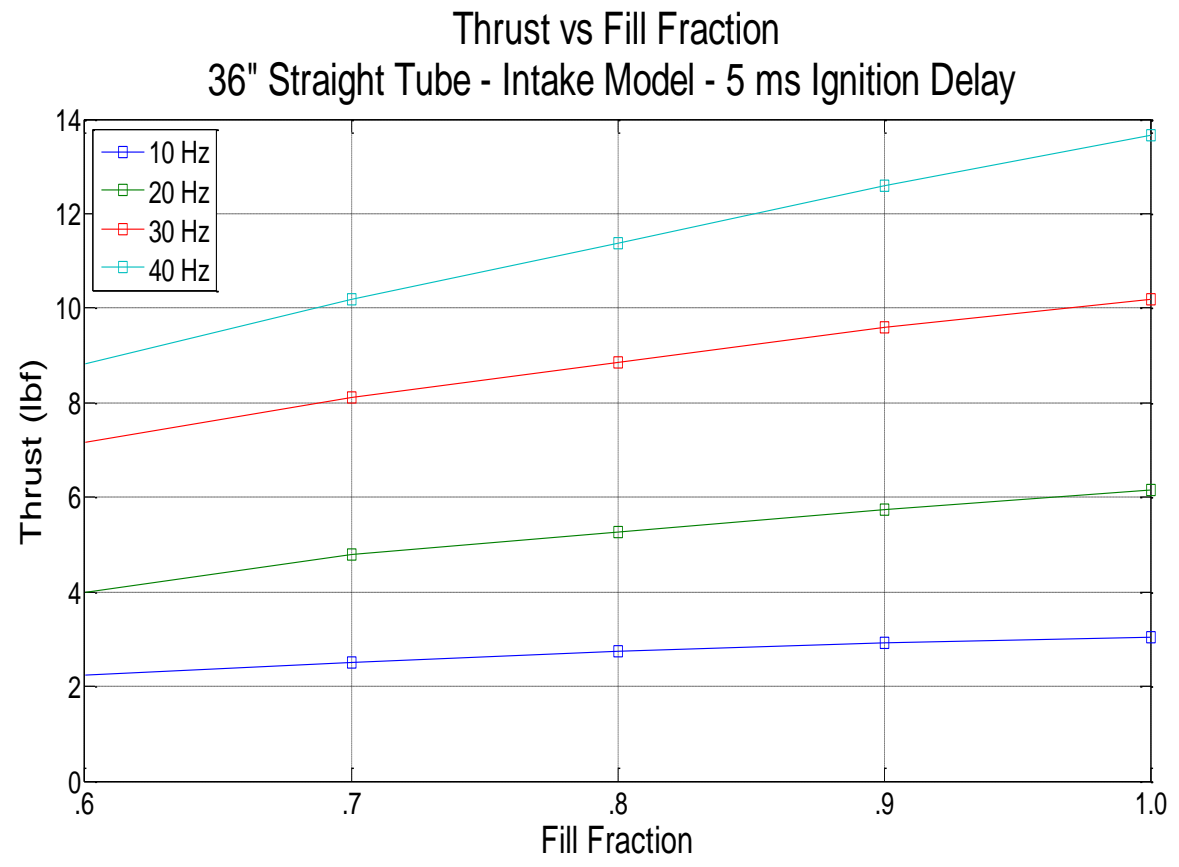

Figure 4.9. Fill Fraction - Model Results - Intake Model $(\Phi=0.7)$

The intake modified program also appeared to more accurately model the performance effects of partial filling when calculated as a fraction of maximum thrust. Figure 4.10 shows that a performance degradation of approximately $30 \%$ is expected at a fill fraction of 0.6. By comparing Figures 4.11 and 4.12 it appears the intake modification produces thrust degrades more closely aligned to expected values than the unmodified program by about $10 \%$. 


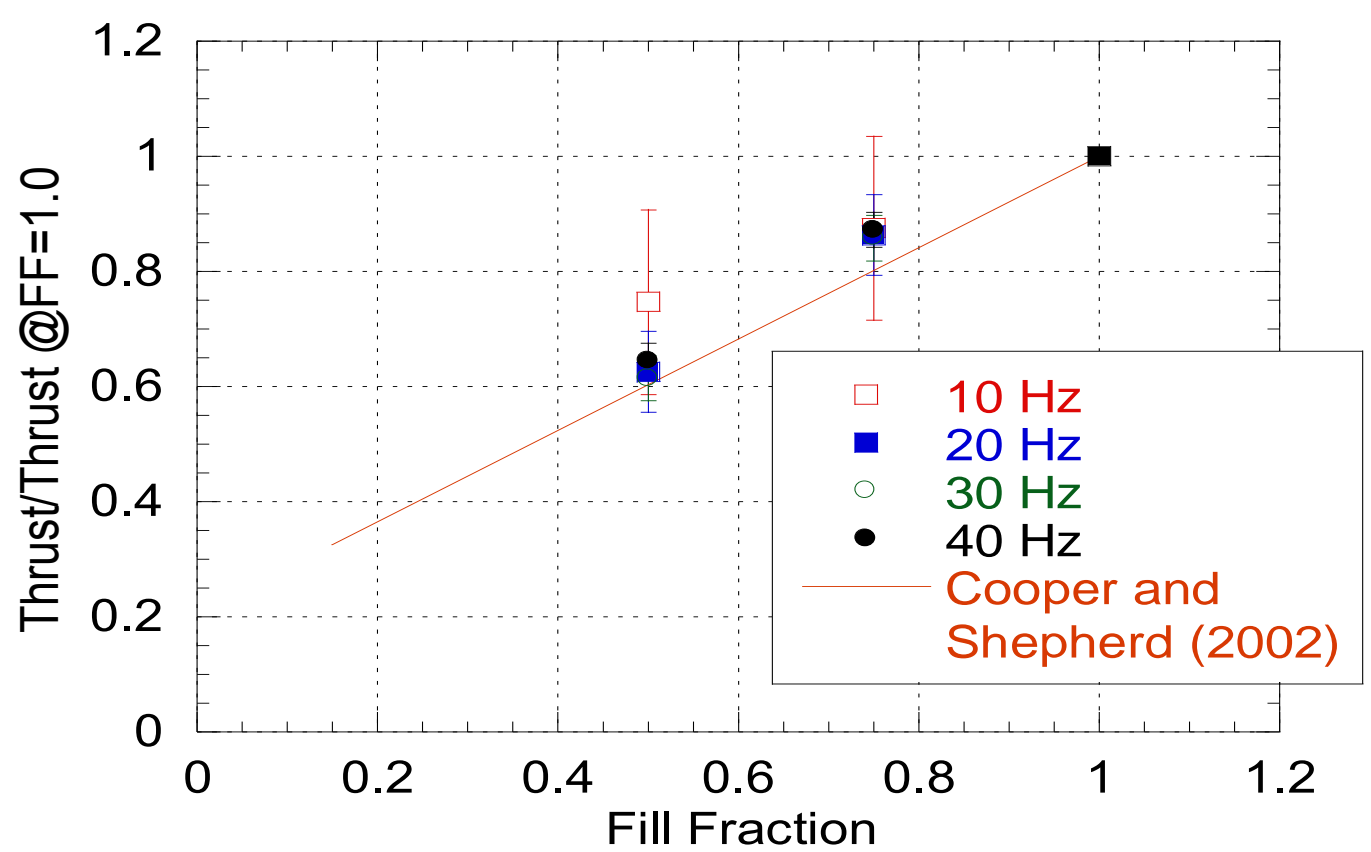

Figure 4.10. Normalized Fill Fraction - Experimental Results

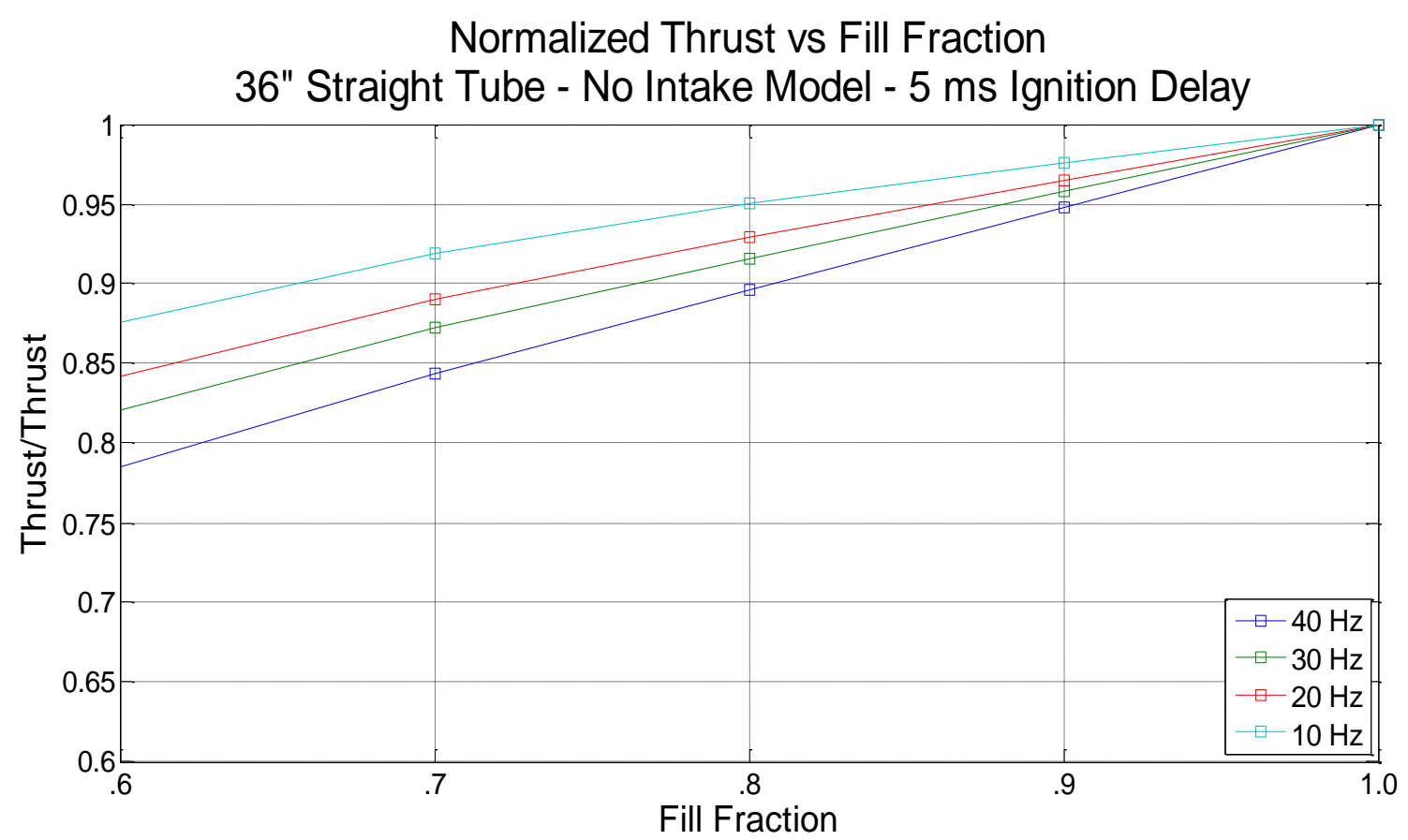

Figure 4.11. Normalized Fill Fraction - Model Results - No Intake Model 


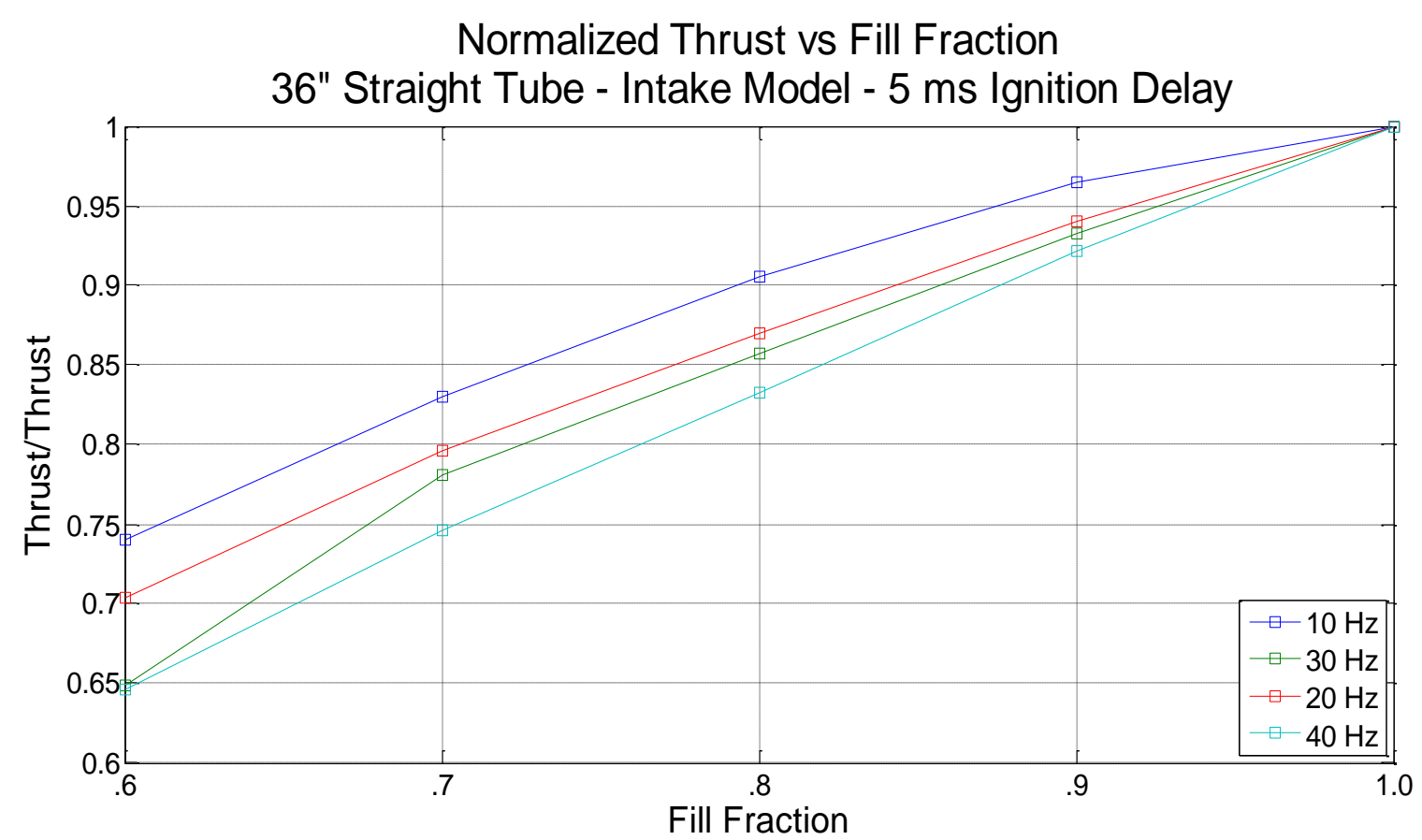

Figure 4.12. Normalized Fill Fraction - Model Results - Intake Model

Another interesting result was a strong correlation between the magnitude of performance effects attributed to the intake model at various fill fractions. Figure 4.13 suggests that at low fill fractions the intake model produced an overall performance degradation of approximately 10$20 \%$. Conversely, at high fill ratios the same intake system was driving a net increase in thrust of as much as $10 \%$. This correlation was consistent across all operational frequencies and fill ratios modeled. 


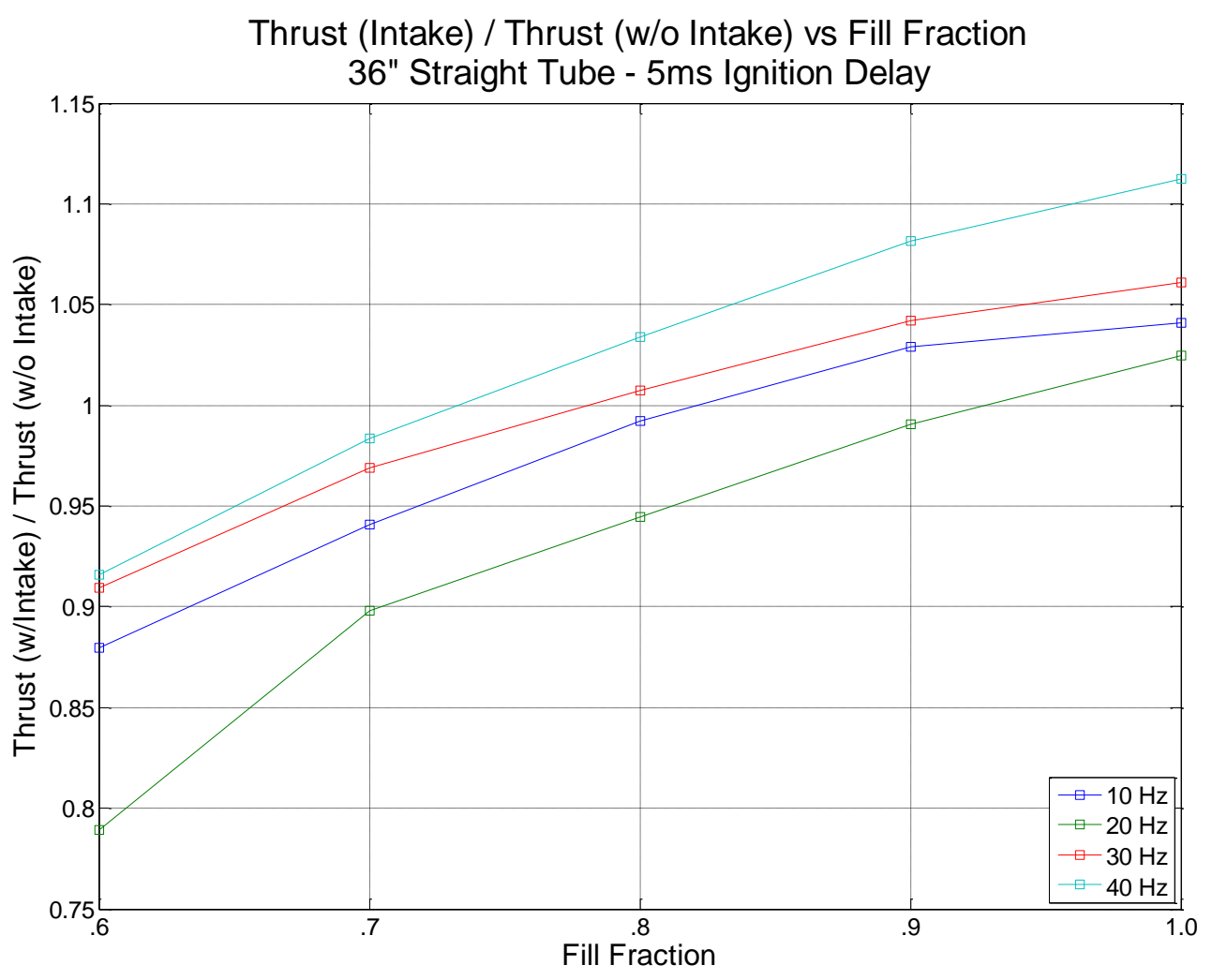

Figure 4.13. Effects of intake model on performance

\subsubsection{IGNITION DELAY EFFECTS}

The intake modified program, however, produced less accurate predictions regarding ignition delay than the unmodified program. Experimental results indicate increases in thrust of as much as $35 \%$ should be possible corresponding to operational frequency of $30 \mathrm{~Hz}$ with a $5 \mathrm{~ms}$ delay, yet both models fell well short of this producing only about $20 \%$ increases. Regardless, the unmodified program produced thrust curves that more appropriately described the effects of ignition timing, especially at frequencies of $20 \mathrm{~Hz}$ and less. Figure 4.14 shows peak thrust values occurring approximately $1 \mathrm{~ms}$ earlier than was recorded experimentally and actually exhibited a slight decrease in thrust for the same delay in the $10-20 \mathrm{~Hz}$ operating range. A comparison between the modified and unmodified versions of the program, shown in Figure 4.15, indicated about a $10 \%$ increase in thrust. This was expected from the fill fraction results discussed earlier. 
Thrust vs Ignition Delay 36" Straight Tube - Intake Model $(\mathrm{PHI}=0.7)$

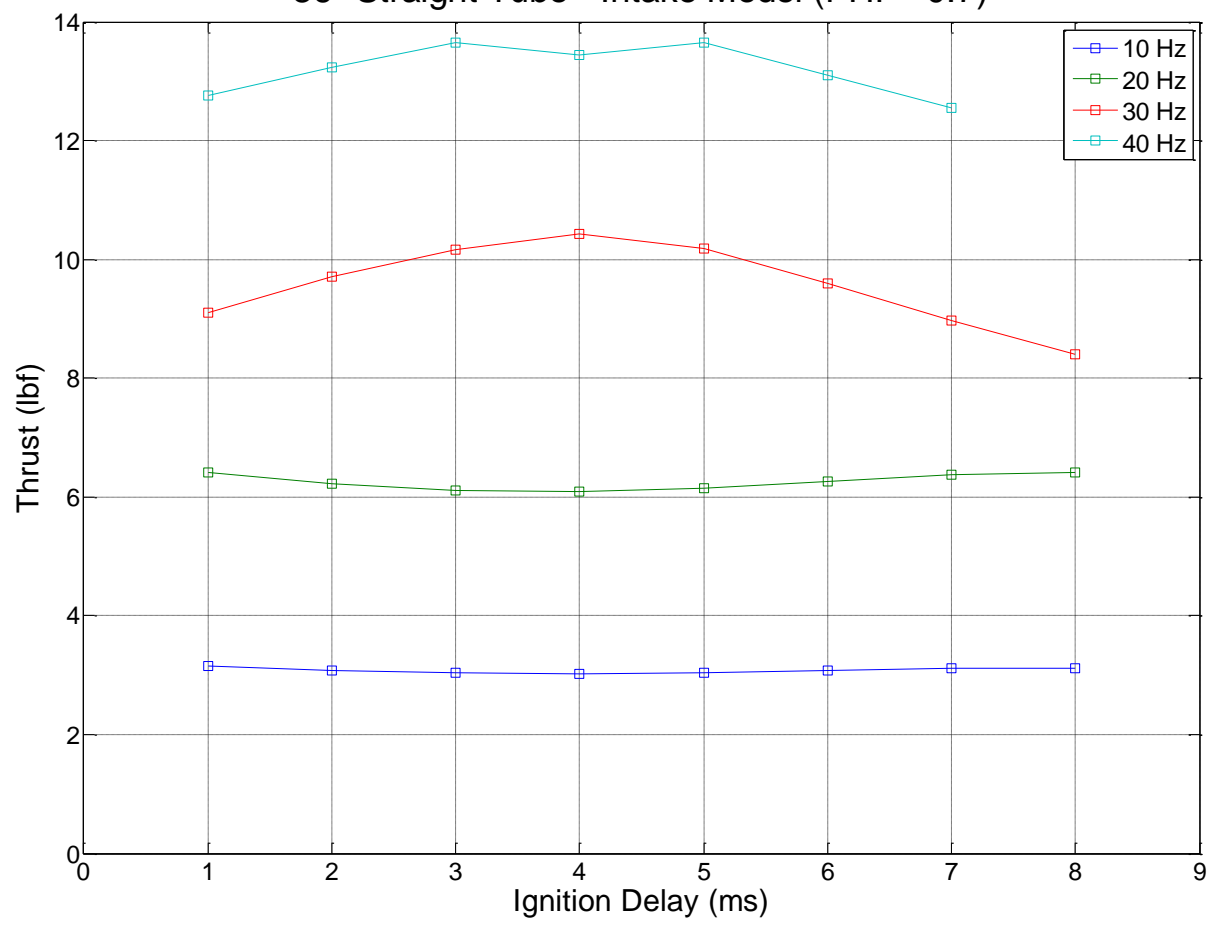

Figure 4.14. Ignition Delay - Model Results - Intake Model $(\Phi=0.7)$

Thrust (Intake) / Thrust (w/o Intake) vs Ignition Delay 36" Straight Tube - Fill Fraction $=1.0$

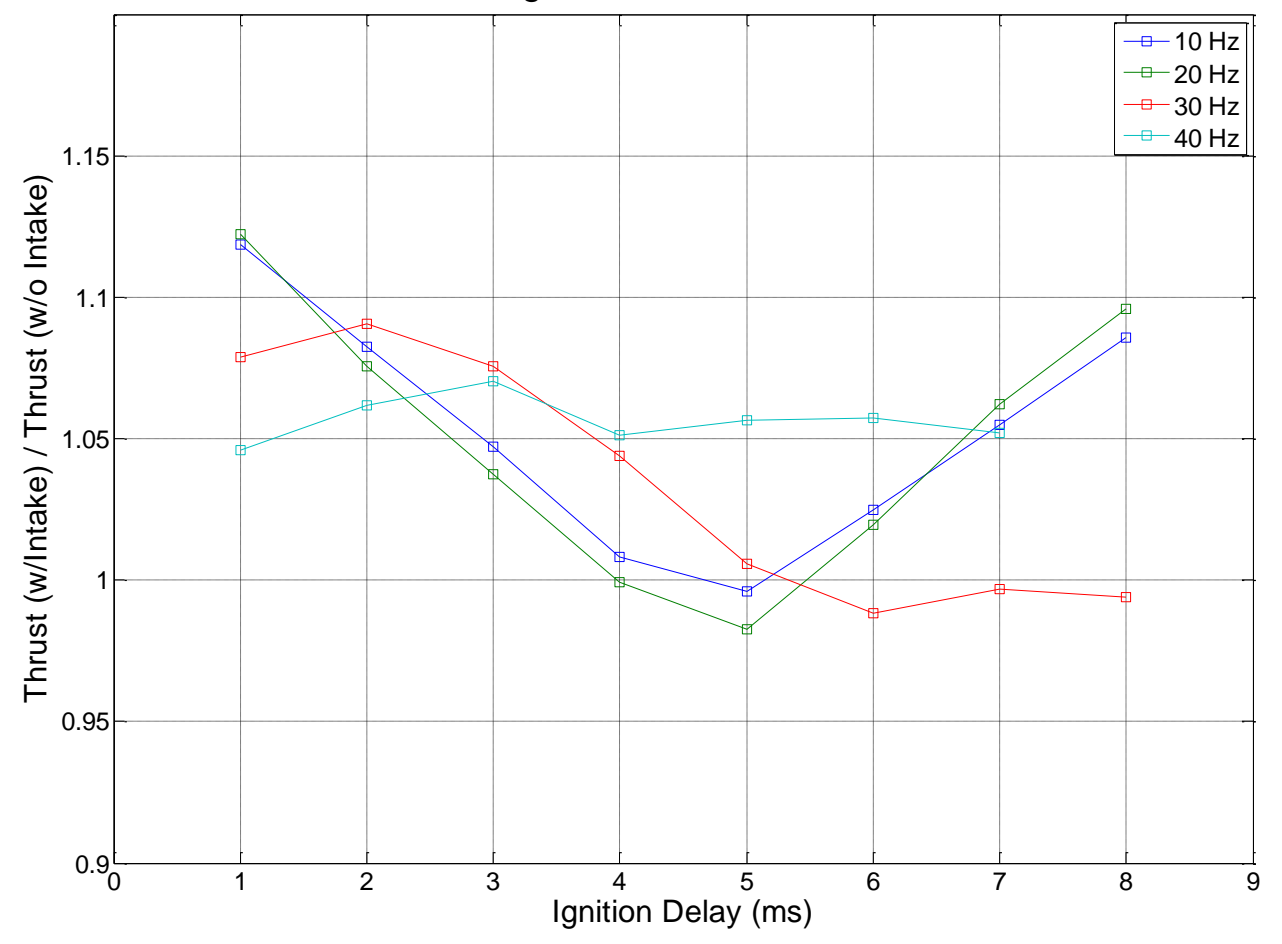

Figure 4.15. Effects of intake model on performance 


\subsubsection{HEAD PRESSURE PROFILE}

Head cavity pressure contours were also compared between the two programs as well as against experimental data. The pressure profiles produced by both programs were accurate approximations of the experimental results, however each exhibited different strengths and weaknesses. Figure 4.16 was used as a reference pressure profile with the caveat that the program was run with an equivalence ratio of only 0.7 . Accounting for this required alteration, the modified program displayed in Figure 4.18 produced a more accurate peak pressure spike at a fill fraction of 1.0, while the unmodified program shown in Figure 4.17 produced more accurate peak pressure spikes at fill fractions of 0.5 .

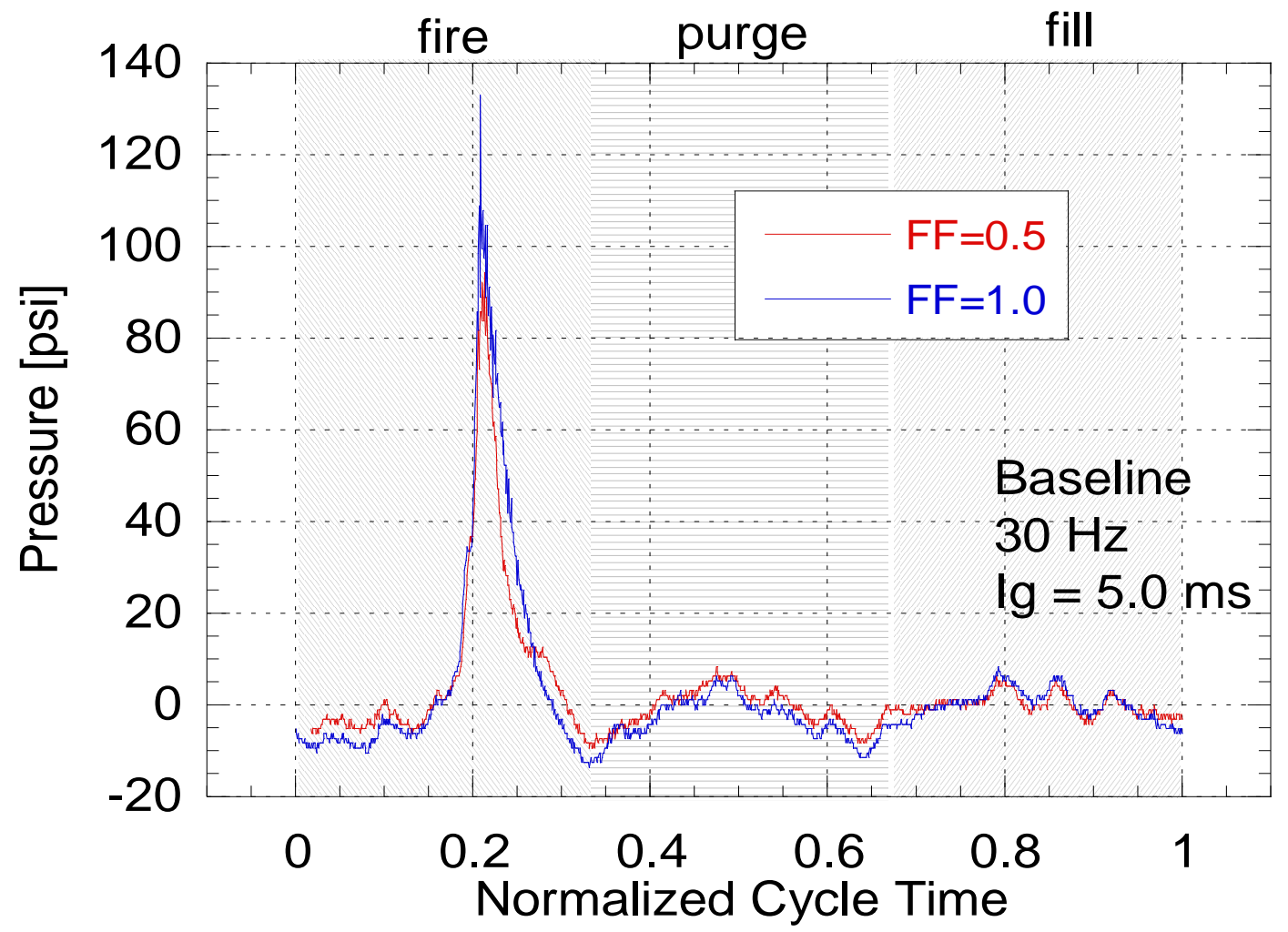

Figure 4.16. Head Pressure - Experimental Results $(\Phi=1.0)$ 


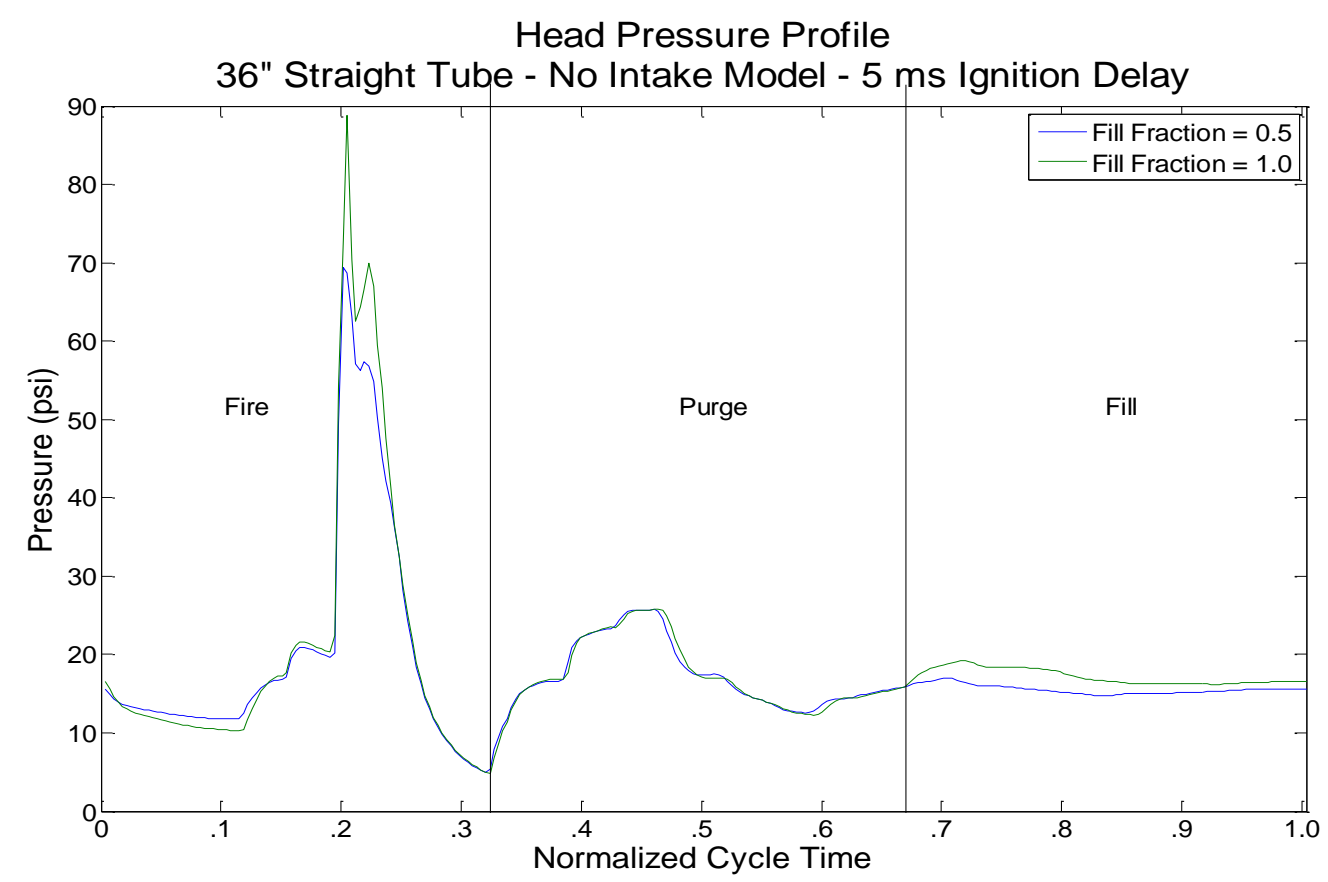

Figure 4.17. Head Pressure -Model Results - No Intake $(\Phi=0.7)$

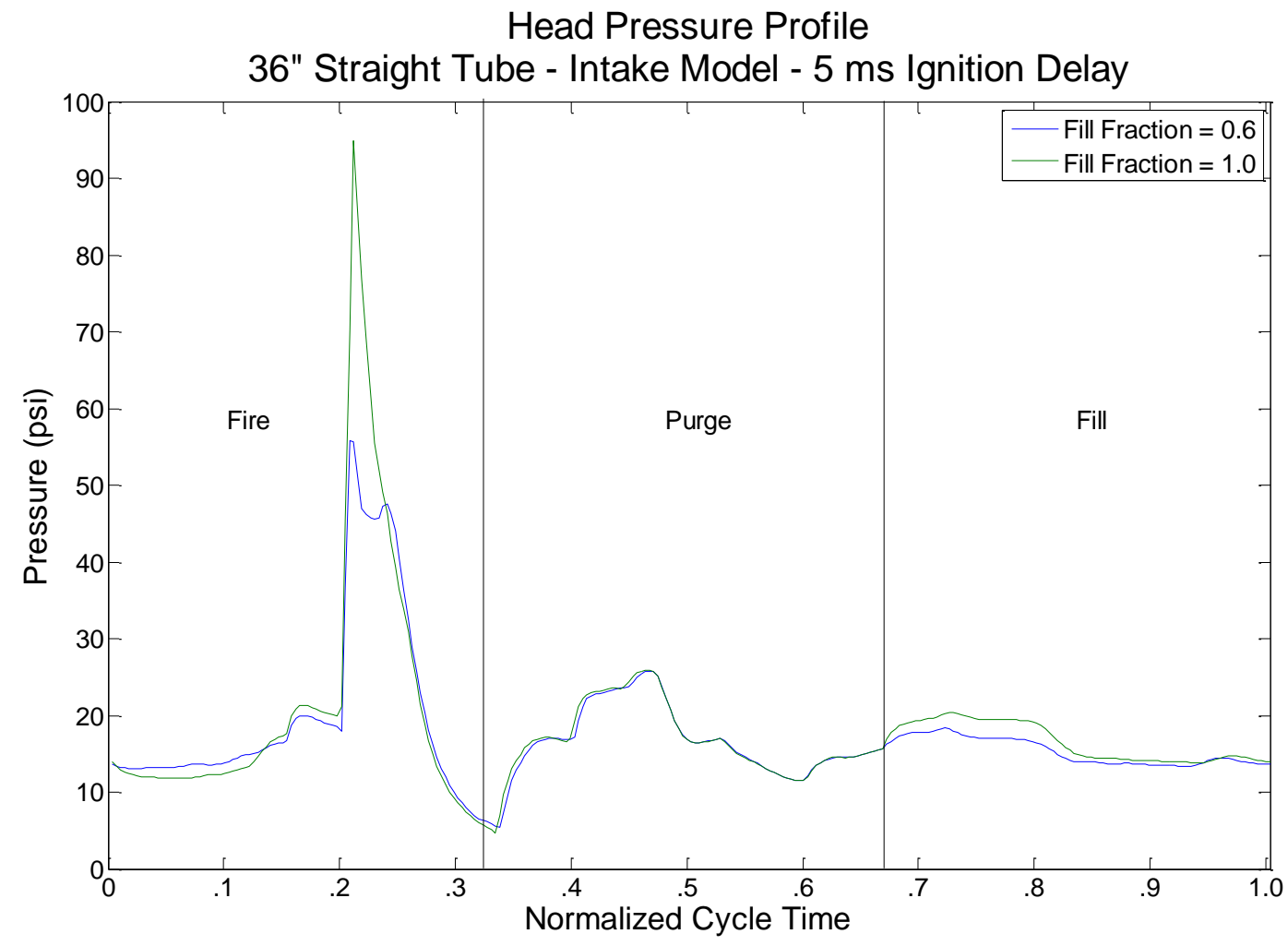

Figure 4.18. Head Pressure -Model Results - Intake Model $(\Phi=0.7)$ 


\subsubsection{COLD FLOW COMPARISONS}

Finally, cold flow properties were modeled using the intake modified version of the MATLAB program. A comparison between Figures 4.19 and 4.20 shows the relative accuracy of the intake model as compared to the data collected by AFRL. Although general trends appear correct, the model appears to be producing curves that more accurately represent an operating frequency closer to $25 \mathrm{~Hz}$ (Figure 4.21). This corresponds to approximately a $14 \%$ error in resonance frequency from the expected value. $2 \%$ of this error can be attributed to the $1 \mathrm{D}$ approximation of the tube dimensions. The other $12 \%$ is accounted for by approximations used in the program to calculate the speed of sound ( $\gamma$ and R). The program assumes a stoichiometric hydrogen-air mixture; however, the experimental data was collected using air alone. The differences in gas constants and specific heat ratios account for a $12 \%$ increase in speed of sound and a cold flow profile that more closely resembles a $25 \mathrm{~Hz}$ operating frequency.

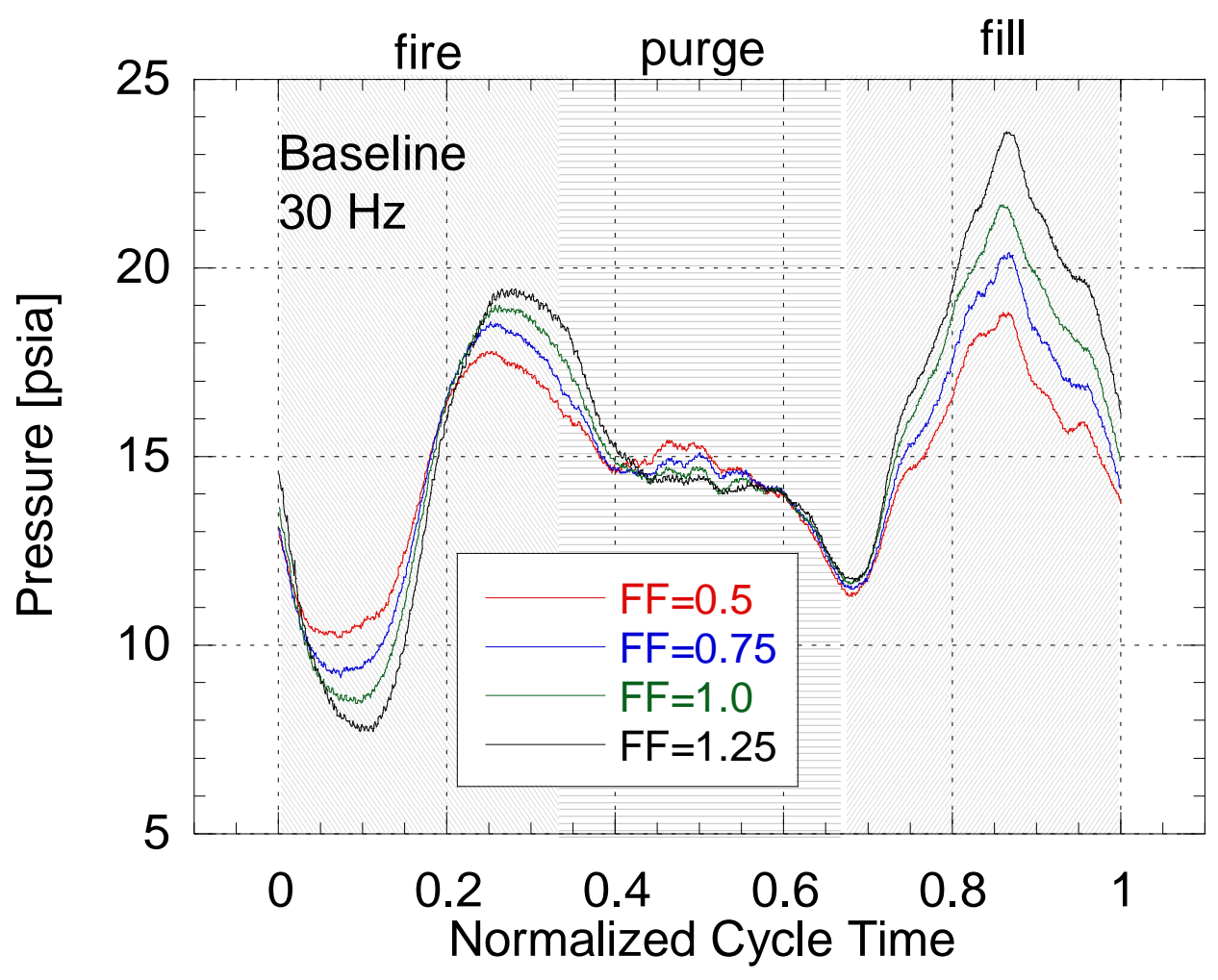

Figure 4.19. Cold Flow Pressure at $30 \mathrm{~Hz}-$ Experimental Results 


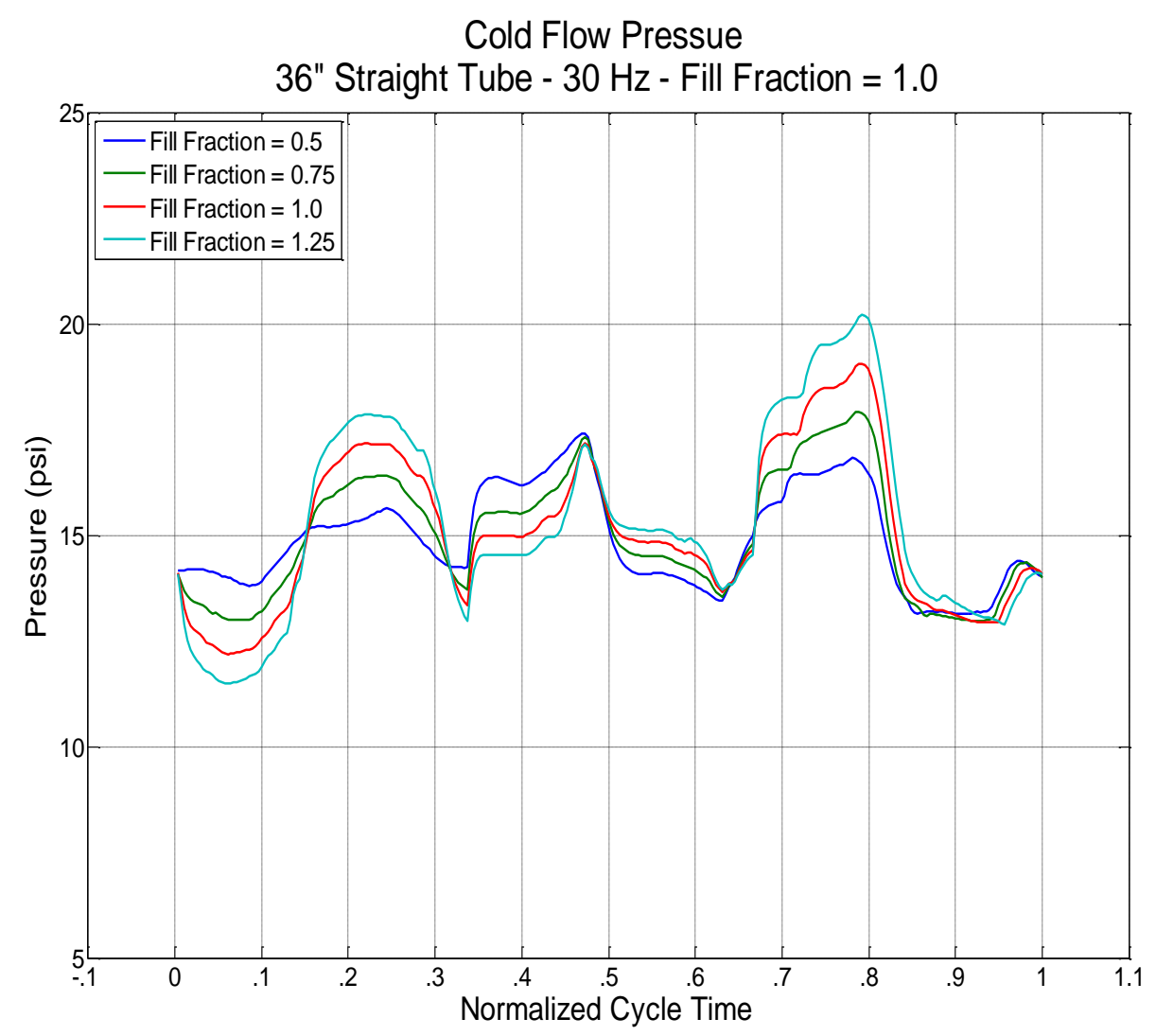

Figure 4.20. Cold Flow Pressure at $30 \mathrm{~Hz}-$ Intake Model Results

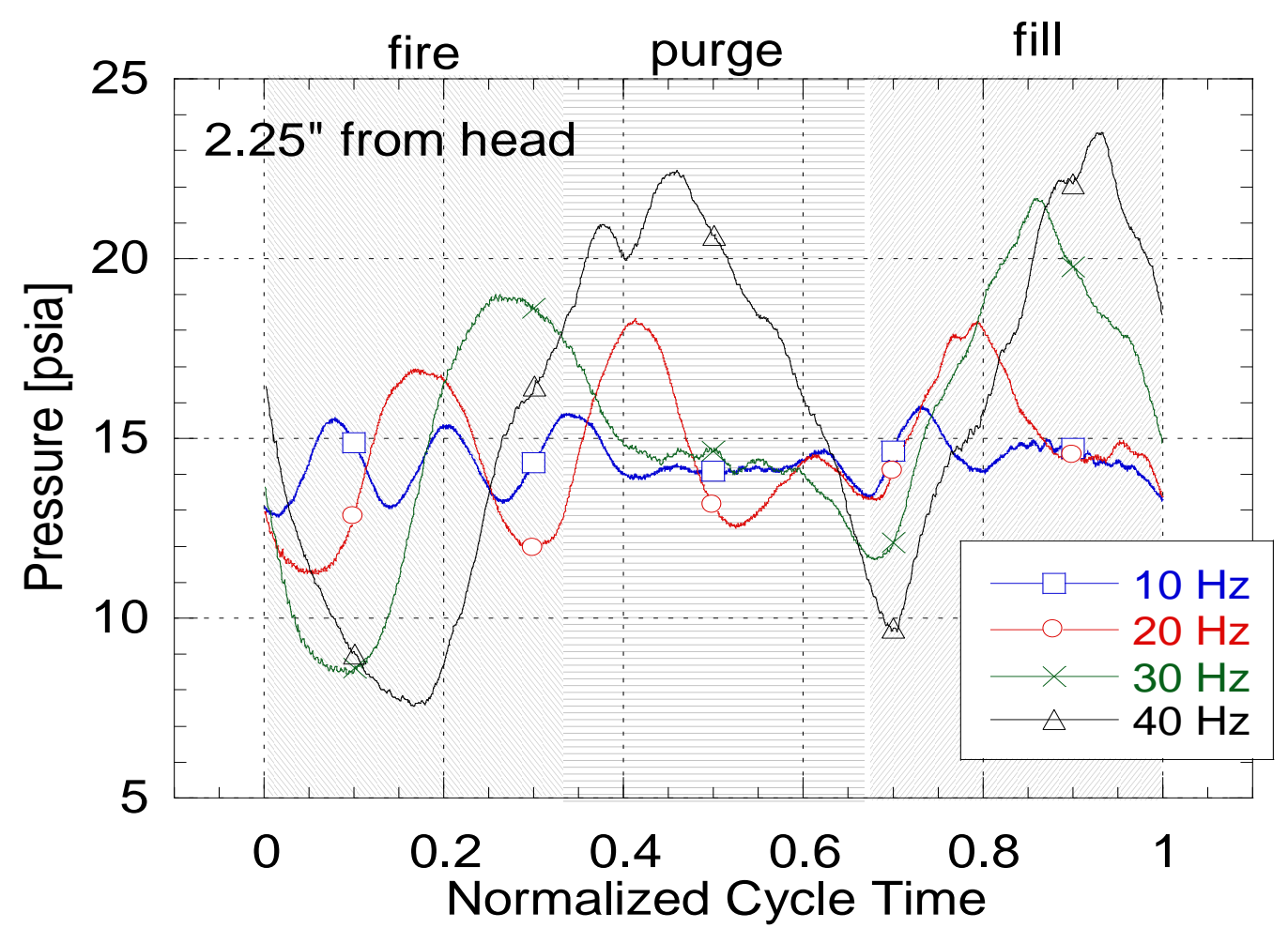

Figure 4.21. Cold Flow Pressure from 10-30 Hz - Experimental Results 


\subsection{DISCUSSION}

As expected, the heavily loop based logic used in the original FORTRAN program runs extremely slow in the MATLAB environment — by a factor of nearly 60 . The original FORTRAN program is capable of completing one cycle in as little as 5 seconds whereas the MATLAB version requires approximately 5 minutes to run the same setup. The addition of the intake model can drive this time up to as much as 20 minutes depending on the size and resolution required of the system being modeled. This tradeoff is offset by the ease of development and post processing capabilities offered by MATLAB; however, efforts should be made to optimize the inlet and Roe solver portions of the program for the MATLAB architecture as approximately $97 \%$ of computation time is dedicated to these objects. Vectorization of the code could be used to reduce the overall run time as well as converting these scripts into MATLAB functions. The original program contains a large number of nested for loops that are extremely time consuming to run in the MATLAB environment. Regardless, even with substantial optimization it would be difficult, if not impossible, to ever achieve run times at or near those seen in the original FORTRAN model.

Increased accuracy could also be achieved through further modification of the program. As discussed earlier, oscillations at various phases of the PDE cycle introduce exhaust gasses into the combustion tube. The code assumes ambient temperature and pressure for this fluid as well as a reaction fraction of zero. It is reasonable to assume that the exhaust gasses may be at substantially higher temperatures or may contain varying concentrations of fuel mixture depending on when the ingestion occurs during the cycle. Any combination of these effects would significantly affect the overall performance. 
An interesting observation related to this exhaust ingestion was an increase in thrust performance for the intake modified program at high frequencies and fill fractions as compared the unmodified program. The increase is likely attributed to the combination of unevenly distributed reaction fraction within the combustion tube at the point of ignition combined with the exhaust gas ingestion described above. The distribution present in the intake modified program has a lower concentration of reaction fraction at the exhaust end as compared to the unmodified program. As a result, the modified program is less likely to expel reaction fraction out the exhaust end of the PDE. This is likely the source of these performance discrepancies.

Lastly, increased accuracy could be obtained by including a $\mathrm{Q}_{0}$ vector that would allow each numerical cell to have an independent value of $\mathrm{Q}_{0}$ given the local equivalence ratio at any given time. This will ensure a more accurate model than using an average equivalence ratio for the entire system and only accounting for the variations in reaction fraction as is currently done. This approach will also eliminate the need to use an equivalence ratio of 0.7 in order to ensure unrealistic thrust values are not achieved, yet still produce enough energy to produce consistent detonations at low fill fractions. 


\section{CHAPTER 5 - CONCLUSIONS AND FUTURE WORK}

The Q1D simulation presented in this thesis has proven to be a simple yet reasonably accurate and versatile model that can be easily modified and adapted to a large spectrum of common input parameters. The addition of the intake and valve models appear to function as desired, producing variations in equivalence ratios throughout the PDE cycle and generally approximating the cold flow experimental data; however, the additional computational cost imposed by MATLAB is significant and must be taken into consideration.

Further modification of the program is required to increase the accuracy of the chemical reaction process in order to exploit the full potential of these dynamic PDE characteristics. This will enable the program to model average equivalence ratios at or near 1.0 without incorrectly representing stored chemical energy when local distributions exceed 1.0. It will also allow for direct comparisons against experimental data without the use of approximate thrust conversions as was used in this thesis.

While this particular version of the model did not explore pseudo-2D area changes, it is possible to modify the program in future research to accomplish this. The Roe-solver, however, is only capable of handling very gradual changes in area as abrupt changes will trigger unmanageable source values which will cause the model will diverge and the program to crash. If area changes are keep gradual, effects such as nozzle augmentation can be taken into consideration. 


\section{REFERENCES}

1 Daniel Paxson, Frederick Schauer, and David Hopper, "Performance Impact of Deflagration to Detonation Transition Enhancing Obstacles," 47th AIAA Aerospace Sciences Meeting including The New Horizons Forum and Aerospace Exposition, American Institute of Aeronautics and Astronautics, 2009.

2 Frederick Schauer, Chris Miser, Colin Tucker, Royce Bradley, and John Hoke, "Detonation Initiation of Hydrocarbon-Air Mixtures in a Pulsed Detonation Engine," 43rd AIAA Aerospace Sciences Meeting and Exhibit, American Institute of Aeronautics and Astronautics, 2005.

3 The University of Texas at Arlington Academics Research Center, "Pulsed Detonation Engines" Available: http://arc.uta.edu/research/pde.htm.

4 Paul Litke, Frederick Schauer, Daniel Paxson, Royce Bradley, and John Hoke, "Assessment of the Performance of a Pulsejet and Comparison with a Pulsed-Detonation Engine," 43rd AIAA Aerospace Sciences Meeting and Exhibit, American Institute of Aeronautics and Astronautics, 2005.

5 Venkat Tangirala, and A. Dean, "Performance Estimations of a Pulse Detonation Engine with Exit Nozzle," 42nd AIAA/ASME/SAE/ASEE Joint Propulsion Conference \& Exhibit, American Institute of Aeronautics and Astronautics, 2006.

6 Venkat Tangirala, and Paul Harris, "Performance Estimation for Subsonic-to-Supersonic Operating Conditions of a Pulse Detonation Engine," 43rd AIAA/ASME/SAE/ASEE Joint Propulsion Conference \& Exhibit, American Institute of Aeronautics and Astronautics, 2007.

7 Innovative Scientific Solutions Inc, "Frequently Asked Questions," Frequently Asked Questions Available: http://www.innssi.com/PDE_Faq.html.

8 Scott Anderson, Jon Tonouchi, Gary Lidstone, Kirk Lupkes, and Javier Alfonso, "Performance Trends for a Product Scale Pulse Detonation Engine," 40th AIAA/ASME/SAE/ASEE Joint Propulsion Conference and Exhibit, American Institute of Aeronautics and Astronautics, 2004.

9 Paul Harris, Robert Stowe, and S. Guzik, "Design Methodology for a Pulse Detonation Engine as a Ramjet Replacement," 40th AIAA/ASME/SAE/ASEE Joint Propulsion Conference and Exhibit, American Institute of Aeronautics and Astronautics, 2004. 
${ }^{10}$ Shmuel Eidelman, and Shmuel Eidelman, "Pulse Detonation Engine - A status review and technology development road map," 33rd Joint Propulsion Conference and Exhibit, American Institute of Aeronautics and Astronautics, 1997.

${ }^{11}$ Coleman, M. L., Overview of Pulse Detonation Propulsion Technology, Chemical Propulsion Information Agency, 2001.

12 Rajendran Mohanraj, and Charles Merkle, "A numerical study of pulse detonation engine performance," 38th Aerospace Sciences Meeting and Exhibit, American Institute of Aeronautics and Astronautics, 2000.

13 Roy, G. D., Frolov, S. M., Borisov, A. A., and Netzer, D. W., "Pulse detonation propulsion: challenges, current status, and future perspective," Progress in Energy and Combustion Science, vol. 30, 2004, pp. 545-672.

14 Shmuel Eidelman, and Xiaolong Yang, "Analysis of the pulse detonation engine efficiency," 34th AIAA/ASME/SAE/ASEE Joint Propulsion Conference and Exhibit, American Institute of Aeronautics and Astronautics, 1998.

15 Michael Aarnio, J. Hinkey, and T. Bussing, "Multiple cycle detonation experiments during the development of a pulse detonation engine," 32nd Joint Propulsion Conference and Exhibit, American Institute of Aeronautics and Astronautics, 1996.

16 T. New, Philip Panicker, Frank Lu, and H. Tsai, "Experimental Investigations on DDT Enhancements by Schelkin Spirals in a PDE," 44th AIAA Aerospace Sciences Meeting and Exhibit, American Institute of Aeronautics and Astronautics, 2006.

17 Rocco Farinaccio, Paul Harris, and Robert Stowe, "Turbulent Flow Effects on DDT Run-up Distance for a Pulse Detonation Engine," 40th AIAA/ASME/SAE/ASEE Joint Propulsion Conference and Exhibit, American Institute of Aeronautics and Astronautics, 2004.

18 Zeng-Chan Zhang, S. Yu, Hao He, and Philip Jorgenson, "Direct calculations of plume dynamics of a pulse detonation engine by the CE/SE method," 37th Joint Propulsion Conference and Exhibit, American Institute of Aeronautics and Astronautics, 2001.

19 T. Jenkins, and R. Hanson, "Soot diagnostic for pulse detonation engine studies," 35th Intersociety Energy Conversion Engineering Conference and Exhibit, American Institute of Aeronautics and Astronautics, 2000.

${ }^{20} \mathrm{~K}$. Kailasanath, "A review of research on pulse detonation engine nozzles," 37th Joint Propulsion Conference and Exhibit, American Institute of Aeronautics and Astronautics, 2001.

${ }^{21}$ D. Allgood, E. Gutmark, and V. Katta, "Effects of exit geometry on the performance of a pulse detonation engine," 40th AIAA Aerospace Sciences Meeting \& Exhibit, American Institute of Aeronautics and Astronautics, 2002. 
22 Shaye Yungster, "Analysis of Nozzle and Ejector Effects on Pulse Detonation Engine Performance," 41st Aerospace Sciences Meeting and Exhibit, American Institute of Aeronautics and Astronautics, 2003.

${ }^{23}$ Hua Qiu, Cha Xiong, and Chuan-jun Yan, "The Thermodynamic Performance of Ideal SingleTube Air-Breathing Pulse Detonation Engine," 42nd AIAA/ASME/SAE/ASEE Joint Propulsion Conference \& Exhibit, American Institute of Aeronautics and Astronautics, 2006.

${ }^{24}$ Richard Dyer, Thomas Kaemming, and Ryan Baker, "Reaction Ratio and Nozzle Expansion Effects on the PDE," 39th AIAA/ASME/SAE/ASEE Joint Propulsion Conference and Exhibit, American Institute of Aeronautics and Astronautics, 2003.

25 Shaye Yungster, and Hugh Perkins, "Multiple-Cycle Simulation of a Pulse Detonation Engine Ejector," 38th AIAA/ASME/SAE/ASEE Joint Propulsion Conference \& Exhibit, American Institute of Aeronautics and Astronautics, 2002.

${ }^{26}$ Daniel Allgood, Ephraim Gutmark, John Hoke, Royce Bradley, and Fred Schauer, "Performance Measurements of Multi-Cycle Pulse Detonation Engine Exhaust Nozzles," 43rd AIAA Aerospace Sciences Meeting and Exhibit, American Institute of Aeronautics and Astronautics, 2005.

27 Shota Kitano, Yuichiro Kimura, Hiroyuki Sato, and A. Hayashi, "Micro-Size Pulse Detonation Engine Performance," 45th AIAA Aerospace Sciences Meeting and Exhibit, American Institute of Aeronautics and Astronautics, 2007.

28 Aaron Glaser, Nicholas Caldwell, Ephraim Gutmark, John Hoke, Royce Bradley, and Fred Schauer, "Experimental Study of Ejectors Driven by a Pulse Detonation Engine," 45th AIAA Aerospace Sciences Meeting and Exhibit, American Institute of Aeronautics and Astronautics, 2007.

29 Eric Wintenberger, and Joseph Shepherd, "A Model for the Performance of an Airbreathing Pulse Detonation Engine," 39th AIAA/ASME/SAE/ASEE Joint Propulsion Conference and Exhibit, American Institute of Aeronautics and Astronautics, 2003.

30 Venkat Tangirala, Anthony Dean, Nobuyuki Tsuboi, and Koichi Hayashi, "Performance on a Pulse Detonation Engine Under Subsonic and Supersonic Flight Conditions," 45th AIAA Aerospace Sciences Meeting and Exhibit, American Institute of Aeronautics and Astronautics, 2007.

31 John Hinkey, Joseph Williams, Scott Henderson, Thomas Bussing, John Hinkey, Joseph Williams, Scott Henderson, and Thomas Bussing, "Rotary-valved, multiple-cycle, pulse detonation engine experimental demonstration," 33rd Joint Propulsion Conference and Exhibit, American Institute of Aeronautics and Astronautics, 1997. 
${ }^{32}$ Fuhua Ma, Jeong-Yeol Choi, and Vigor Yang, "Numerical Modeling of Valveless Airbreathing Pulse Detonation Engine," 43rd AIAA Aerospace Sciences Meeting and Exhibit, American Institute of Aeronautics and Astronautics, 2005.

${ }^{33}$ Stephen Guzik, Paul Harris, and Alain De Champlain, "An Investigation of Pulse Detonation Engine Configurations Using the Method of Characteristics," 38th AIAA/ASME/SAE/ASEE Joint Propulsion Conference \& Exhibit, American Institute of Aeronautics and Astronautics, 2002.

${ }^{34}$ Aaron Glaser, Nicholas Caldwell, and Ephraim Gutmark, "Acoustic Characterization of a Pulse Detonation Engine," 12th AIAA/CEAS Aeroacoustics Conference (27th AIAA Aeroacoustics Conference), American Institute of Aeronautics and Astronautics, 2006.

${ }^{35}$ Daniel Allgood, Aaron Glaser, Nicholas Caldwell, and Ephraim Gutmark, "Acoustic Measurements of a Pulse Detonation Engine," 10th AIAA/CEAS Aeroacoustics Conference, American Institute of Aeronautics and Astronautics, 2004.

${ }^{36}$ Rajendran Mohanraj, Charles Merkle, and Houshang Ebrahimi, "Modeling of pulse detonation engine operation," 39th Aerospace Sciences Meeting and Exhibit, American Institute of Aeronautics and Astronautics, 2001.

${ }^{37}$ Nicholas Caldwell, Aaron Glaser, and Ephraim Gutmark, "A Review of Pulse Detonation Engine Research at the University of Cincinnati," 43rd AIAA/ASME/SAE/ASEE Joint Propulsion Conference \& Exhibit, American Institute of Aeronautics and Astronautics, 2007.

${ }^{38}$ Wintenberger, E., Austin, J. M., Cooper, M., Jackson, S., and Shepherd, J. E., "Impulse of a Single-Pulse Detonation Tube,” Aug. 2002.

39 David Munday, Andrew St. George, Robert Driscoll, William Stoddard, Bradley Romanchuk, and Ephraim Gutmark, "The Design and Validation of a Pulse Detonation Engine Facility with and without Axial Turbine Integration," 51st AIAA Aerospace Sciences Meeting including the New Horizons Forum and Aerospace Exposition, American Institute of Aeronautics and Astronautics, 2013.

${ }^{40}$ Houshang Ebrahimi, and Alan Kawasaki, "Numerical investigation of exhaust plume radiative transfer phenomena," 34th AIAA/ASME/SAE/ASEE Joint Propulsion Conference and Exhibit, American Institute of Aeronautics and Astronautics, 1998.

${ }^{41}$ Kazuya Watanabe, and Akiko Matsuo, "Numerical Simulation of Pulse Detonation Engine with a Thermally Perfect Overall Reaction Model," 44th AIAA Aerospace Sciences Meeting and Exhibit, American Institute of Aeronautics and Astronautics, 2006.

${ }^{42}$ Hyungwon Kim, Dale Anderson, Frank Lu, and Donald Wilson, "Numerical simulation of transient combustion process in pulse detonation engine," 38th Aerospace Sciences Meeting and Exhibit, American Institute of Aeronautics and Astronautics, 2000. 
${ }^{43}$ Algieri, A., "An Experimental Analysis of the Fluid Dynamic Efficiency of a Production Spark-Ignition Engine during the Intake and Exhaust Phase," International Scholarly Research Network, 427976: .

${ }^{44}$ Aaron Glaser, Adam Rasheed, Robert Dunton, and Venkat Tangirala, "Measurement of Pressure-Rise in a Pulse Detonation Engine," 47th AIAA Aerospace Sciences Meeting including The New Horizons Forum and Aerospace Exposition, American Institute of Aeronautics and Astronautics, 2009. 


\section{APPENDIX}

\begin{tabular}{|lllllll|}
\hline \multicolumn{2}{l}{ INPUT COMPLETE...CALCULATING } & & & & \\
CYCLE & MF_ERR & TEMPCH & THRUST & MDOT & ZAVG & TIME(s) \\
1 & 0.020949 & 71.455 & 15.619 & 9.6097 & 1 & 263.09 \\
2 & 0.015197 & 32.42 & 15.378 & 9.6097 & 1 & 271.31 \\
3 & 0.011707 & 28.379 & 15.284 & 9.6111 & 1 & 268.76 \\
4 & 0.0099494 & 24.207 & 15.235 & 9.6111 & 1 & 266.57 \\
5 & 0.0088755 & 20.217 & 15.204 & 9.6097 & 1 & 287.39 \\
6 & 0.0081435 & 17.445 & 15.182 & 9.6111 & 1 & 284.67 \\
7 & 0.0076218 & 15.097 & 15.166 & 9.6111 & 1 & 276.6 \\
8 & 0.0072256 & 13.138 & 15.153 & 9.6111 & 1 & 269.73 \\
9 & 0.0069189 & 11.151 & 15.143 & 9.6097 & 1 & 268.71 \\
10 & 0.0066735 & 9.2939 & 15.135 & 9.6111 & 1 & \\
P0E_APRI $=$ & & & & & & \\
1.6822 & & & & & & \\
P0E_FOA $=$ & & & & & \\
1.6453 & & & & & \\
\hline
\end{tabular}

Figure A.1. Sample MATLAB Model Command Output
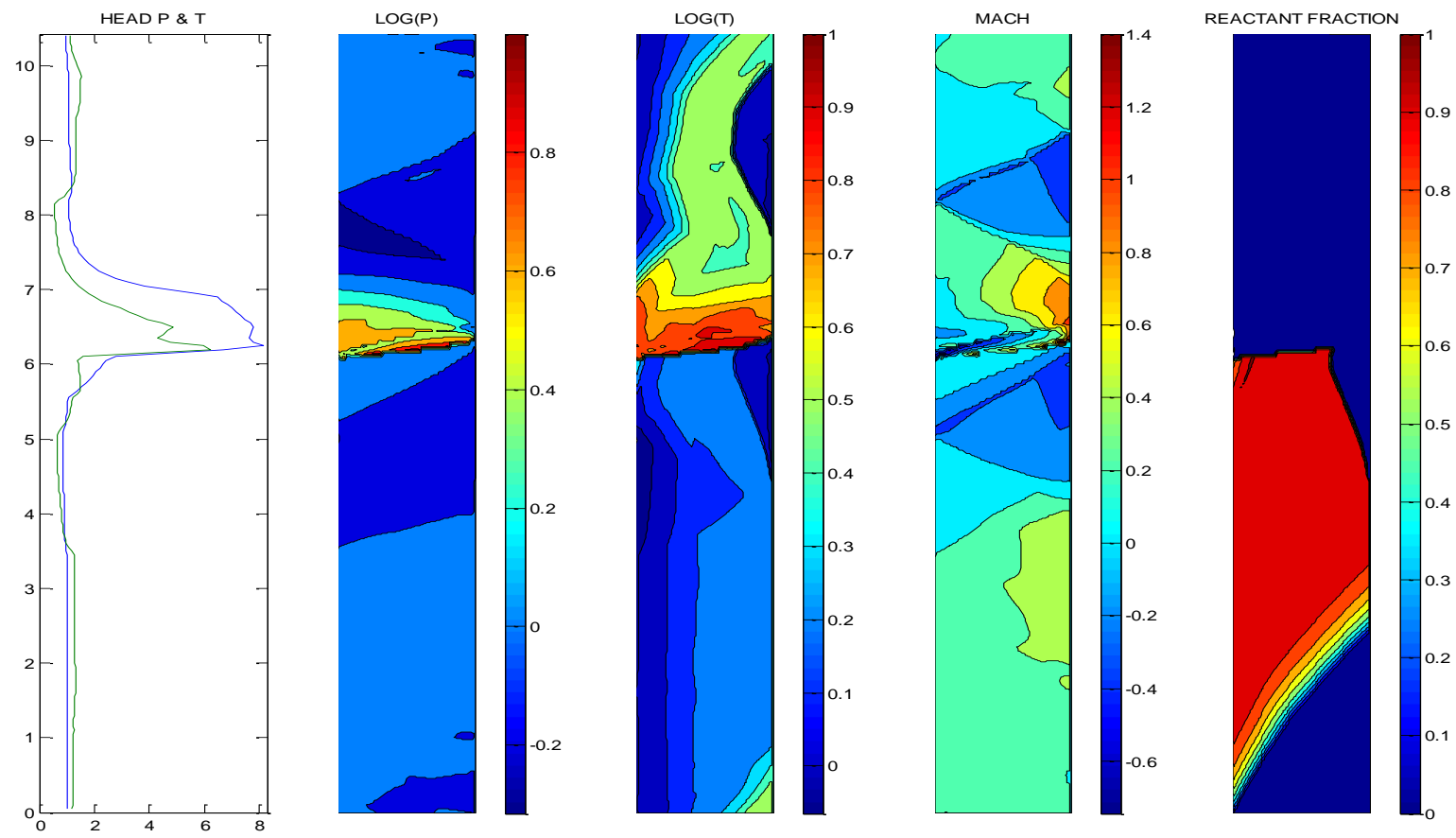

Figure A.2. Sample MATLAB X-T Output - No Intake 


\begin{tabular}{|c|c|c|c|c|c|c|}
\hline \multicolumn{7}{|c|}{ INPUT COMPLETE...CALCULATING } \\
\hline CYCLE & MF_ERR & TEMPCH & THRUST & MDOT & ZAVG & TIME(s) \\
\hline 1 & 0.031413 & -4.0876 & 3.7756 & 10.168 & 0.058759 & 1100.8 \\
\hline 2 & 0.012785 & -1.723 & 2.8647 & 7.6133 & 0.82002 & 1050 \\
\hline 3 & 0.0093429 & -1.7397 & 2.5163 & 7.2458 & 0.9696 & 1077.5 \\
\hline 4 & 0.0075368 & -1.7465 & 2.3419 & 7.2286 & 0.99849 & 985.65 \\
\hline 5 & 0.0063936 & -1.7481 & 2.2374 & 7.2302 & 1.0005 & 1070.5 \\
\hline \multicolumn{7}{|c|}{$\begin{array}{c}\text { P0E_APRI = } \\
1.0939\end{array}$} \\
\hline \multicolumn{7}{|c|}{ P0E_FOA = } \\
\hline
\end{tabular}

Figure A.3. Sample MATLAB Model Command Output - Intake Model

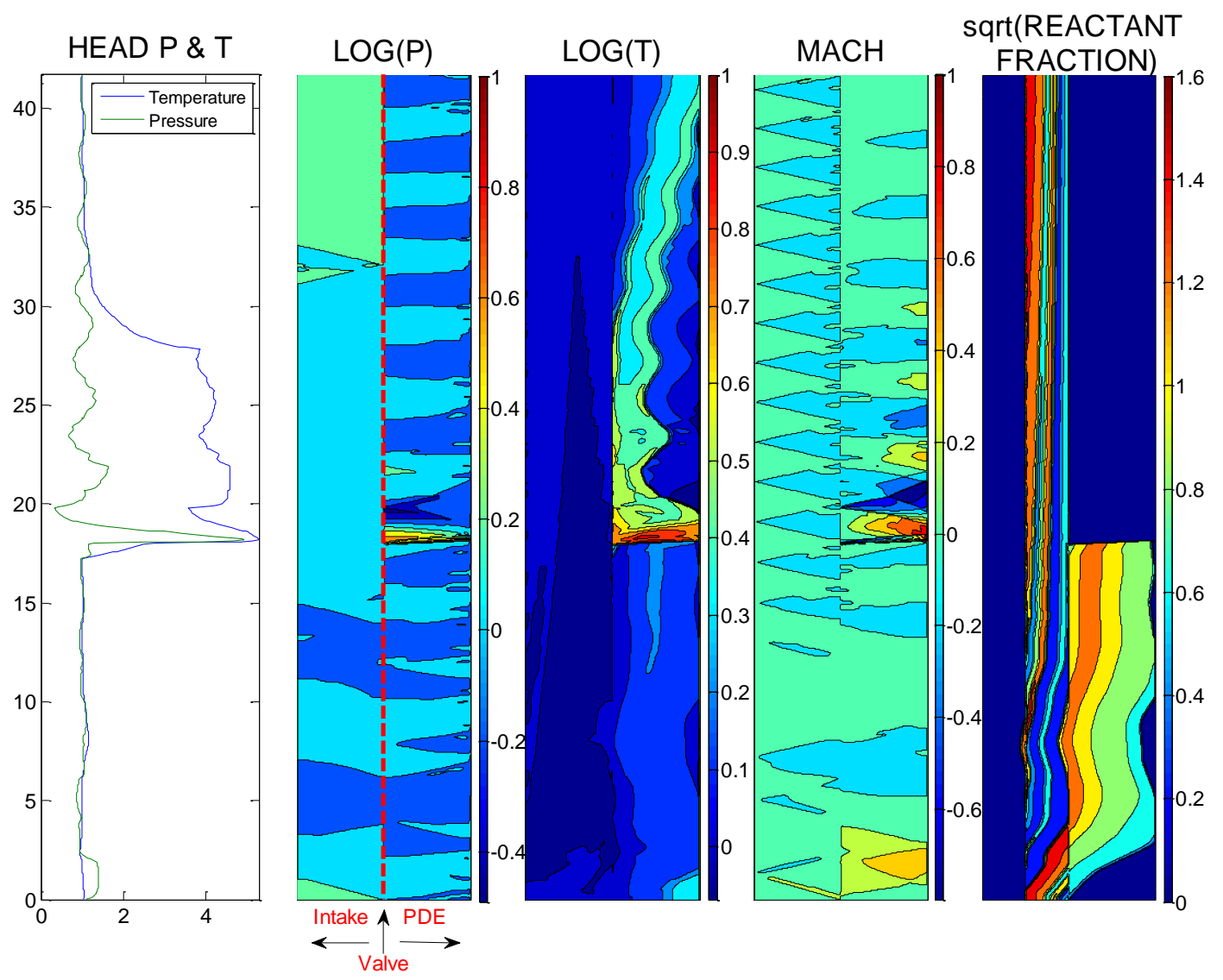

Figure A.4. Sample MATLAB X-T Output - Intake Model 